\title{
Measurement, interpretation and recommended use of laboratory strength properties of fibrous peat
}

Brendan C. O'Kelly PhD, FTCD, CEnv, CEng, MICE

Associate Professor, Department of Civil, Structural and Environmental

Engineering, Trinity College Dublin, Dublin, Ireland (bokelly@tcd.ie)

(Orcid:0000-0002-1343-4428)

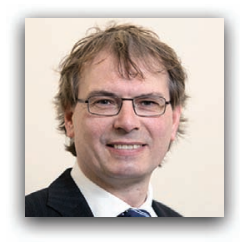

Peat deposits are complex natural formations encountered in many geographical areas. Peat itself is considered as a challenging geomaterial, with many aspects of its behaviour seemingly remaining enigmas. This state-of-the-art review paper provides an extensive summary of current knowledge on the strength and shear behaviour of fibrous peats. Critical assessments and interpretations of the undrained strength, effective-stress strength and at-rest earth pressure coefficient parameter values determined for fibrous peat materials using standard and advanced laboratory apparatus are presented, focusing particularly on the consolidated undrained triaxial compression and direct simple shear approaches. Based on documented case histories of embankments, dikes and natural peat slopes, guidance is given for operational shear strength assessments in peat, aimed at bearing capacity and slope stability calculations, considering both the normalised undrained strength ratio and limit equilibrium effective-stress strength approaches. In particular, the botanical origin, structural anisotropy, humification level, likely initial overconsolidated state, tensile resistance associated with the peat fibres and possible scale effect related to the test-specimen size are discussed in the context of the strength mobilised for different testing apparatus. The test methodologies and interpretations of experimental results presented for fibrous peat in this paper should be transferable to other fibrous soil and soil-like materials.

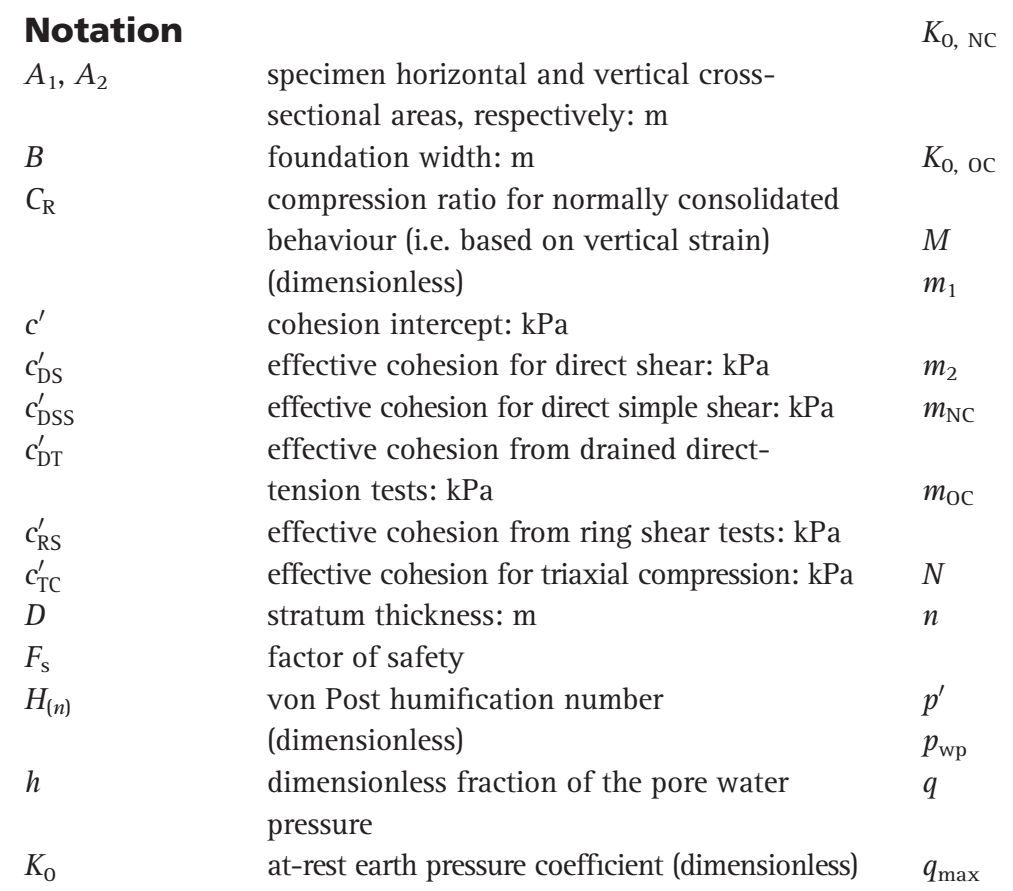

at-rest earth pressure coefficient for normally consolidated material (dimensionless)

at-rest earth pressure coefficient for overconsolidated material (dimensionless) gradient of critical state line (dimensionless) gradient of $\log s_{\mathrm{u}} / \sigma_{\mathrm{vc}}^{\prime}$ against $\log$ OCR relationship (dimensionless) at-rest rebound parameter (dimensionless) gradient of $\log s_{\mathrm{u}} / \sigma_{\mathrm{vc}}^{\prime}$ against log VSL relationship for VSL $\leq 1$ (dimensionless) gradient of $\log s_{\mathrm{u}} / \sigma_{\mathrm{vc}}^{\prime}$ against log VSL relationship for VSL > 1 (dimensionless) loss on ignition: $\%$ number of experimental measurements (dimensionless) mean effective stress: $\mathrm{kPa}$ pore-water pressure deviator stress for triaxial condition (i.e. $\sigma_{1}^{\prime}-\sigma_{3}^{\prime}$ ): $\mathrm{kPa}$ peak deviator stress: $\mathrm{kPa}$ 


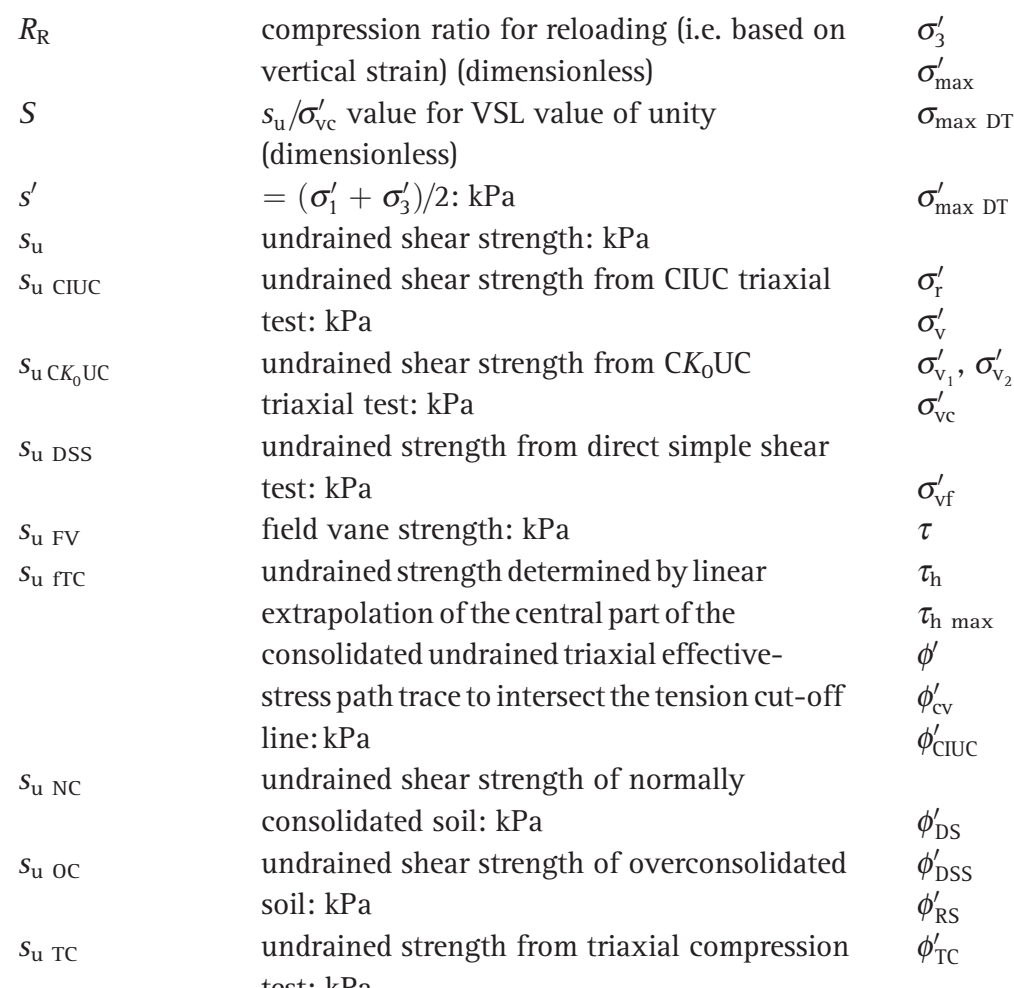

$s_{\mathrm{uTC}} / \sigma_{\mathrm{vc}}^{\prime} \quad$ normalised undrained strength ratios for

and $s_{\mathrm{uDSS}} / \sigma_{\mathrm{vc}}^{\prime} \quad$ triaxial compression and direct simple shear conditions, respectively (dimensionless)

$\left(s_{\mathrm{u} \mathrm{DSS}} / \sigma_{\mathrm{vc}}^{\prime}\right)_{\mathrm{OC}} \quad$ normalised undrained strength ratio for precompressed specimen determined from direct simple shear test: dimensionless $\left(s_{\mathrm{u} \mathrm{TC}} / \sigma_{\mathrm{vc}}^{\prime}\right)_{\mathrm{NC}} \quad$ normalised undrained strength ratios for and $\left(s_{\mathrm{u} \mathrm{DSS}} / \sigma_{\mathrm{vc}}^{\prime}\right)_{\mathrm{NC}}$ normally consolidated behaviour in triaxial compression and direct simple shear tests, respectively (dimensionless)

$t$

$w_{\mathrm{o}}$

Z

$Z_{\mathrm{w}}$

$\alpha$

$\gamma$

$\varepsilon_{\mathrm{a}}$

$\varepsilon_{\mathrm{a}}^{\mathrm{H}}$

$\varepsilon_{\mathrm{h}}$

$\varepsilon_{\mathrm{vol}}$

$\mu$

$\mu_{\mathrm{FV}}$

$v^{\prime}$

$\rho_{\mathrm{s}}$

$\sigma$

$\sigma_{1}^{\prime}$ $=\left(\sigma_{1}^{\prime}-\sigma_{3}^{\prime}\right) / 2$

in situ water content: $\%$

depth of sliding failure surface below ground surface level: $m$

height of groundwater table measured from the failure surface upwards: $m$

orientation of major principal stress to the vertical direction: degree

shear strain: \%

axial (vertical) strain: \%

axial strain (Hencky): \%

horizontal strain: $\%$

volumetric strain: \%

strain rate dependency of strength

(dimensionless)

correction factor for field vane test results

(dimensionless)

drained Poisson's ratio (dimensionless)

particle density: $\mathrm{Mg} / \mathrm{m}^{3}$

standard deviation

major principal effective stress: $\mathrm{kPa}$

\begin{tabular}{|c|c|}
\hline$\sigma_{3}^{\prime}$ & minor principal effective stress: $\mathrm{kPa}$ \\
\hline$\sigma_{\max }^{\prime}$ & preconsolidation pressure: $\mathrm{kPa}$ \\
\hline$\sigma_{\max } \mathrm{DT}$ & $\begin{array}{l}\text { undrained tensile strength from direct- } \\
\text { tension test: } \mathrm{kPa}\end{array}$ \\
\hline$\sigma_{\max \text { DT }}^{\prime}$ & $\begin{array}{l}\text { drained tensile strength from direct-tension } \\
\text { test: } \mathrm{kPa}\end{array}$ \\
\hline$\sigma_{\mathrm{r}}^{\prime}$ & radial effective stress: $\mathrm{kPa}$ \\
\hline$\sigma_{\mathrm{v}}^{\prime}$ & vertical effective stress: $\mathrm{kPa}$ \\
\hline$\sigma_{\mathrm{v}_{1}}^{\prime}, \sigma_{\mathrm{v}_{2}}^{\prime}$ & particular in situ vertical effective stress values \\
\hline$\sigma^{\prime}$ & $\begin{array}{l}\text { vertical consolidation stress at start of } \\
\text { shearing stage: } \mathrm{kPa}\end{array}$ \\
\hline$\sigma_{\mathrm{vf}}^{\prime}$ & vertical effective stress at failure: $\mathrm{kPa}$ \\
\hline$\tau$ & shear stress: $\mathrm{kPa}$ \\
\hline$\tau_{\mathrm{h}}$ & horizontal shear stress: $\mathrm{kPa}$ \\
\hline$a x$ & maximum horizontal shear stress: $\mathrm{kPa}$ \\
\hline 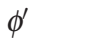 & peak effective friction angle: ${ }^{\circ}$ \\
\hline$\phi_{\mathrm{cr}}^{\prime}$ & critical state friction angle: ${ }^{\circ}$ \\
\hline$\phi_{\text {CIUC }}^{\prime}$ & $\begin{array}{l}\text { effective friction angle from CIUC triaxial } \\
\text { testing }\end{array}$ \\
\hline$\phi_{\mathrm{DS}}^{\prime}$ & effective friction angle for direct shear: ${ }^{\circ}$ \\
\hline$\phi_{\text {DSS }}^{\prime}$ & effective friction angle for direct simple shear: ${ }^{\circ}$ \\
\hline$\phi_{\mathrm{RS}}^{\prime}$ & effective friction angle from ring shear tests: ${ }^{\circ}$ \\
\hline$\phi^{\prime}$ & $\begin{array}{l}\text { effective friction angle for triaxial } \\
\text { compression: }{ }^{\circ}\end{array}$ \\
\hline
\end{tabular}

Introduction

Peat and other highly organic soil deposits are encountered in many geographical areas, covering large areas of the world's land mass, and they are considered challenging materials in geotechnical engineering practice, with many aspects of their behaviours seemingly remaining enigmas. Various definitions exist throughout the world for differentiating peat from other soils, but typically, soil materials with greater than $20 \%$ and $75 \%$ organics (dry mass basis) are classified as high-organic soil and peat (ASTM D 4427-13 (ASTM, 2013)), respectively.

Peat deposits are complex natural formations, and they consist of the fragmented remains of dead plant vegetation, at various stages of decomposition, which have accumulated over time under waterlogged conditions. To gain an understanding of the strength properties of peat material, one must understand how peat is formed, its degree of decomposition, fibrous nature, very high compressibility and relatively high permeability. The physical nature and origins of peat deposits are explained from an engineering perspective in the paper by Hobbs (1986), which the reader is referred to for further information on these aspects. Morphological differences arise from the circumstances producing the peatland formation and its constituent plant types. These differences extend to the structure, fabric, level of humification and proportion of non-organic constituents, factors that have considerable impacts on engineering behaviour (Hobbs, 1986; O'Kelly, 2015a; O'Kelly and Pichan, 2013).

As such, peat material has extremely high water content, high organic matter content, low specific gravity of solids, low bulk and 
dry densities and it typically exhibits low shear strength, very high compressibility and creep rates, and although it is invariably waterlogged in situ, it is not fully saturated on account of gases (such as carbon dioxide $\left(\mathrm{CO}_{2}\right)$, hydrogen sulfide $\left(\mathrm{H}_{2} \mathrm{~S}\right)$ and methane $\left(\mathrm{CH}_{4}\right)$ ) generated internally due to the ongoing biochemical degradation of the organic fraction. Fibres in peat material are in the forms of decomposed wood remains, leaves, stems and leave stalks, rootlets, rhizoids and any other elongated plants or plant remains. In an intact state, the peat fibres themselves have relatively high tensile strength and they also provide conduits for the preferential flow of water through the bulk material (Hobbs, 1986; O'Kelly, 2015a; O'Kelly and Pichan, 2013). For peat deposits, the fibre deposition and subsequent large vertical strains experienced during the onedimensional (1D) consolidation in situ produce an inherent structural cross-anisotropy (Helenelund, 1967; Landva and Pheeney, 1980; Yamaguchi et al., 1985a), the degree of which is dependent on the material's level of humification (Hendry et al., 2012), although an exception is upland blanket bog peat material (Long and Jennings, 2006).

In recent decades, engineering problems associated with peat deposits, such as failures of embankments (Den Haan and Feddema, 2013) and dikes (Bezuijen et al., 2005; McInerney et al., 2006; O'Kelly, 2008), large-scale slope failures (Boylan et al., 2008; Long and Jennings, 2006; Long et al., 2011) and wind-turbine foundation failures (Lindsay and Bragg, 2005), have focused much attention on the research of peat mechanical properties. Further, historically, some dikes and canals (e.g. in the Netherlands and Ireland) have been constructed on peat deposits and (or) using peat material in their construction, which leaves a legacy of high-risk structures.

Although the engineering properties of fibrous peats are significantly different from those of most inorganic soils, nevertheless, according to Mesri and Ajlouni (2007), the same fundamental mechanisms and factors control the behaviours of inorganic soil and fibrous peat. There has been mild questioning whether the effective-stress principle in its classical form and also whether the application of the effective-stress strength parameters $\left(c^{\prime}, \phi^{\prime}\right)$ in the Mohr-Coulomb failure criterion are appropriate to peat (Boylan et al., 2008). More generally, the effective stress for saturated soil is expressed as the difference between the total stress and some fraction $(h)$ of the pore-water pressure $\left(p_{\mathrm{wp}}\right)$ value. According to Rong et al. (2017), the value of $h$ depends on the porosity and the proportion of the particle surfaces to which the $p_{\mathrm{wp}}$ is applied, decreasing significantly with increasing effective stress for clays with high plastic limit values. They concluded that without consideration of the reduction in the factor $h$, effective-stress strength parameter values for high plasticity soils are overestimated for consolidated undrained triaxial compression tests. However, broad consensus is that the principle of effective stress and routinely used soil mechanics strength models, including Mohr-Coulomb, correlate with the mechanical behaviour of peat to a sufficiently high degree (Mesri and Ajlouni, 2007; O'Kelly, 2015a; Yang et al., 2016; Zhang and O'Kelly, 2014). The main constitutive theories and models for fibrous peats and other highly organic soils are reviewed by Zhang and O'Kelly $(2013,2015)$.

Various laboratory investigations (Adams, 1961, 1965; Edil and Dhowian, 1981; Hanrahan and Walsh, 1965; Hanrahan et al., 1967; Yamaguchi et al., 1985a) have studied the shear strength properties of several types of peat materials and have shown that their behaviours are essentially frictional, with (very) high effective friction angle $\left(\phi^{\prime}\right)$ values, although they also possess some small cohesion $\left(c^{\prime}\right)$ value. For inorganic soil (particle density $\left(\rho_{\mathrm{s}}\right)$ typically ranging $2 \cdot 55-2 \cdot 70 \mathrm{Mg} / \mathrm{m}^{3}$ ), the small apparent $c^{\prime}$ value, if present for the normally consolidated (NC) condition, is usually ignored in geotechnical analyses for typical engineering-design stress levels (i.e. conservative approach). However, for peaty material $\left(\rho_{\mathrm{s}} \approx\right.$ $\left.1 \cdot 4-1 \cdot 6 \mathrm{Mg} / \mathrm{m}^{3}\right)$, the combination of the low bulk unit weight and waterlogged condition results in low or negligible field effective stresses, such that its small $c^{\prime}$ value can be significant - for instance, in relation to realistic stability assessments for upland blanket bog peat deposits (Boylan et al., 2008; Dykes, 2008).

The challenges of experimental investigations of peat material derive from the difficulties in obtaining, handling and preparing undisturbed test specimens because of the material's extremely high water content and the fibres present, its potential for significant biodegradation in a laboratory environment (Pichan and O'Kelly, 2013) and problems in achieving appropriate stress levels in standard laboratory strength apparatus and in analysing the experimental results (interpreting specimen failure). For instance, biogenic gas generated internally in the peat specimen during longer-duration triaxial strength tests (Acharya et al., 2016; Kellner et al., 2005) causes an increase in pore pressure and a reduction in the effective confinement pressure acting on the test specimen and, hence, in the mobilised shear strength (O'Kelly, 2013), according to the effective stress Mohr-Coulomb strength criterion.

Due to structural anisotropy, the shearing resistance and, hence, the values of undrained shear strength $\left(s_{\mathrm{u}}\right), c^{\prime}$ and $\phi^{\prime}$ vary for many peat deposits depending on the orientation of the shearing plane relative to the inherent cross-anisotropic fabric given by the general horizontal alignment of the fibres present. Further, it is necessary to investigate peat strength (and deformability), not only in compression and shear, but also in tension. In other words, for a given NC fibrous peat material, generally, $s_{\mathrm{u}}$ TC $\gg s_{\mathrm{u} \text { DSS, }} c_{\mathrm{TC}}^{\prime}>$ $c_{\mathrm{DS}}^{\prime}>c_{\mathrm{DSS}}^{\prime}$ and $\phi_{\mathrm{TC}}^{\prime} \gg \phi_{\mathrm{DS}}^{\prime}>\phi_{\mathrm{DSS}}^{\prime}$ (e.g. see Farrell and Hebib (1998)), where the subscripts TC, DS and DSS denote triaxial compression, direct shear (i.e. shear box) and direct simple shear, respectively. Numerous examples are given later in the paper to demonstrate these behaviours. An exception is upland blanket bog peat material, for which the fibres are typically orientated and spaced randomly (Long and Jennings, 2006), with no detected pattern in measured horizontal and vertical undrained tensile strengths (Dykes, 2008).

The purpose of this state-of-the-art review paper is to present an assessment and interpretation of the laboratory undrained strength 
and the effective-stress strength and at-rest earth pressure coefficient $\left(K_{0}\right)$ parameter values measured for fibrous peats, with these parameters required in the design of embankments and other engineered structures over such deposits and for stability assessments for natural peat slopes.

Not only structural anisotropy and the scale effect due to material heterogeneity, but also the dimensions of the test specimen relative to the fibre length in the peat test material (O'Kelly, 2015a; Zwanenburg and Van, 2015) influence deduced $s_{\mathrm{u}}, c^{\prime}$ and $\phi^{\prime}$ values. According to Zwanenburg et al. (2012), it is unclear whether the failure mechanism in $\mathrm{TC}$ testing is sufficiently representative so as to allow the determination of pertinent deformation parameter values for behaviour at the application scale. DSS testing is generally regarded as providing parameter values appropriate for the analysis of planar translational slides. Further, significant features of fibrous peat deposits often overlooked in geotechnical analysis and design are their likely initial overconsolidated (OC) state and tensile strength, with the latter dependent on the orientation of the loading direction relative to the general cross-anisotropic fabric given by the fibres. Both of these features contribute to the relatively high true effective cohesion values that can be mobilised for the low effective stresses often encountered in situ on account of the low peat density combined with the high groundwater table. True cohesion is also derived from the connectivity between the elementary structures in fibrous peat - that is, shear and tension failures involve tearing of the elementary structures, entangled fibres and cellular connections (Boylan et al., 2008; Landva et al., 1986; O'Kelly, 2015a; O'Kelly and Orr, 2014).

Since the lower bound stress-level capabilities of most standard laboratory strength-testing equipment may not encompass the in situ effective stresses for many peat deposits and, furthermore, corrections related to apparatus compliance (and membrane stiffness in some set-ups) would in any case constitute a large proportion of the measured strength value (O'Kelly, 2015a), one is often compelled to perform laboratory strength testing at stress levels greater than the in situ effective stresses. Hence, much of the knowledge gained regarding peat strength has been for effectivestress levels significantly greater than those normally encountered in situ. Since most natural peat deposits are $\mathrm{OC}$ to some degree, a linear extrapolation of the laboratory derived $\mathrm{NC}$ failure envelop downwards to the in situ effective-stress levels (for instance, in performing stability assessments for the upland blanket peat deposits mentioned earlier) would result in an underestimation of the peat's in situ strength. Further, although the tensile strength of fibrous peat may have a particular importance in understanding stability problems, particularly for upland blanket peat deposits (Dykes, 2008), direct-tension testing of fibrous peat is rarely performed in practice. All of the mentioned aspects are carefully explored in the paper. As evident from the preceding sections, the engineering behaviour/properties of peat material depend on its fibre content, which is also the case observed for fibre-reinforced soil. Hence, a section is included in this paper on the subject of fibre-reinforced soil engineering, which has developed greatly as a ground improvement technique over the past 30-35 years.

The main discussion then focuses on how laboratory strength testing of fibrous peat material needs to be executed and interpreted in order to become representative of the field behaviour. Based on documented case histories, this paper gives guidance on operational shear strength assessment in peat, aimed at performing bearing capacity and slope stability calculations by using the normalised undrained strength ratio (i.e. $s_{\mathrm{u}} / \sigma_{\mathrm{vc}}^{\prime}$ ) and limit equilibrium effective-stress strength $\left(c^{\prime}, \phi^{\prime}\right)$ approaches in conjunction with laboratory-derived strength parameter values. It is hoped that this work will contribute to the overall understanding of this topic, including the best way forward for determining the pertinent undrained and effective-stress strength properties of peat materials. However, it should be kept in mind the great spatial variability in engineering properties and fibrosity of peat deposits (Hobbs, 1986; Landva and Pheeney, 1980; O'Kelly and Sivakumar, 2014). Although not the subject of this paper, it is also useful to determine the soil parameter values for geotechnical designs by using in situ tests and geophysical techniques that can measure pertinent soil parameters continuously to the required depth (e.g. see Long and Boylan (2012) and Zwanenburg and Jardine (2015)). This is important since a slip surface can go from weak spot to weak spot within the peat deposit, resulting in an overall mobilised strength value lower than the mean of the measured strength values (progressive failure).

\section{Botanical composition, degree of humification and strength properties}

The upper $0 \cdot 1-0.6 \mathrm{~m}$ deep layer of a peat deposit is known as the 'acrotelm', defined by the normal range of water table fluctuations and within which the living roots help to bind the loosely accumulating plant remains together. Below this is the 'catotelm' layer, which comprises more highly decomposed and waterlogged peat material. For peat classification, the type of parent vegetation should always be reported, either by using terms such as 'moss peat' or 'grass peat' or, preferably, by referring to the predominant plant type(s) present - for example, Sphagnum peat or sedge peat (Farrell, 2012; Helenelund, 1967; O'Kelly, 2015a). The water content, organic content, fibrosity, degree of humification and (dry) density should also be included in the classification for geomechanical purposes, with the standard oven-drying temperature range of $105-110^{\circ} \mathrm{C}$ used for water content determinations on inorganic soils also appropriate for routine water content determinations on fibrous peat materials (O'Kelly and Sivakumar, 2014; Skempton and Petley, 1970). In many cases, however, tested peats are poorly described (often only the water content and loss on ignition values are given), making comparisons between reported geomechanical properties for different peat materials investigated difficult.

The extent to which differences in botanical composition influence the strength and stiffness of peat material is the subject of some debate, with documented evidence on the subject relatively sparse. Mesri and Ajlouni (2007), for instance, contest that the engineering 
properties of peats are relatively independent of the botanical differences. On the other hand, Farrell (2012) reported that the geotechnical behaviour of peat is very dependent on its genesis. According to Helenelund (1967), the type of the surface moss has a considerable influence on the tensile strength of the peat mat; for instance, Polytrichum commune produces greater tensile strength than Polytrichum strictum does, with both of these moss types apparently having greater tensile strength than Sphagnum moss. O'Kelly (2015b) reported nominal undrained shear strength profiles determined from field vane measurements $\left(s_{\mathrm{u}} \mathrm{FV}\right)$ for Ballydermot Raised Bog, with this peat deposit comprising three distinct sublayers: a desiccated zone within a Sphagnum peat layer that was underlain by fen/reed peat (Figure 1), with the reported strength values calculated as $\mu_{\mathrm{FV}} \times s_{\mathrm{u} \mathrm{FV}}$, where $\mu_{\mathrm{FV}}$ is a correction factor with a value of 0.5 (Mesri and Ajlouni, 2007; Zwanenburg and Jardine, 2015). The significant difference in the shear strength profiles for the waterlogged Sphagnum and fen/reed peat layers is related to their different botanical compositions and is also partly due to the hydrological conditions at the test site, with the fen/reed peat layer underlain by higher-permeability subartesian inorganic layers that tended to act as a bottom drainage boundary, inducing downward flow in the lowermost portion of the peat deposit. This example illustrates the importance of knowledge of the bog hydrology in understanding the in situ geomechanical behaviour.

The strength properties of peat material are strongly influenced by its degree of humification (fibre content) (Boylan and Long, 2014). For

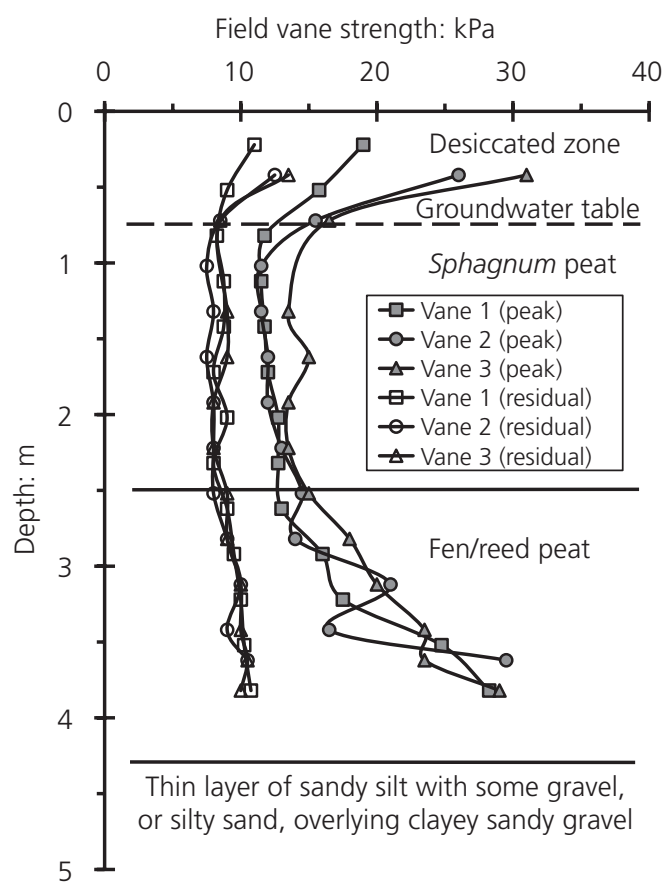

Figure 1. Nominal undrained shear strength against depth profiles from field vane tests performed at a cutaway section of the Ballydermot Raised Bog $\left(w_{0}=500-1350 \% ; H_{(5)}-H_{(7)}\right.$ von Post category) (adapted from O'Kelly (2015b) with permission of Elsevier) instance, the effective friction angle, $\phi_{\mathrm{TC}}^{\prime}$, correlates to some extent with bulk unit weight and organic content (Den Haan and Feddema, 2013; Edil and Wang, 2000), with $\phi_{\mathrm{TC}}^{\prime}$ increasing with increasing organic content and reducing bulk unit weight (see Figure 2), since more fibrous peat material has a higher natural water content and, hence, lower bulk unit weight. Referring to Figure 3, the tensile strength of upland blanket bog peat shows a general reducing trend with increasing degree of humification (reducing fibrosity) since more degraded fibres, and hence significantly reduced reinforcement, would be expected in more humified peat material.

The extent of cross-anisotropy not only increases with increasing fibre content (Hendry et al., 2012) and for lower levels of humification, but also tends to be affected by the type of peat deposit (fen, bog, reed etc.). In other words, the decomposition of fibrous peat material reduces its level of structural anisotropy (Pichan and O'Kelly, 2012; O'Kelly and Pichan, 2013). However, not all fibrous peat deposits have a general cross-anisotropic fabric - for example,

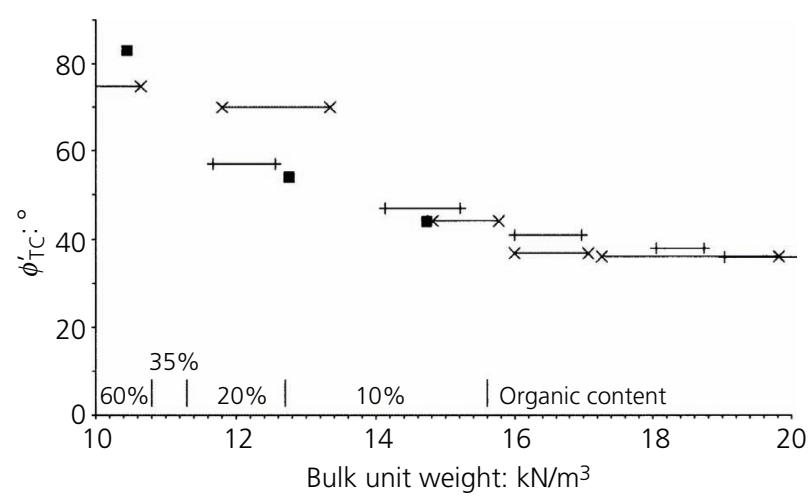

Figure 2. Effective friction angle for triaxial compression testing of some Dutch organic soils, as functions of bulk unit weight and organic content (adapted from Den Haan and Feddema (2013))

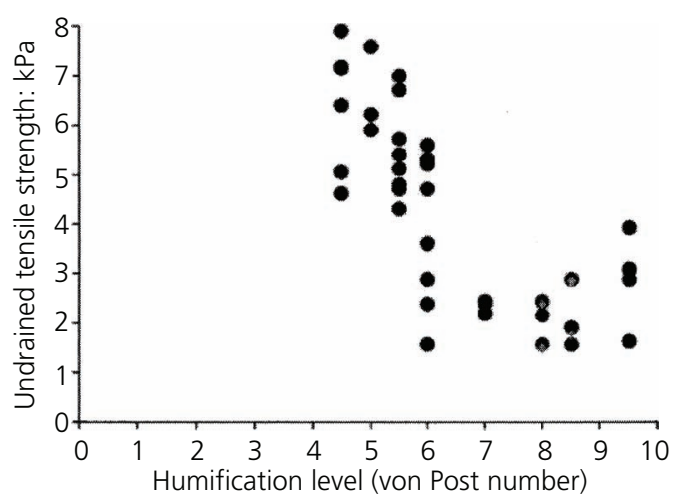

Figure 3. Undrained tensile strength (against humification level) determined from direct-tension tests on $100 \mathrm{~mm}$ square by $60 \mathrm{~mm}$ thick field-wet block samples of Cuilcagh, Geevagh and Maghera Blanket Bog peats (adapted from Dykes (2008) with permission of Springer) 
Measurement, interpretation and recommended use of laboratory strength properties of fibrous peat O'Kelly the fibres in upland blanket bog peat material are typically orientated and spaced randomly (Long and Jennings, 2006).

Figure 4 gives a clear indication of the hierarchy in the extent of structural anisotropy expected for different botanical peat types of Polder Zegveld (the Netherlands), with the axial $\left(\varepsilon_{\mathrm{a}}\right)$, horizontal $\left(\varepsilon_{\mathrm{h}}\right)$ and volumetric $\left(\varepsilon_{\mathrm{vol}}\right)$ strain values calculated from shrinkage measurements taken in the vertical and horizontal directions during air-drying of representative test specimens. Referring to Figure 4, compared with the other peat types investigated, the decomposed

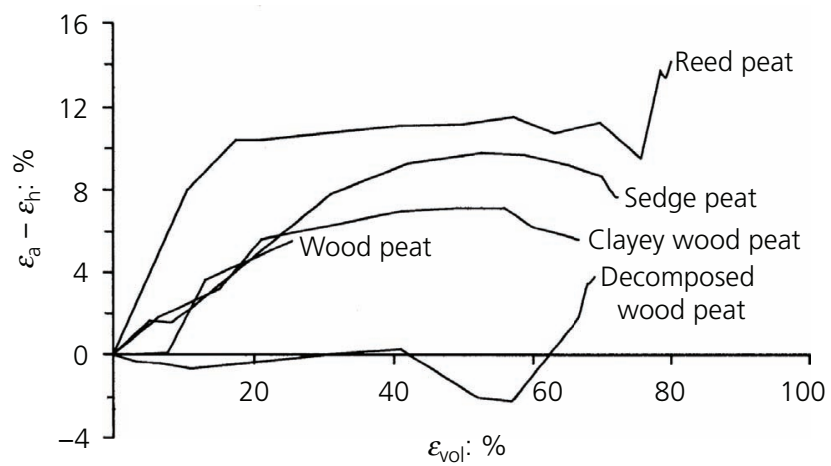

Figure 4. Anisotropy of different peat materials from Polder Zegveld, the Netherlands, as revealed by shrinkage tests (adapted from Den Haan and Kruse (2007)): $\varepsilon_{\mathrm{a}}$, $\varepsilon_{\mathrm{h}}$ and $\varepsilon_{\mathrm{vol}}$ are vertical, horizontal and volumetric specimen strains, respectively wood peat dried without distortion (i.e. $\varepsilon_{\mathrm{a}} \approx \varepsilon_{\mathrm{h}}$ ), indicating that this amorphous peat material is essentially isotropic.

\section{Laboratory strength testing of fibrous peat}

The effective-stress strength properties are usually determined in the laboratory setting by using consolidated undrained (CU) or consolidated drained (CD) triaxial testing (Figure 5), with the consolidation stage performed under an isotropic or anisotropic (usually $K_{0}$ ) stress condition. The shearing stage is performed in either TC or triaxial extension mode (usually the former), with the orientation of the major principal stress $(\alpha)$ fixed at an angle of 0 or $90^{\circ}$, respectively, relative to the vertical direction. For peat material, the 'end-of-primary' condition for the consolidation stage should be established from analysis of the measured $p_{\mathrm{wp}}$ dissipation (rather than volumetric strain) against time data (Edil and den Haan, 1994; O'Kelly and Zhang, 2013). From these tests, the $\mathrm{CU}$ triaxial approach is generally preferred on account of the shorter duration of the associated specimen shearing stage.

As described in the section headed 'DSS testing', constantvolume DSS and ring shear (RS) testing, with measurement of the $p_{\text {wp }}$ response, and CD DS and CD RS testing (refer to Figure 5) can also be performed for the same purpose. Of these, the DSS approach is preferred on account of the gross strain (and hence stress) non-uniformities induced in the test specimens during shearing for RS and particularly DS (Landva et al., 1986) testing. For instance, axial compression of the peat test specimen on account of ongoing consolidation occurring during the drained

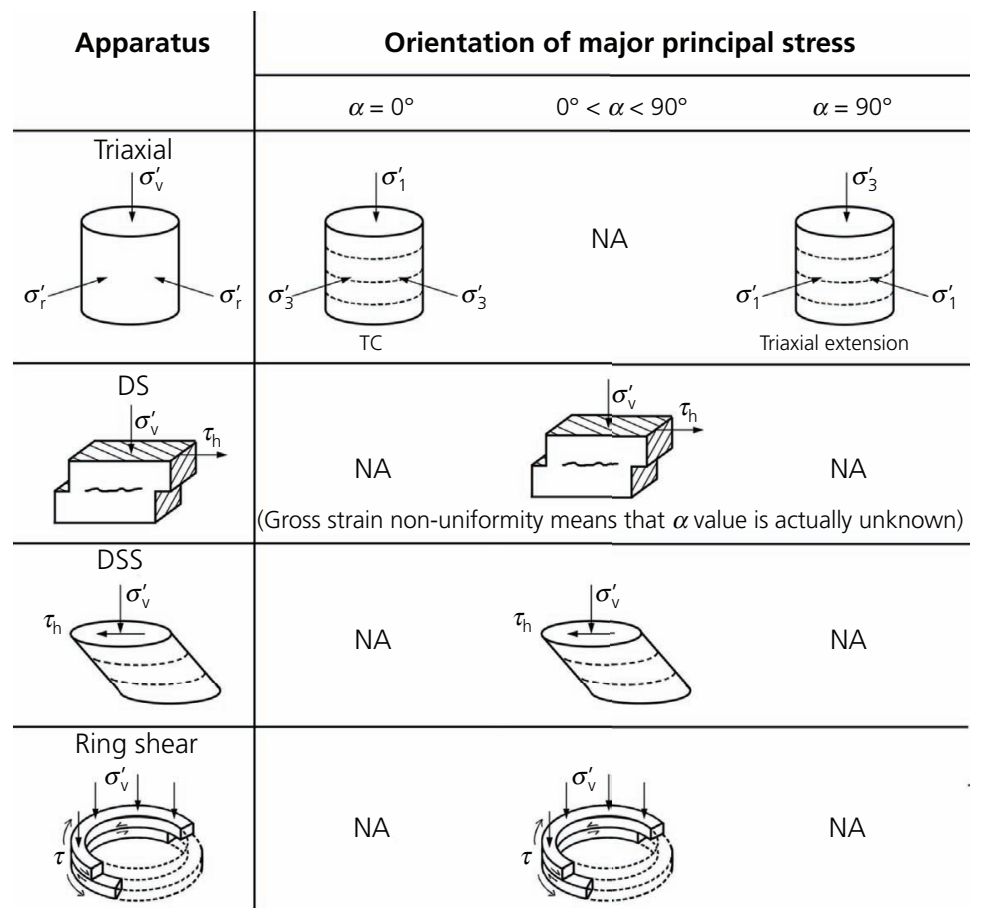

Figure 5. Specimen stress, deformation and boundary conditions for some customary laboratory-strength apparatus (adapted from O'Kelly (2015a)). NA, not applicable 
shearing stage of DS tests means that the specimen shear plane must try and continuously realign upwards with respect to the mid-height (i.e. predetermined shear plane) of the shear box. For the DSS, DS and RS modes, as the applied horizontal force is increased, the major principal stress continuously reorientates from its initial vertical direction at the start of the shearing stage. However, the $\alpha$ value is actually unknown for the DS shearing mode because of the gross strain non-uniformity developed in the test specimen. The measurement of the tensile strength of peat, which is usually performed using tension box apparatus, is described in the section headed 'Tensile strength of fibrous peat'.

Another strength measurement approach is to use the hollow cylinder apparatus (e.g. see O'Kelly and Naughton (2005, 2009)), which has greatly improved the understanding of the constitutive behaviour of sands, silts and clays. A few investigations have been performed using this device for fibrous and clayey peats (e.g. anisotropic consolidation and cyclic shear loading of $70 \mathrm{~mm}$ outer diameter, $30 \mathrm{~mm}$ inner diameter and $70 \mathrm{~mm}$ long peat specimens reported by Yamaki et al. (2015)), although the usefulness of this approach for peat material is questionable since greater levels of disturbance are likely during preparation of the hollow cylindrical test specimens (Helenelund, 1967) and oblique orientations of the stress tensor for shear strength tests may tend to rotate the fibres, most likely in a non-homogeneous fashion (Den Haan and Kruse, 2007). Hence, the main focus of this review paper is on the CU triaxial, DSS and direct-tension testing methods.

\section{CU TC testing}

The challenges encountered in standard CU TC testing of peat were described by Edil and Wang (2000), Farrell (2012), Long (2005) and O'Kelly (2015a), among others. These include large volume reductions during the consolidation stage, so that the verticality of the test specimen may not be maintained, and the zero radial effective-stress condition $\left(\sigma_{\mathrm{r}}^{\prime}=\sigma_{3}^{\prime}=0\right)$ is approached or sometimes reached during the undrained compression stage, yet the deviator stress $(q)$ against axial strain $\left(\varepsilon_{\mathrm{a}}\right)$ traces often do not develop peaks before equipment strain limits are reached for $\varepsilon_{\mathrm{a}} \approx$ $20 \%$ (see Figure 6). Further, the principal stress ratio $\left(\sigma_{1}^{\prime} / \sigma_{3}^{\prime}\right)$ against axial strain traces continue to increase with increasing strain, with typical $\sigma_{1}^{\prime} / \sigma_{3}^{\prime}$ values developed for CU TC testing of fibrous peats ranging $10-100$. The $c_{\mathrm{TC}}^{\prime}$ value is intimately dependent on the interpretation of the $\phi_{\mathrm{TC}}^{\prime}$ value (Den Haan and Kruse, 2007; O'Kelly, 2015a) (true also for the other approaches to shear strength measurement described earlier), with low $c_{\text {TC }}^{\prime}$ values ranging $0-6 \mathrm{kPa}$ typically reported for fibrous peats (Edil and Zhang, 2000). In addition, according to Zwanenburg and Jardine (2015), $K_{0}$ is difficult to estimate reliably for peat materials, and anisotropic reconsolidation of the peat test specimen is difficult to apply for the very low effective stresses often encountered in situ.

According to Cola and Cortellazzo (2005), $K_{0}$ consolidated specimens develop higher $p_{\mathrm{wp}}$ values in undrained TC when compared with isotropically consolidated undrained compression (CIUC) specimens for the same deviator stress level, such that the $\sigma_{\mathrm{r}}^{\prime}=0$ condition can be reached for $\varepsilon_{\mathrm{a}}>\sim 5 \%$ in $\mathrm{C} K_{0} \mathrm{UC}$ triaxial tests (e.g. see Figure 6(b)). In other words, since fibrous peat deposits have an inherent structural anisotropy, $K_{0}$ and isotropic triaxial consolidation produce different induced anisotropies (fabrics) and, hence, result in different stress-strain-strength behaviours. As described by Zwanenburg and Van (2015), for the $\mathrm{C} K_{0} \mathrm{UC}$ condition, with the specimen's initial diameter maintained during the consolidation stage, the fibres are stretched as the specimen starts to bulge under undrained shearing, activating the

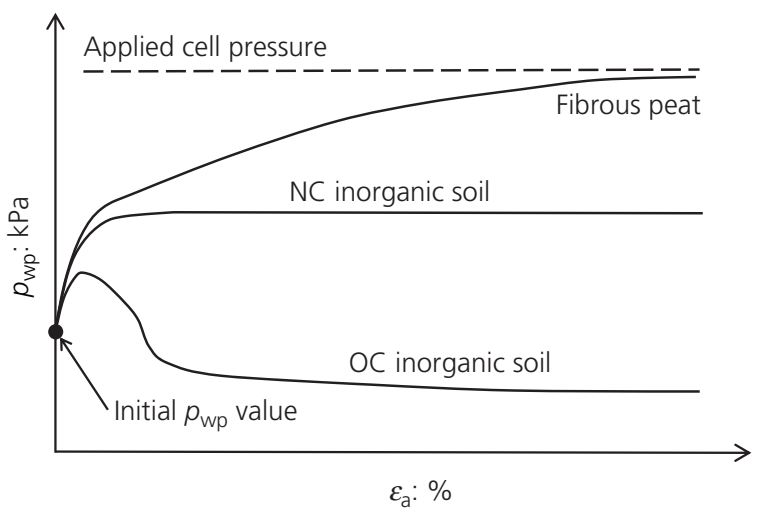

(a)

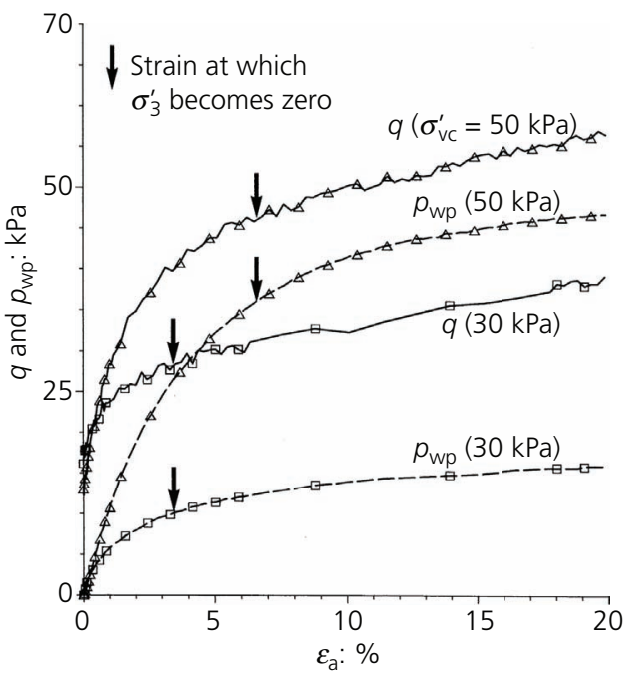

(b)

Figure 6. Undrained TC: (a) indicative $p_{\mathrm{wp}}$ responses for fibrous peat and inorganic soils; (b) deviator stress and $p_{\mathrm{wp}}$ against axial strain traces from $K_{0}$-consolidated undrained compression $\left(C K_{0} \cup C\right)$ triaxial testing of $70 \mathrm{~mm}$ dia. undisturbed Correzzola peat specimens $\left(W_{\mathrm{O}}=\right.$ $770 \% ; H_{(5)}$ von Post) (adapted from Cola and Cortellazzo (2005) with permission of Springer) 


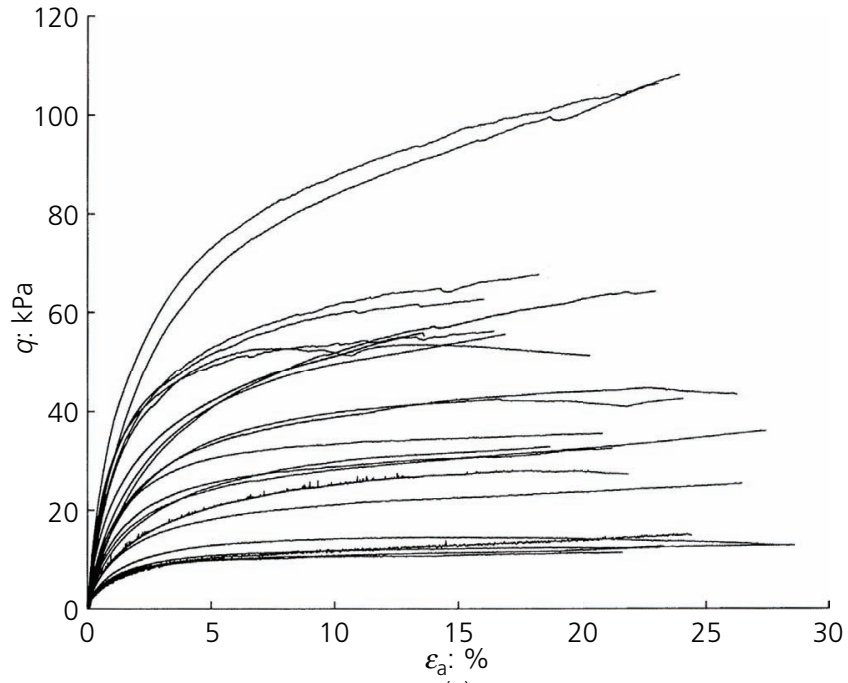

(a)

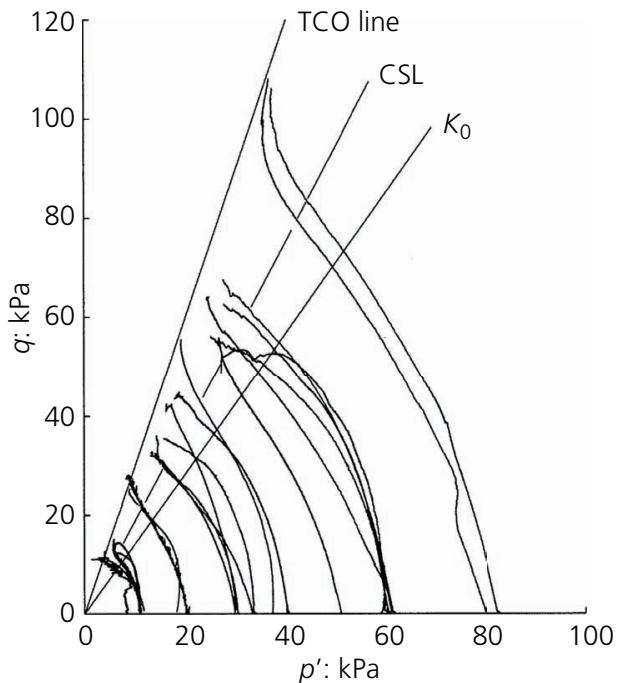

(b)

Figure 7. CIUC TC testing of $65 \mathrm{~mm}$ dia. Uitdam sedge-reed peat specimens ( $w_{\mathrm{o}}=645-1240 \%$; $H_{(2)}-H_{(3)}$ von Post): (a) deviator stress against axial strain (adapted from Zwanenburg and Jardine (2015)); (b) ESPs (adapted from Zwanenburg and Jardine (2015)). Note the location of the critical state line (CSL) shown in Figure 7(b) was interpreted as part of the present investigation

fibre reinforcement effect and thereby resulting in strain hardening behaviour. For the CIUC condition, however, the specimen diameter reduces and larger volumetric strain occurs during the consolidation stage, such that as the specimen starts to bulge under undrained shearing, the fibres are not stretched (since the specimen diameter is smaller than its initial value) such that their reinforcement effect is not activated to the same extent. Hence, the effective-stress path (ESP) traces for CIUC tested fibrous peat specimens generally do not reach the 'tension cut-off' (TCO) line.

Referring to the $p^{\prime}-q$ plot in Figure 7(b), if they reach the TCO line (i.e. $\sigma_{\mathrm{r}}^{\prime}=0$ condition), the ESP traces for $\mathrm{CU}$ TC of fibrous peat specimens will then follow up along the TCO line with an inclination $M$ of 3:1 (e.g. see Den Haan and Kruse (2007), Yamaguchi et al. (1985a), Zwanenburg and Jardine (2015) and Zwanenburg et al. (2012)), making it difficult to define when specimen failure occurs. Note that $M=3$ gives $\phi_{\mathrm{TC}}^{\prime}=90^{\circ}$, indicating an axial tensile failure mode, which has been observed experimentally for CU TC testing of large fibrous peat specimens (400 $\mathrm{mm}$ dia.), as described in the section headed 'Scale effect related to test-specimen size'. Note that the TCO line in Figure 7 (b) has been drawn passing through the origin $\left(\Rightarrow c_{\mathrm{TC}}^{\prime}=0\right)$, which is a reasonable assumption for NC peat material - that is, this would result in a slightly conservative approach. However, for low effective stresses, this failure condition would not accurately represent the real behaviour of undisturbed fibrous peat on account of its generally $\mathrm{OC}$ state and relatively high tensile strength (discussed in the sections headed 'Tensile strength of fibrous peat' and 'Failure envelope and stress paths for TC').

The $\sigma_{\mathrm{r}}^{\prime}=0$ condition that develops during CU TC testing of some fibrous peats has been explained in terms of the internal lateral resistance against shear deformation provided by the predominantly horizontally-orientated plant fibre remnants present in the peat material (Cola and Cortellazzo, 2005; Landva, 2007; Landva and La Rochelle, 1983). This so-called fibre tensioning occurs during expansive (tensile) strain on the horizontal plane, giving the material its low drained Poisson's ratio, $v^{\prime}$, and strong anisotropy in strength (see Den Haan and Kruse (2007)). For instance, $v^{\prime}$ values of $0 \cdot 10$ (Zwanenburg, 2005), $0 \cdot 11,0 \cdot 14$ (Rowe et al., 1984) and 0.15 (Rowe and Mylleville, 1996; Tan, 2008) have been reported from CU TC testing of fibrous peats.

Recent experimental laboratory and numerical work presented by Zhang et al. (2017) investigated the tensile contribution of the fibres in undisturbed fibrous peat for undrained TC, with the structural cross-anisotropy modelled by extending a hyperviscoplastic formulation proposed for peat material using a fibre layer characterised by a vector field. Based on $240 \mathrm{~mm}$ dia. RS tests on Escuminac Sphagnum peat, Landva and La Rochelle (1983) presented a technique for estimating the apparent increase in lateral resistance provided by the fibres and the resulting effect on the shearing behaviour of fibrous peat. Hendry et al. (2012) proposed a procedure for estimating the interparticle frictional strength of fibrous peat from CU triaxial testing of $38 \mathrm{~mm}$ dia. specimens, while Cola and Cortellazzo (2005) presented a bilinear failure criterion for fibrous peats based on soil-reinforcement interaction mechanisms. To measure (isolate) the effects and contributions of the peat fibres, fibre content and in situ structure on the strength and stiffness properties, Cola and Cortellazzo (2005) performed CU triaxial tests on undisturbed specimens and reconstituted specimens without fibres, while Hendry et al. (2012) performed CU triaxial and DS tests on Shelby peat specimens, remoulded peat specimens and fibre-only remoulded specimens. 
Fibre tensioning does not, however, explain the similar behaviours exhibited for CU TC testing of amorphous peat and organic clay materials lacking such a fibre framework. O'Kelly (2015a) postulated that greater creep and strain rate dependency $(\mu)$ expected for such materials, combined with the slow axial strain rates necessary for equilibration of excess $p_{\mathrm{wp}}$ during the undrained compression stage, would result in lower mobilised deviator stress, greater excess $p_{\mathrm{wp}}$ and hence reduced $\sigma_{\mathrm{r}}^{\prime}$ values, thereby producing higher $M$ and $\phi_{\mathrm{TC}}^{\prime}$ values (refer to Figure 8). Compared with $\mu=0 \cdot 1$ \pm 0.05 typical of inorganic soils (Koumoto and Houlsby, 2001; Kulhawy and Mayne, 1990; Ladd and Foott, 1974), $38 \mathrm{~mm}$ dia. blended (amorphous) Clara Bog peat material, for instance, had a reported $\mu$ value of $0 \cdot 28$ for undrained TC (O'Kelly, 2017). In other words, a tenfold decrease in strain rate produced a $28 \%$ decrease in the mobilised $s_{\mathrm{u}}$ TC value. High $\phi_{\mathrm{TC}}^{\prime}$ and strain rate dependency values $(\mu=0 \cdot 20-0 \cdot 39$ for $N=57-70 \%$, where $N$ is the ignition loss) have also been deduced from $\mathrm{CU}$ TC testing of municipal sludge and residue materials (O'Kelly, 2016, 2017) - for example, the alum-water-treatment residue material investigated had $\phi_{\text {CIUC }}^{\prime}=39^{\circ}$.

Triaxial effective-stress friction angle, undrained strength and normalised undrained strength ratio for

conventionally sized NC peat specimens

Standard TC and triaxial extension (e.g. see Farrell and Hebib (1998) and Yamaguchi et al. (1985a, 1985b)) testing of fibrous peat invariably manifests exceptionally high $\phi_{\mathrm{TC}}^{\prime}$ values, typically ranging $50-55^{\circ}$ (see Table 1 ), as compared with $\phi_{\mathrm{TC}}^{\prime}<35^{\circ}$ for soft clay and silt materials.

The pertinent question is how much of the high laboratorymeasured peak friction angle values for fibrous peats can be counted on to operate in an effective-stress analysis for field conditions. According to Den Haan and Feddema (2013), it appears possible to do full justice to the peculiar combination of low strength and stiffness and high friction angle of fibrous peats by means of the numerical (finite-element (FE)) method and by employing a viscous version of the Cam-clay model. However, present engineering practice generally employs empirical methods to obtain acceptable (reduced) values of $\phi_{\mathrm{TC}}^{\prime}$ for effective-stress

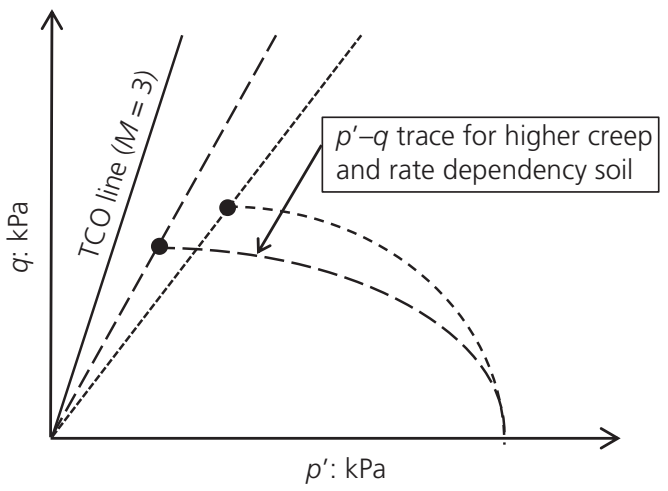

Figure 8. High $M$ (and hence $\phi_{T C}^{\prime}$ ) manifested from high creep and rate dependency of amorphous peat and organic clay in CU TC
Table 1. Effective friction angles of various fibrous peats from standard TC tests on vertically carved specimens (after Mesri and Ajlouni (2007) with permission from ASCE)

\begin{tabular}{|c|c|c|c|}
\hline Peat & $w_{0}: \%$ & $\phi_{\mathrm{TC}}^{\prime}:^{\circ}$ & Reference \\
\hline Muskeg & $375-430$ & $50-60$ & Adams (1961) \\
\hline Moose River & $330-600$ & 48 & Adams (1965) \\
\hline Muskeg & 800 & 46 & Ozden and Wilson (1970) \\
\hline Muck & - & $52-60$ & Tsushima et al. (1977) \\
\hline Omono & - & $50-60$ & Yasuhara and Takenaka (1977) \\
\hline Muck & - & 51 & Tsushima and Oikawa (1982) \\
\hline Middleton & $500-600$ & 57 & $\begin{array}{l}\text { Edil and Dhowian (1981) and } \\
\text { Edil and Wang (2000) }\end{array}$ \\
\hline Portage & 600 & 54 & \\
\hline Escuminac & $1240-1380$ & $40-50$ & Landva and La Rochelle (1983) \\
\hline San Joaquin & $200-500$ & 44 & Marachi et al. (1983) \\
\hline Ohmiya & 960-1190 & $51-55$ & $\begin{array}{l}\text { Yamaguchi et al. (1985a, } \\
\text { 1985b, 1985c) }\end{array}$ \\
\hline Urawa & $980-1260$ & 53 & \\
\hline Middleton & $510-850$ & 60 & Ailouni (2000) \\
\hline
\end{tabular}

stability analysis. For instance, Den Haan and Feddema (2013) and Den Haan and Kruse (2007) reported that in the Netherlands, multistage TC testing in which the loading stages are terminated at axial strains between $2 \%$ and $5 \%$ is performed, with the stress envelopes corresponding to these strain levels taken to represent failure. However, the resulting cohesion intercept value is a testing artefact, such that compared with single-stage TC testing, multistage TC testing is considered less reliable (Tomczak, 2013). For initial void ratio and effective confining pressure combinations that during shear lead to contractive response followed by dilative behaviour, Mesri and Ajlouni (2007) reported that the constant-volume friction angle $\phi_{\mathrm{cv}}^{\prime}$ value is mobilised at the phase transformation (yield) point on the ESP trace - that is, where contractive response changes into dilative behaviour (after Ishihara et al. (1975)) (e.g. see Figure 9 for a derived $\phi_{\mathrm{cv}}^{\prime}$ value of $44^{\circ}$ for the Middleton peat).

Referring to Figure 7(b), after reaching the TCO line, the triaxial ESP trace continues up along the TCO line, indicating a further

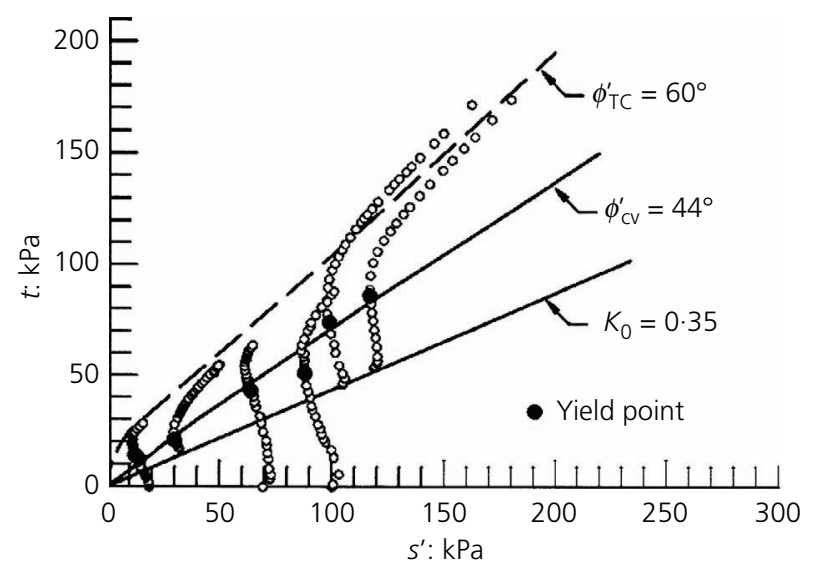

Figure 9. $s^{\prime}-t$ traces from CU TC testing of Middleton peat (adapted from Mesri and Ajlouni (2007) with permission from ASCE) 
increase in deviator stress with increasing axial strain. However, as described by Termaat (1994), from the moment that the ESP trace reaches the TCO line, the test changes to a semi-drained condition (as illustrated in Figure 10(b)), with some pore water squeezed out from the fibrous peat specimen into the gap that forms between it and the enclosing rubber membrane (Cola and Cortellazzo, 2005). In other words, only the test data before this change point indicating the start of the semi-drained condition can be used for interpretation of the undrained response (Termaat, 1994).

Den Haan and Kruse (2007) proposed a graphical procedure to estimate the field-equivalent triaxial shear strength of fibrous peat, which appears similar to the interpretation presented earlier by Termaat (1994). Referring to Figure 10(c), in their approach, the central part of the ESP trace for the undrained compression stage, in which the $p_{\mathrm{wp}}$ value is still increasing, is extended linearly to intersect the TCO line. In other words, the effect of dilation during the latter part of the compression stage is disregarded, thereby giving a reduced undrained shear strength, $s_{\mathrm{u} \text { fTC}}$, value for the peat and, in doing so, reproducing the classical ESP shape associated with undrained TC testing of inorganic soil.

Correlating with consolidation stress leads to normalised undrained strength ratio, $s_{\mathrm{uTC}} / \sigma_{\mathrm{vc}}^{\prime}$, values ranging $0 \cdot 47-0.78$ for conventionally sized triaxial specimens of fibrous peats (see Table 2), indicating that significant strength gains are achieved with consolidation, compared with the typical range of $0 \cdot 30-0 \cdot 35$ for NC clay and silt materials (Ladd, 1991).

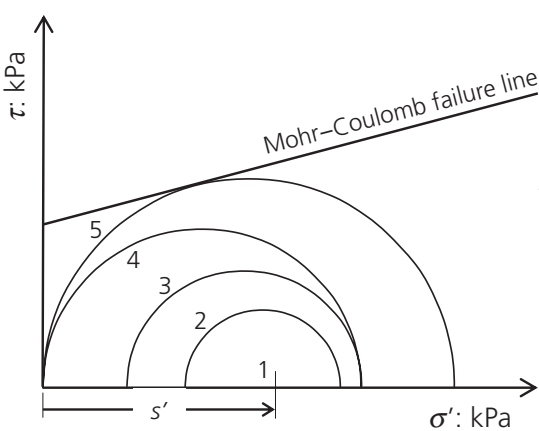

(a)

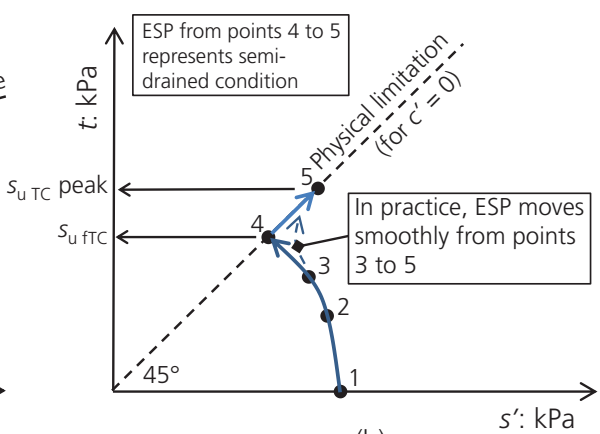

(b)

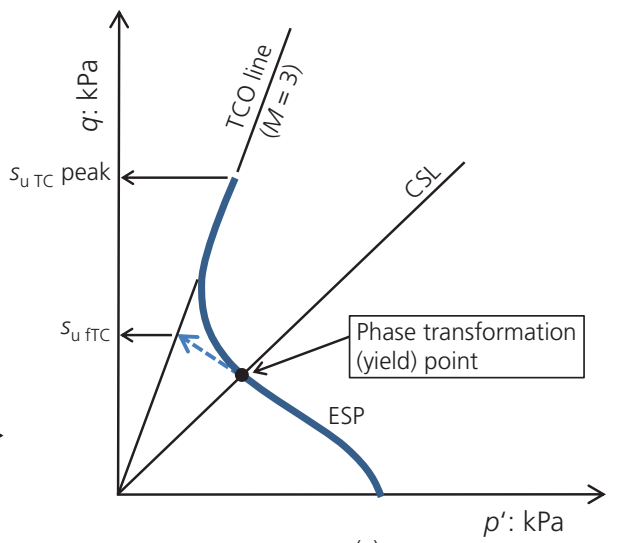

(c)

Figure 10. CU TC testing of fibrous peat: (a) Mohr circle representation; (b) $s^{\prime}-t$ plot; (c) estimation of field-equivalent triaxial shear strength, $S_{\mathrm{u}}$ fTC from linear extrapolation of the central part of the ESP trace to intercept the TCO line

Table 2. Normalised undrained strength ratios for conventionally sized specimens of various fibrous peats in TC

\begin{tabular}{|c|c|c|c|}
\hline Peat & $w_{\mathrm{o}}: \%$ & $s_{\mathrm{u} \mathrm{TC}} / \sigma_{\mathrm{vc}}^{\prime}$ & References \\
\hline Antioch, Algiers & $230-1000$ & $0.48-0.60$ & Moran, Proctor, Mueser and Rutledge (1958) \\
\hline Burnaby & $400-1200$ & $0.47-0.58$ & Lea and Brawner (1959) \\
\hline Moose River & $330-600$ & 0.68 & Adams (1965) \\
\hline Ottawa & $900-1200$ & $0 \cdot 50$ & Forrest and MacFarlane (1969) \\
\hline Omono & - & 0.54 & Yasuhara and Takenaka (1977) \\
\hline - & - & $0.52-0.54$ & Tsushima et al. (1977) \\
\hline Middleton & $500-600$ & $0.55-0.75$ & Dhowian (1978) and Edil and Wang (2000) \\
\hline Portage & 600 & $0 \cdot 70$ & - \\
\hline Ohmiya & $960-1190$ & 0.55 & Yamaguchi et al. (1985a, 1985b, 1985c) \\
\hline Urawa & $980-1260$ & 0.52 & - \\
\hline - & - & $0 \cdot 54-0 \cdot 78$ & Den Haan (1997) \\
\hline Antoniny & - & $0 \cdot 47$ & Lechowicz (1994) \\
\hline Middleton & $510-850$ & $0.53^{a}$ & Ajlouni (2000) \\
\hline Marken & - & $C K_{0} \cup C: 0.62^{b}$ & Den Haan and Kruse (2007) \\
\hline Booneschans & $200-620$ & CIUC: $0.61^{b}$ & Zwanenburg et al. (2012) \\
\hline \multirow[t]{2}{*}{ Uitdam } & $800-1020$ & CIUC: $0.59(n, 23 ; \sigma, 0.13)^{\mathrm{b}, \mathrm{c}}$ & Zwanenburg and Jardine (2015) \\
\hline & & $C K_{0} \cup C: 0.54(n, 8 ; \sigma, 13)^{\mathrm{b}, \mathrm{c}}$ & Zwanenburg and Van (2015) \\
\hline
\end{tabular}

${ }^{\text {a With }} s_{\mathrm{u}} \mathrm{TC}$ defined at the phase transformation point

${ }^{b}$ Based on $S_{\mathrm{u}} \mathrm{fTC}$

${ }^{c} \mathrm{NC}$ specimens

$n$, number of tests; $\sigma$, standard deviation 
For NC Middleton fibrous peat, $\left(s_{\mathrm{uTC}} / \sigma_{\mathrm{vc}}^{\prime}\right)_{\mathrm{NC}}$ was reported as 0.53 (Ajlouni, 2000), with $s_{\mathrm{uTC}}$ defined at the phase transformation point on the ESP trace described earlier, whereas $\left(s_{\mathrm{ufTC}} / \sigma_{\mathrm{vc}}^{\prime}\right)_{\mathrm{NC}}$ values of 0.62 for $\mathrm{C} K_{0} \mathrm{UC}$ (see Figure 11$), 0 \cdot 61$ for CIUC (Zwanenburg et al., 2012) and 0.59 ( $\pm 22 \%)$ for CIUC (Zwanenburg and Jardine, 2015) were deduced based on estimated $s_{\mathrm{u}}$ fTC values for Marken peat, Booneschans fibrous peat and Uitdam sedge-reed peat materials, respectively, where $\sigma_{\mathrm{vc}}^{\prime}$ is the vertical consolidation stress at the start of the compression stage in the CU TC tests.

The preceding investigations demonstrate that, as well as having a material dependence and strength heterogeneity, the $\left(s_{\mathrm{u} \mathrm{TC}} / \sigma_{\mathrm{vc}}^{\prime}\right)$ values reported for fibrous peats are also an artefact of their methods of determination. Reported laboratory undrained strength values may relate to the measured peak resistance, the true undrained strength, $s_{\mathrm{u} \text { fTC }}$, the phase transformation (yield) point or other shear resistance value corresponding to an axial strain limitation of the triaxial apparatus or arbitrarily defined strain level adopted as 'failure' (e.g. 15\% axial strain was used to define specimen 'failure' in CU TC tests on peat materials reported by Hayashi et al. (2012)). Further, the mobilised undrained strength value depends on the stress history (discussed in the section headed 'Normalised undrained strength ratio'), whether the test specimen is $K_{0}$ or isotropically consolidated, the strain rate applied during the compression stage and possibly also depends on the test-specimen size (i.e. scale effect) (see the section headed 'Scale effect related to test-specimen size'). For instance,

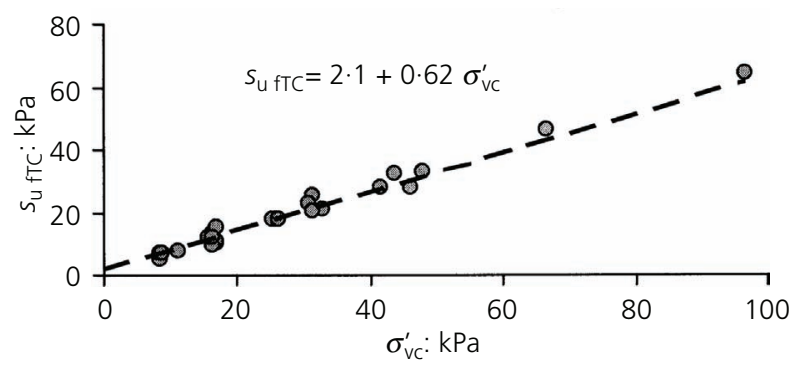

Figure 11. Field-equivalent triaxial shear strength against vertical effective-stress data from $C K_{0} \cup C$ triaxial testing of Marken peat specimens (adapted from Den Haan and Kruse (2007))
Zwanenburg and Van (2015) reported $\left(s_{\mathrm{ufTC}} / \sigma_{\mathrm{vc}}^{\prime}\right)_{\mathrm{NC}}$ values of 0.59 and 0.54 for CIUC and $\mathrm{C} K_{0} \mathrm{UC}$ triaxial testing, respectively, of $65 \mathrm{~mm}$ dia. specimens of Uitdam sedge-reed peat $\left(w_{\mathrm{o}}=\right.$ $800-1020 \%$ and $H_{(2)}-H_{(3)}$ von Post category: scale $H_{(1)}$ to $H_{(10)}$ indicates no decomposition to complete decomposition, respectively) - that is, $s_{\mathrm{u} \mathrm{C} K_{0} \mathrm{UC}} / \sigma_{\mathrm{vc}}^{\prime} \approx 0.92 \times s_{\mathrm{u} \mathrm{CIUC}} / \sigma_{\mathrm{vc}}^{\prime}$. There is also some evidence (Lechowicz, 1994; Przystański, 1994) implying that the value of $s_{\mathrm{u}} / \sigma_{\mathrm{vc}}^{\prime}$ for a given $\mathrm{NC}$ peat material is dependent on the vertical effective-stress increment (discussed in the section headed 'Normalised undrained strength ratio').

\section{At-rest earth pressure coefficient for conventionally sized NC peat specimens}

Table 3 presents a database of at-rest earth pressure coefficient values reported for conventionally sized $\mathrm{NC}$ fibrous peat specimens. According to Edil and Wang (2000) and Den Haan and Kruse (2007), the value of $K_{0, \mathrm{NC}}$ is lower for more fibrous peat on account of the internal lateral resistance provided by the fibres (fibre tensioning), and correlates with bulk density (see Figure 12), since a more fibrous peat material has a higher water content and, hence, a lower bulk density.

Compared with $K_{0}$-consolidation testing in the triaxial cell, the assessment of $K_{0}$ values for fibrous peats and other organic soils is relatively more straightforward from horizontal and vertical effective-stress measurements obtained using, for example, instrumented $63.5 \mathrm{~mm}$ dia. $K_{0}$-consolidation cell (Edil and Alanazy, 1992; Edil and Wang, 2000) or $63 \mathrm{~mm}$ dia. constant-rateof-strain (CRS) $K_{0}$ oedometer devices. Sample data are presented in Figure 13(b) for Uitdam sedge-reed peat specimens tested using the Deltares CRS $K_{0}$ oedometer apparatus (Figure 13(a)).

For indirect determinations of the $K_{0}$ value, a comparison of direct measurements for vertically carved NC fibrous peat specimens in TC with those computed using the Jaky (1948) correlation (Equation 1) supports the conclusion that the Jaky correlation for $\mathrm{NC}$ young soils is in terms of the $\phi_{\mathrm{cv}}^{\prime}$ parameter (Mesri and Ajlouni, 2007; Mesri and Hayat, 1993) - that is, $K_{0, \mathrm{NC}}$ values deduced on the basis of peak $\phi_{\mathrm{TC}}^{\prime}$ are significantly lower than experimentally measured $K_{0, \mathrm{NC}}$ values

1. $K_{0, \mathrm{NC}}=1-\sin \phi_{\mathrm{cv}}^{\prime}$

Table 3. At-rest earth pressure coefficient $K_{0}$, NC determined for conventionally sized specimens of various NC fibrous peats

\begin{tabular}{lccl} 
Peat & $\mathbf{W}_{\mathbf{0}} \mathbf{\%}$ & $\boldsymbol{K}_{\mathbf{0}, \mathbf{N C}}$ & \multicolumn{1}{c}{ References } \\
\hline Moose River & $330-600$ & 0.30 & Adams (1965) \\
Middleton & 510 & 0.31 & Edil and Dhowian (1981) and Edil and Wang (2000) \\
Portage & 600 & 0.30 & Ajlouni (2000) \\
Middleton & $510-850$ & 0.35 & Cola and Cortellazzo (2005) \\
Correzzola & $606-790$ & 0.36 & Zwanenburg (2012) \\
Uitdam & $700-1100$ & $0.27(n, 8 ; \sigma, 0.03)$ & Zwanenburg et al. (2012) \\
Booneschans & $200-620$ & 0.26 & Den Haan and Feddema (2013) \\
Sliedrecht & 500 & 0.29 &
\end{tabular}

$n$, number of tests; $\sigma$, standard deviation 
Geotechnical Research

Volume 4 Issue GR3
Measurement, interpretation and

recommended use of laboratory strength

properties of fibrous peat

O'Kelly

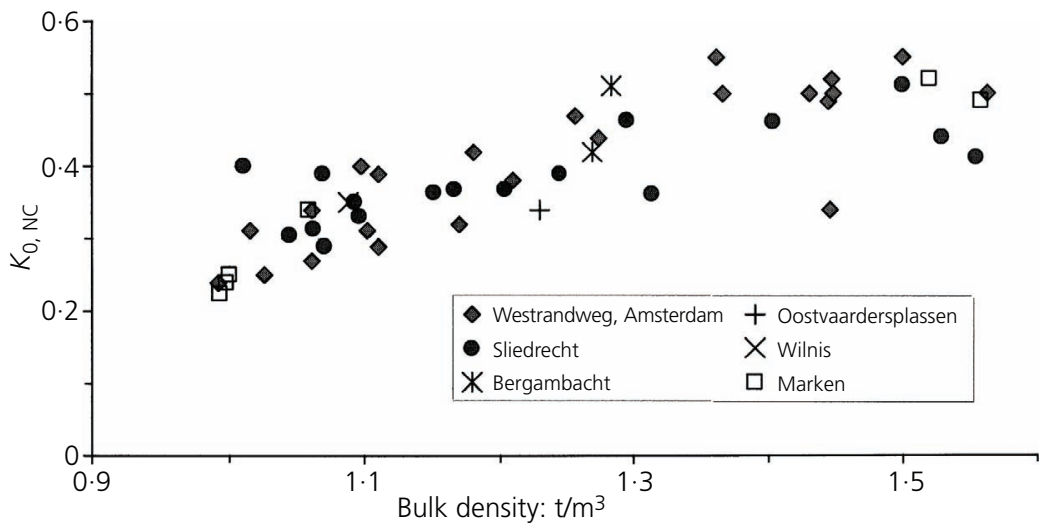

Figure 12. Correlation of $K_{0}, \mathrm{NC}$, as determined from constant-rate-of-strain (CRS) $K_{0}$ oedometer testing, against bulk density for some Dutch peats and organic soils (adapted from Den Haan and Kruse (2007))
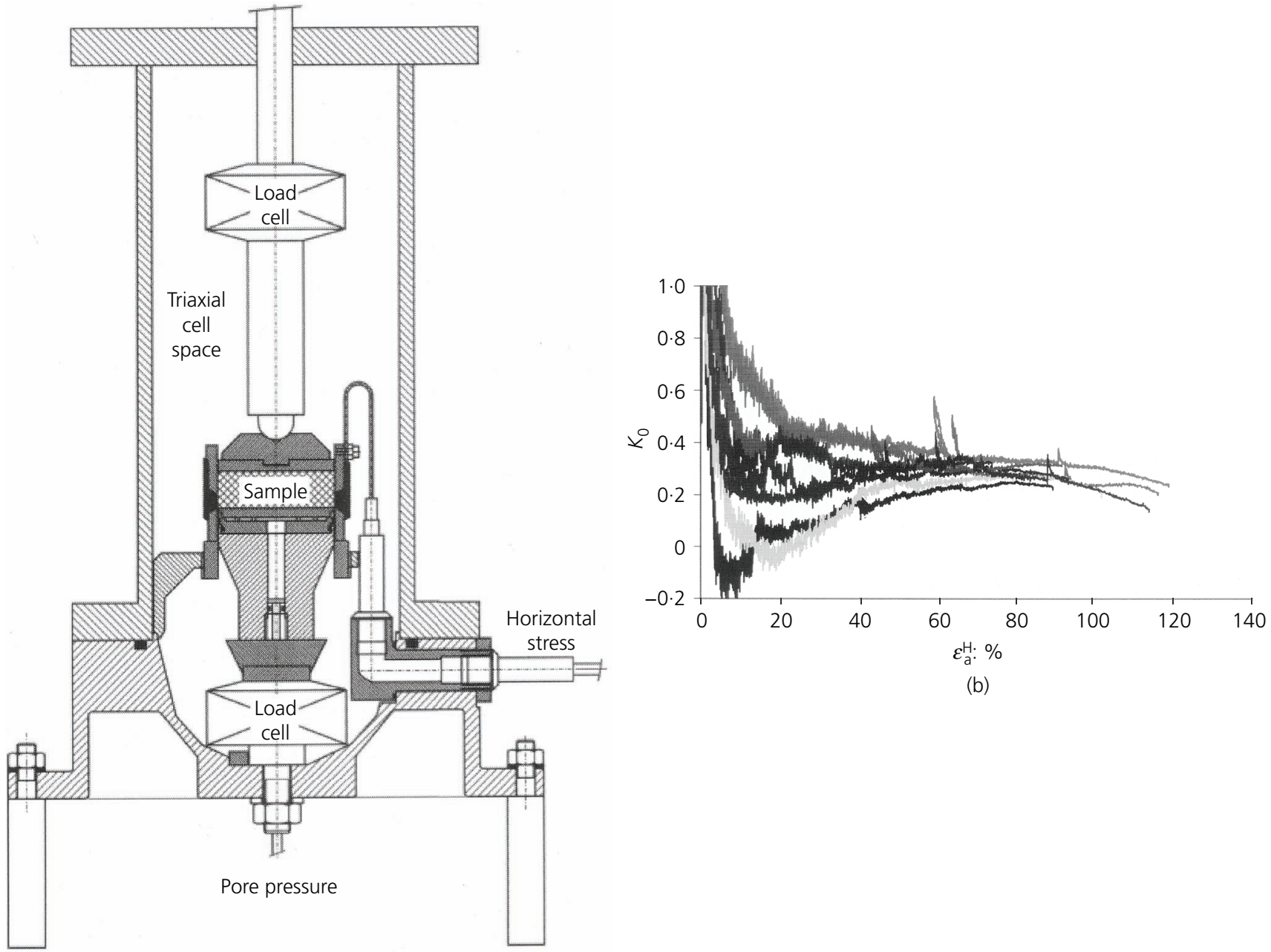

(b)

(a)

Figure 13. Deltares CRS $K_{0}$ oedometer device for testing $63 \mathrm{~mm}$ dia. $\times 20-35 \mathrm{~mm}$ high soil specimens: (a) schematic diagram of apparatus (reproduced from Den Haan and Kamao (2003) with permission from The Japanese Geotechnical Society); (b) at-rest earth pressure coefficient against natural strain $\left(\varepsilon_{a}^{\mathrm{H}}\right)$ from testing of Uitdam sedge-reed peat specimens ( $w_{\mathrm{o}}=645-1240 \% ; H_{(2)}-H_{(3)}$ von Post) (adapted from Zwanenburg (2012)) 
As explained earlier, $\phi_{\mathrm{cv}}^{\prime}$ is mobilised at the phase transformation point on the triaxial ESP trace. As an example, a $\phi_{\mathrm{cv}}^{\prime}$ value of $\sim 47^{\circ}$ was deduced as part of the present investigation of the Uitdam sedge-reed peat from the best-fit line to the phase transformation points identified on the $p^{\prime}-q$ traces (i.e. the CSL shown) in Figure 7(b), indicating a $K_{0}$, NC value of 0.27 , according to Equation 1 . The same $K_{0,}$ NC value was reported by Zwanenburg (2012) for the Uitdam sedge-reed peat material from CRS $K_{0}$ oedometer measurements.

Whether $K_{0,}$ NC increases or decreases in value during ageing (secondary compression) has been the subject of speculation, research and mild controversy (Schmertmann, 1983), with most of the evidence pointing to a slight increase occurring. According to Den Haan (2002), however, this depends on the position of the $\left(M, K_{0}, \mathrm{NC}\right)$ state during virgin compression, with $K_{0, \mathrm{NC}}$ neither increasing nor decreasing noticeably after full ageing for soil with a low $v^{\prime}$ value (i.e. includes fibrous peats).

\section{TC testing}

As documented by Farrell (2012), Farrell and Hebib (1998), Hollingshead and Raymond (1972), O'Kelly and Zhang (2013) and Zhang and O'Kelly (2014), among others, standard CD TC testing is of no practical use in the determination of realistic $\phi_{\mathrm{TC}}^{\prime}$ (or $\phi_{\mathrm{cv}}^{\prime}$ ) values for fibrous peats since the $q, \sigma_{1}^{\prime} / \sigma_{3}^{\prime}$ and volumetric compression against $\varepsilon_{\mathrm{a}}$ traces continue to increase, approximately linearly (see Figure 14), for very large axial strains (even at $\varepsilon_{\mathrm{a}}>30 \%$ (O'Kelly and Zhang, 2013). Further, compared with the undrained compression stage for CU TC testing, the drained compression stage for CD TC testing necessitates a significantly slower axial strain rate and hence requires a substantially longer period to complete the test.

Under drained TC, the fibrous peat specimen essentially undergoes $1 \mathrm{D}$ consolidation on account of fibre tensioning and the combination of the material's high secondary consolidation and low axial strain rate necessary for substantial dissipation of the excess $p_{\mathrm{wp}}$, with no evidence of a shear plane developing. For instance, O'Kelly and Zhang (2013) reported $v^{\prime}$ values ranging 0.02-0.03 for drained TC of $38 \mathrm{~mm}$ dia. undisturbed Clara Bog peat $\left(H_{(4)}\right.$ von Post) specimens with $\varepsilon_{\mathrm{a}}$ ranging $0-20 \%$. Hence, the 'effective friction angle' inferred for fibrous peat from drained TC testing is approximately directly related to the applied axial strain, with apparently broadly similar values deduced for undisturbed and reconstituted fibrous peat and amorphous (blended) peat specimens (Edil and Wang, 2000; O'Kelly and Zhang, 2013) considering a given axial strain level (see Figure 15).

\section{DSS testing}

In DSS tests, the specimen is $K_{0}$ consolidated and is then deformed in a simple shear fashion at constant height (and, hence, volume)

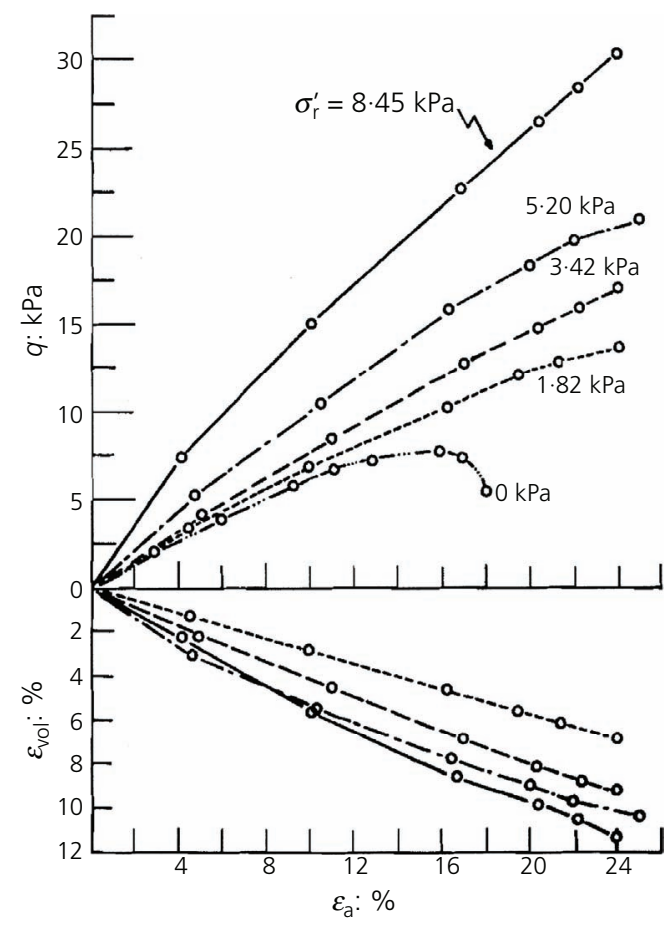

(a)

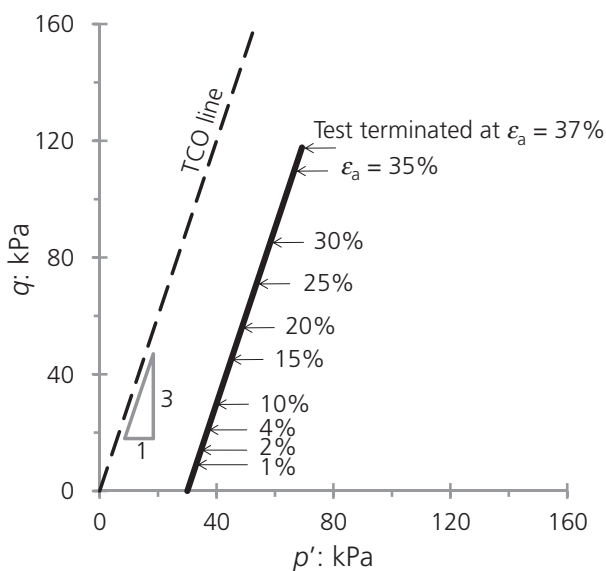

(b)

Figure 14. CD TC: (a) deviator stress and volumetric strain responses for $50 \mathrm{~mm}$ dia. fine fibrous to amorphous peat specimens from the Cataraqui marsh (adapted from Hollingshead and Raymond (1972) (C) Canadian Science Publishing); (b) ESP trace for $38 \mathrm{~mm}$ dia. reconstituted Clara Bog peat specimen ( $W_{\mathrm{o}}=590 \% ; H_{(4)}$ von Post) tested with $\sigma_{\mathrm{r}}^{\prime}=30 \mathrm{kPa}$ (adapted from O'Kelly and Zhang (2013) with permission from the Geotechnical Testing Journal, Volume 36, Issue 3, copyright ASTM International, 100 Barr Harbor Drive, West Conshohocken PA 19428, www.astm.org.) 
Measurement, interpretation and

recommended use of laboratory strength

properties of fibrous peat

O'Kelly

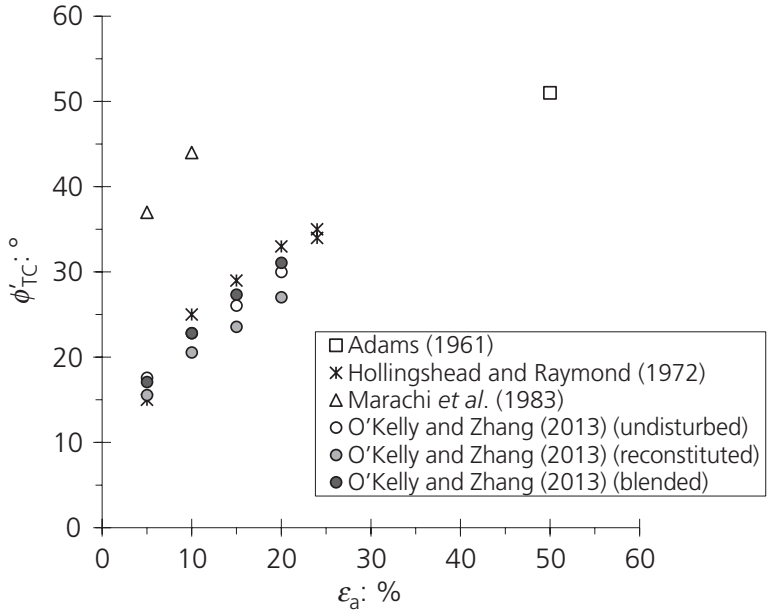

Figure 15. Effective friction angle values inferred from CD TC testing of fibrous peats (adapted from O'Kelly and Zhang (2013) with permission from the Geotechnical Testing Journal, Volume 36, Issue 3, copyright ASTM International, 100 Barr Harbor Drive, West Conshohocken PA 19428, www.astm.org.)

during the shearing stage. For a fully saturated specimen, the change in the vertical stress required to maintain a constant specimen height during shear is, for all practical purposes, equal to the change in the $p_{\mathrm{wp}}$ value that would occur for a truly undrained test (Dyvik et al., 1987). An assumption for the stress state at specimen failure needs to be made in order to estimate the friction angle of the test material. One of the two most commonly used assumptions, which also provide a reasonable range for the friction angle value, is that the horizontal sliding planes are failure planes that is, planes of maximum obliquity (although, as discussed later in this section, this is generally not the case for fibrous peat material). Then, using the conventional interpretation, a line fitted through the data points on a maximum horizontal shear stress $\left(\tau_{\mathrm{h} \text { max }}\right)$ against $\sigma_{\mathrm{vf}}^{\prime}$ plot gives the drained strength parameters $c_{\mathrm{DSS}}^{\prime}$ and $\phi_{\mathrm{DSS}}^{\prime}$

2. $\phi_{\mathrm{DSS}}^{\prime}=\tan ^{-1}\left(\tau_{\mathrm{h} \max } / \sigma_{\mathrm{vf}}^{\prime}\right)$

where $\sigma_{\mathrm{vf}}^{\prime}$ is the vertical effective stress at failure (i.e. corresponding to $\tau_{\mathrm{h} \max }$ ) and $\tau_{\mathrm{h} \max }$ is the peak horizontal shear stress or, alternatively, is often taken as corresponding to $15 \%$ shear strain, whichever occurs first (Boylan and Long, 2014).

Some general comments on the conventional DSS approach follow. Firstly, in the study by Dyvik et al. (1987), the constant-volume DSS tests and truly undrained DSS tests reported were performed on saturated NC Drammen clay specimens; hence, the validity of their test findings in relation to unsaturated and (or) OC peat specimens is somewhat uncertain. Hanrahan (1954), for instance, reported that the volumetric gas fraction for Irish Sphagnum peats may be considerably greater than $5 \%$, and at this degree of saturation, most of the gas occurs as occluded bubbles. Secondly, the simple shear condition is not achieved for the DSS test, in that complementary shear stresses are not generated on the side end surfaces of the test specimen during shearing, such that the distribution of shear stress is non-uniform across its top and bottom surfaces, reducing to zero at the specimen corners. The resultant unbalanced couple has to be counteracted by an opposite couple generated by a non-uniform distribution of normal stress acting on the top and bottom surfaces of the test specimen (Airey et al., 1985). Further, although widely used in practice because it gives a low (and thus conservative) $\phi_{\text {DSS }}^{\prime}$ value, according to Airey and Wood (1987) and Farrell et al. (1999), the conventional interpretation of DSS test results by using Equation 2 is considered incorrect. Other interpretations have been proposed (e.g. $\phi_{\mathrm{DSS}}^{\prime}=$ $\sin ^{-1}\left(\tau_{\mathrm{h} \max } / \sigma_{\mathrm{vf}}^{\prime}\right)$ (Farrell et al., 1999) - that is, the horizontal planes are planes of maximum shear stress). Moreover, as noted by Long (2005), the stress regime in the DSS specimen is complicated and a simple interpretation of the test results needs to be treated with caution. Considering the increasingly non-uniform internal strains and large zones of extension developing within the test specimen (observed using the particle image velocimetry (PIV) analysis technique) during the shearing stage, Boylan and Long (2009) recommended further research, considering a range of peat types, on the relation between specimen crack formation and measured shear resistance in order to identify criteria for assigning failure based on observations of the specimen deformation response rather than waiting for a peak shear stress (as a proxy for $s_{\mathrm{u} \text { DSs }}$ ) to develop. Den Haan and Grognet (2014), for instance, defined a 'yield strain' criterion based on the width of the crack that forms in most tests along the shortening diagonal of the fibrous peat test specimen during shearing, in some cases developing only near peak shear resistance mobilisation and in others earlier. These considerations are important since the adopted failure criterion influences the deduced strength parameter values.

For standard commercially available DSS devices, the $s_{\mathrm{u}}$ DSS value deduced from the average stresses mobilised on the specimen top and bottom surfaces is likely to underestimate the simple shear undrained strength value by $\sim 10 \%$ on account of the imperfect DSS test condition imposed (Airey and Wood, 1987; Doherty and Fahey, 2011). Standard DSS equipment may also have difficulty testing peat at the low vertical effective-stress levels $(<5 \mathrm{kPa})$ often encountered in situ. Since most natural peat deposits are OC to some degree, the assessment of the peat strength based on a linear extrapolation of the measured $\mathrm{NC}$ failure envelop downwards to the in situ stress levels produces an underestimation of the strength value (see the section headed 'Normalised undrained strength ratio'). Recent advances include DSS devices with a plane-strain configuration between glass plates (Boylan and Long, 2009; Den Haan and Grognet, 2014) for testing peat specimens at low normal stresses, without the requirement for an enclosing specimen membrane, thereby reducing the apparatus resistance and improving the constant-volume condition. These DSS devices also allow the deformation of the side surface of the test specimen to be monitored during shearing by using the PIV image analysis technique (Figure 16). 
Measurement, interpretation and

recommended use of laboratory strength

properties of fibrous peat

O'Kelly

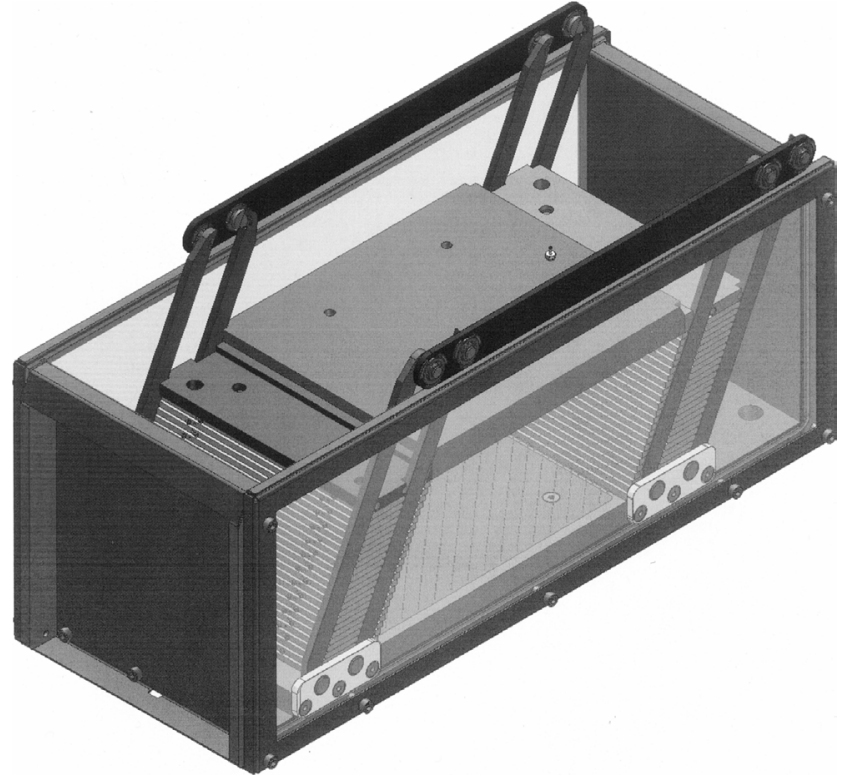

Figure 16. Deltares large DSS apparatus for testing $260 \mathrm{~mm}$ long, $220 \mathrm{~mm}$ wide and 60-120 $\mathrm{mm}$ high peat specimens at low normal stresses (Den Haan and Grognet, 2014)

According to Den Haan and Grognet (2014), the larger-sized test specimen $(260 \mathrm{~mm}$ long in the shearing direction, $220 \mathrm{~mm}$ wide and 60-120 mm high) used in their DSS device enables more faithful representation of the often coarse structure of peat material, increases the accuracy with which small loads can be applied to the test specimen and reduces the apparatus resistance to acceptably small proportions (note that this specimen's aspect ratio is similar to that used in the standard DSS apparatus). The whole assembly, illustrated in Figure 16, is placed in a watertight container so that the specimen is fully submerged during testing, since at the low stresses of interest, the reduction of effective stress caused by immersion can be significant. DSS testing using such devices should contribute to a better understanding of actual peat behaviour. For instance, preliminary investigations reported by Den Haan and Grognet (2014) indicated that a feature of all 11 tests performed on Uitdam sedge-reed peat by using their large DSS device was that a clear $\tau_{\mathrm{h} \text { max }}$ condition was reached, with little or no softening or continuing hardening occurring for $\gamma>40 \%$ (Figures 17(a) and 17(b)), unlike the gradual softening behaviour usually found in conventionally sized DSS test specimens for peat (Figure 17(c)) and soft clay materials.

\section{DSS effective friction angle and normalised undrained} strength ratio for conventionally sized peat specimens Table 4 summarises the limited $c^{\prime}$ and $\phi^{\prime}$ values reported or inferred from standard DSS, DS and RS testing presented in the literature for fibrous peat materials. For example, Zwanenburg et al. (2012) reported $c_{\mathrm{DSS}}^{\prime}=2 \cdot 3 \mathrm{kPa}$ and $\phi_{\mathrm{DSS}}^{\prime}=32 \cdot 3^{\circ}$ for Booneschans fibrous peat $\left(w_{\mathrm{o}}=200-620 \%\right)$, with the test material dominated by sedge and wood fragments. Rowe et al. (1984) reported $c_{\mathrm{DSS}}^{\prime}=1 \cdot 1 \mathrm{kPa}$ and $\phi_{\mathrm{DSS}}^{\prime}=26^{\circ}$ from drained DSS testing of Aurora peat. Both investigations indicated that even for DSS testing of vertically carved specimens, fibrous peat material has some small apparent cohesion.

Analysis of the limited data in Table 4 leads to the following tentative conclusions: (a) $\phi_{\mathrm{DSS}}^{\prime}$ for NC fibrous peat tested using standard DSS devices is approximately $28^{\circ} ;(b) c^{\prime}$ values typically range $2-3 \mathrm{kPa}$ for DSS, DS and RS modes; and $(c)$ mean $\phi_{\mathrm{DS}}^{\prime} \approx$ mean $\phi_{\mathrm{RS}}^{\prime}(=$ $\left.32^{\circ}\right)>$ mean $\phi_{\text {DSS }}^{\prime}\left(=28^{\circ}\right)$. This suggests that notwithstanding known shortcomings, DS and RS testing of fibrous peats generally provides $c^{\prime}$ and $\phi^{\prime}$ values that are in reasonable agreement with DSSderived values.

Regarding the normalised undrained strength ratio, $\left(s_{\mathrm{u} \mathrm{DSS}} / \sigma_{\mathrm{vc}}^{\prime}\right)_{\mathrm{NC}}<\left(s_{\mathrm{u} \mathrm{TC}} / \sigma_{\mathrm{vc}}^{\prime}\right)_{\mathrm{NC}}$ for fibrous peat material on account of its structural anisotropy (i.e. for DSS testing, no length change occurs for the test specimen in its shearing direction and so less fibre stretching ensues) and also reflects possibly the influences of consolidation style, the triaxial extrapolation procedure to determine $S_{\mathrm{u}}$ fTC and (or) the imperfect DSS test condition imposed by standard commercially available DSS devices - for example, $s_{\mathrm{u} \mathrm{DSS}} / s_{\mathrm{u} \mathrm{C} K_{0} \mathrm{UC}}=0 \cdot 81$ (Lechowicz, 1994) and 0.87 (Zwanenburg and Jardine, 2015; Zwanenburg and Van, 2015) for Antoniny and Uitdam peats, respectively.

Furthermore, $\left(s_{\mathrm{uDSS}} / \sigma_{\mathrm{vc}}^{\prime}\right)_{\mathrm{NC}}$ is 0.46 for Booneschans fibrous peat (Zwanenburg et al., 2012) and 0.47 for Uitdam sedge-reed peat (Zwanenburg and Jardine, 2015), with $s_{\mathrm{u} \text { DSs }} / \sigma_{\mathrm{vc}}^{\prime}=0.46$ for Taylor River peat with $w_{\mathrm{o}}=500 \%$ (Foott and Ladd, 1981). These $s_{\mathrm{uDSS}} / \sigma_{\mathrm{vc}}^{\prime}$ values are remarkably consistent and considerably greater than the range of $0 \cdot 20-0 \cdot 27$ reported for $\mathrm{NC}$ clay or silt materials (Ladd, 1991). Other limited published $s_{\mathrm{uDSS}} / \sigma_{\mathrm{vc}}^{\prime}$ data for Polish, Irish and Swedish peats (after Carlsten (2000), Farrell and Hebib (1998), Farrell et al. (1999) and Lechowicz (1994)) show much scatter in the range of $0 \cdot 38-0 \cdot 55$. From analysis of the results of $>111$ standard DSS tests on very different peat materials sampled from 16 sites in Ireland, Scotland and the Netherlands (Figure 18), Boylan and Long (2014) suggested that the scatter in the data may be largely due to the effect of stress history, either in the field or the laboratory.

Based on the trend in the data plotted in Figure 18, Boylan and Long (2014) reported a lower-bound $\left(s_{\mathrm{u} \text { DSS }} / \sigma_{\mathrm{vc}}^{\prime}\right)_{\mathrm{NC}}$ value of $0 \cdot 40$ for $\sigma_{\mathrm{vc}}^{\prime}>30 \mathrm{kPa}$, which agrees with the lower bound $0 \cdot 38-0 \cdot 40$ range identified from earlier published DSS data for peat materials investigated by Carlsten (2000), Farrell et al. (1999) and Lechowicz (1994). In other words, $\left(s_{\mathrm{u} \mathrm{DSS}} / \sigma_{\mathrm{vc}}^{\prime}\right)_{\mathrm{NC}} \approx 0.40$ is a lower-bound value for DSS testing of NC peat material (i.e. the consolidation stress $\sigma_{\mathrm{vc}}^{\prime}$ applied in the DSS test is greater than all previous vertical effective stresses acting on the test specimen).

\section{Tensile strength of fibrous peat}

The tensile strength and deformability of fibrous peat depend on a number of factors, including the type of peat (fen, bog, reed etc.); its water content; the degree of humification; the number, length and tensile strength of the plant fibres and root threads present; their orientation relative to the failure plane; and the strength of the 
Geotechnical Research

Volume 4 Issue GR3
Measurement, interpretation and recommended use of laboratory strength properties of fibrous peat O'Kelly

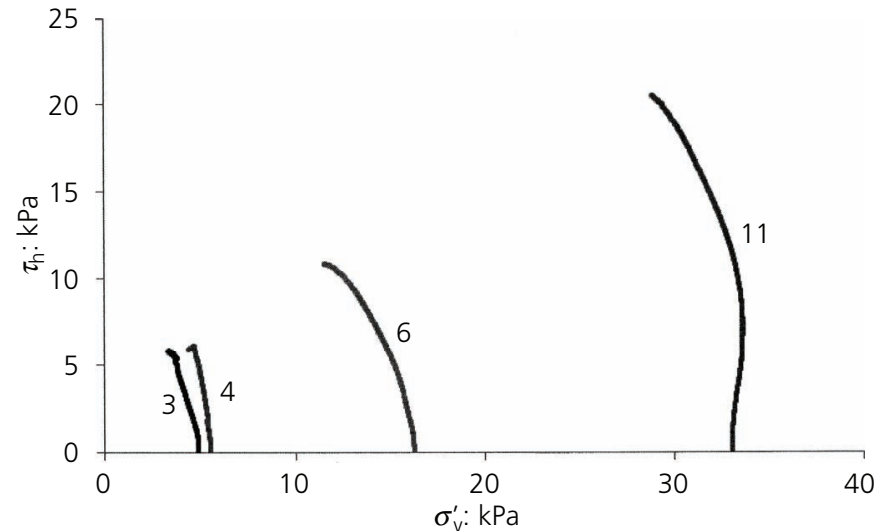

(a)

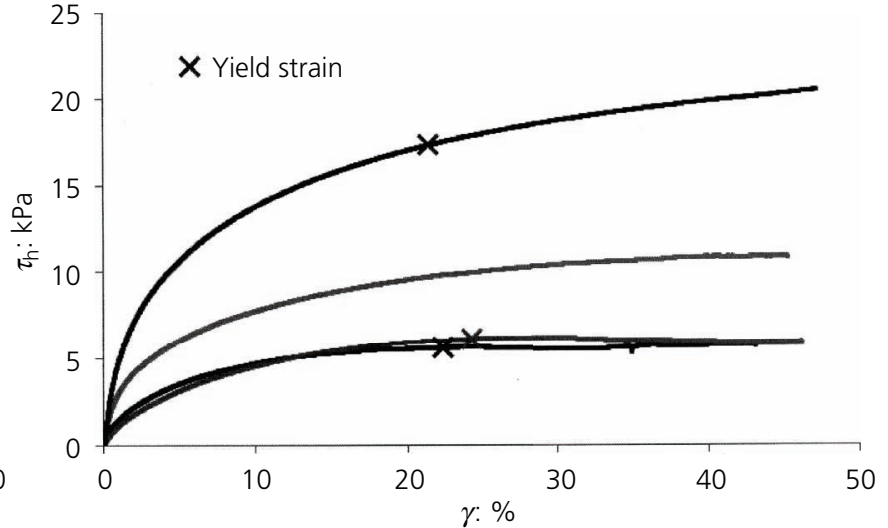

(b)

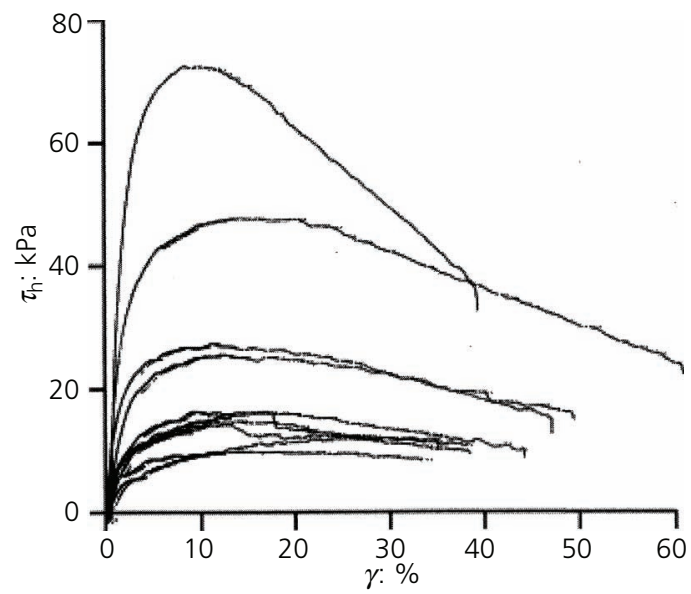

(c)

Figure 17. DSS results for fibrous peats: (a) stress path and (b) shear stress-shear strain plots for Uitdam sedge-reed peat specimens $\left(w_{0}=1050 \% ; H_{(5)}\right.$ von Post) tested using Deltares's large DSS apparatus (adapted from Den Haan and Grognet (2014)); (c) standard DSS testing for Booneschans fibrous peat ( $W_{\mathrm{O}}=200-620 \% ; H_{(5)}$ von Post) (Zwanenburg et al., 2012). Note: yield strain based on width of crack formed in test specimen during shearing

Table 4. Effective-stress strength parameters for fibrous peats from CU DSS, CD DS and CD RS testing

\begin{tabular}{|c|c|c|c|c|c|c|c|c|}
\hline \multirow{2}{*}{ Peat } & \multirow{2}{*}{$w_{\mathrm{o}}: \%$} & \multicolumn{2}{|c|}{ DSS } & \multicolumn{2}{|c|}{ DS } & \multicolumn{2}{|c|}{ RS } & \multirow{2}{*}{ Reference } \\
\hline & & $c_{\mathrm{DSS}}^{\prime}: \mathrm{kPa}$ & $\phi_{\text {DSS }}^{\prime}:^{\circ}$ & $c_{\mathrm{DS}}^{\prime}: \mathrm{kPa}$ & $\phi_{\mathrm{DS}}^{\prime}:^{\circ}$ & $\mathrm{C}_{\mathrm{RS}}^{\prime}: \mathrm{kPa}$ & $\phi_{\mathrm{RS}}^{\prime}:^{\circ}$ & \\
\hline Escuminac & - & - & - & - & - & $2 \cdot 4$ & $27 \cdot 1-32 \cdot 5$ & Landva and La Rochelle (1983) \\
\hline Aurora & - & $1 \cdot 1^{\mathrm{a}}$ & $26^{a}$ & 3 & 27 & - & - & Rowe et al. (1984) \\
\hline Raheenmore & $1200-1400$ & - & 31 & - & 38 & - & - & Farrell and Hebib (1998) \\
\hline (Reed-sedge) & $400-900$ & - & 34 & - & - & - & - & Farrell et al. (1999) \\
\hline Raheenmore & 1170 & - & - & 4 & 33 & $2^{b}$ & $34^{b}$ & Mclnerney et al. (2006) \\
\hline Wilnis & - & $5^{c}$ & $22-24^{c}$ & - & - & - & - & Den Haan and Kruse (2007) \\
\hline Edson & 450 & - & - & 0 & $31^{d}$ & - & - & Hendry et al. (2012) \\
\hline Akita & 590 & - & - & - & - & 8 & $34^{\mathrm{d}, \mathrm{e}}$ & Komatsu et al. (2011) \\
\hline Booneschans & $200-620$ & $2 \cdot 3$ & $32 \cdot 3$ & - & - & - & - & Zwanenburg et al. (2012) \\
\hline
\end{tabular}

${ }^{a}$ CD DSS

${ }^{b}$ Values deduced by the author from figure 7 in Mclnerney et al. (2006)

c Values deduced by the author from figure 39 in Den Haan and Kruse (2007)

${ }^{\mathrm{d}}$ Remoulded test specimen

e Values deduced by the author from figure 9 in Komatsu et al. (2011) 


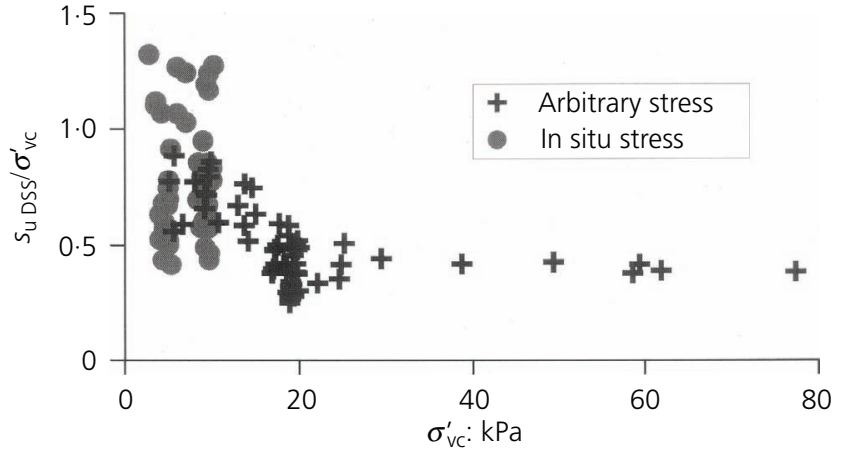

Figure 18. Normalised undrained strength ratio against vertical consolidation stress from DSS testing of peats sampled from 16 sites in Ireland, Scotland and the Netherlands $\left(w_{0}=220-1260 \% ; H_{(2)}-H_{(9)}\right.$ von Post) (adapted from Boylan and Long (2014))

peat matrix. The greatest tensile strength is mobilised for a given peat material when the direction of the applied tensile stress is coincident with its cross-anisotropic plane. Since the tensile strength of the plant fibres (and root threads) is considerably greater than the tensile strength of the peat matrix, some fibres are pulled out of the specimen during a tension test - that is, shear stresses develop between these fibres and the surrounding matrix material, with the magnitude of the resisting shear force contribution dependent on the lengths and thicknesses of the pullout fibres and the shear strength of the peat matrix material (Helenelund, 1967).

The tensile strength of peat is important for understanding stability problems in upland blanket bogs (Dykes, 2008) and 'floating' roads constructed over peatland. Floating roads, built using finite quantities of engineered fill material and brought into immediate service, rely on the tensile strength of the acrotelm peat mat and basal reinforcement layer (geotextile, corduroy or combination of these, if present), along with the shear strength of the underlying catotelm peat, to resist the applied surface loading. In these examples, the fibrous nature and, hence, the relatively high tensile strength of the acrotelm layer (typically $0 \cdot 1-0.6 \mathrm{~m}$ thick) contribute significantly to the overall resistance. Further, the tensile strength of peat seems important in stability assessments for embankments and dikes constructed over peat deposits. For instance, near-vertical and subhorizontal fractures were found to dominate the active side of the failure for asymmetrically loaded full-scale strip foundation trials performed on a Uitdam sedge-reed peat deposit overlying a highly organic soil layer, having a combined thickness of $5 \mathrm{~m}$ (Zwanenburg, 2012). Wide tension cracks were also observed for the trial embankment founded on a $3 \mathrm{~m}$ deep layer of Booneschans fibrous peat (see Figure 19(a)), indicating that this layer had failed locally in tension, although the overall failure mechanism was dominated by translational movement (Zwanenburg et al., 2012).

Direct-tension tests (Rowe et al., 1984) and tension box apparatus (e.g. see Figure 20) allow investigation of the tensile strength of fibrous peat. Beam tests (Helenelund, 1967) also allow investigations of its flexural strength and deformability. However, the focus of this discussion is tension box devices, which consist of two half-boxes, one movable in the horizontal direction and the other fixed. The vertical cross-section of the test specimen, which is secured within the assembled tension box, is usually reduced by making a cut into the top and bottom faces of the test specimen at the vertical joint between the two half-boxes, thereby causing the tension failure to develop in this cross-section under the applied tension loading. For the experimental apparatus shown in Figure 20(a), the test specimen is secured to both halves of the assembled tension box by using nail plates, with two of these nail plates pressed into the bottom face and another two pressed into the top face of the test specimen. As the half-boxes are pulled apart, the soil specimen is stressed in tension and ultimately a vertical failure plane develops through the specimen at the location of the vertical joint. When performing $\mathrm{CU}$ tension testing, separate loading platforms placed on the top surface of the test specimen in both half-boxes generate the required $\sigma_{\mathrm{vc}}^{\prime}$ value in advance of the tension loading stage. Tension box testing can only give a guide to the tensile deformability of the test specimen on account of the grossly non-uniform strains arising from the manner in which the specimen is gripped within the apparatus.

From a full review of the literature, only four reported studies (described in the following sections) presented investigations of the undrained and (or) drained tensile strength properties of undisturbed fibrous peat materials.

\section{Undrained tensile strength}

Dykes (2008) and Helenelund (1967) reported horizontal undrained tensile strength $\sigma_{\max }$ DT values for surface peat layers $(\leq 1.2 \mathrm{~m}$ depth) determined using tension box devices. Helenelund (1967) reported field and laboratory unconsolidated-undrained controlledstress test results (see Figure 21) for Sphagnum peat samples from the Mer Bleue Bog near Ottawa. The tension loads for the field and laboratory tests were incremented by $2 \mathrm{~kg} / \mathrm{min}$ and $2 \mathrm{~kg} / \mathrm{d}$, respectively, achieved by increasing the number of weights on the loading hanger that was connected through a flexible wire through a pulley arrangement to the movable half-box (see Figure 20(a)).

Figure 22 shows sample data from one of the slow laboratory tension tests reported by Helenelund (1967). As evident from this figure, under the maintained tension load (stress), the specimen creep rate increased for higher tensile stress, with the test specimen failing in tension almost $3 \mathrm{~h}$ after the tension stress had been incremented from $5 \cdot 4$ to $6 \cdot 2 \mathrm{kPa}$. The tensile strength was calculated as the mean tensile stress acting in the vertical reduced cross-section of the test specimen located at the joint between the two half-boxes on the moment of failure, reported as always clearly visible, although requiring large axial (horizontal) specimen deformation to achieve (Helenelund, 1967).

Referring to Figure 21(c), for the Sphagnum peat depths of up to $1 \cdot 1 \mathrm{~m}$ investigated, the $\sigma_{\max }$ DT values ranged $3 \cdot 5-11 \cdot 1 \mathrm{kPa}$ 


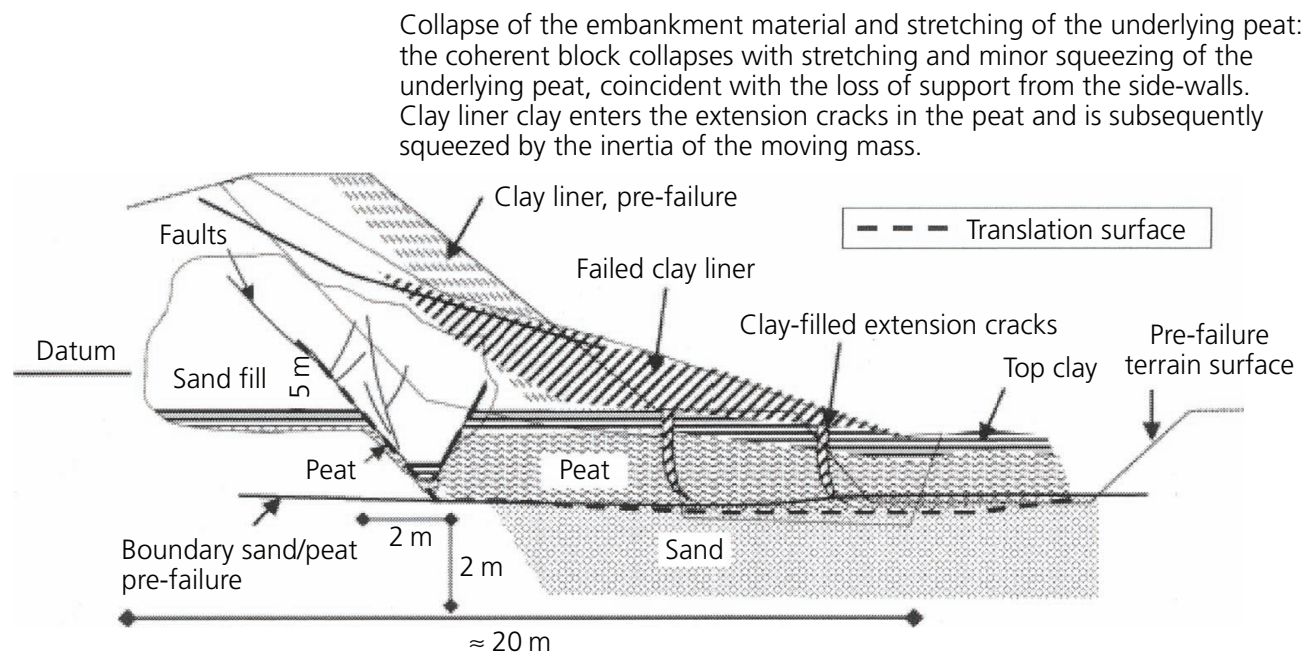

(a)

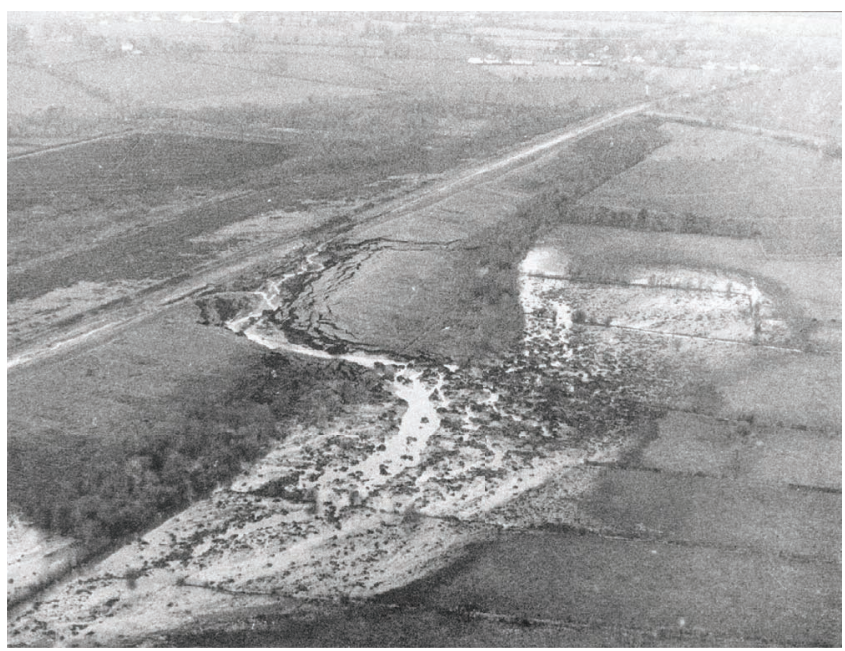

(b)

Figure 19. General translational failure mechanism for dikes and embankments constructed over peat deposits: (a) sketch of final collapse failure for trial embankment constructed on $3 \mathrm{~m}$ deep fibrous peat layer, Booneschans, the Netherlands (adapted from Zwanenburg et al. (2012)); (b) translational failure of Grand Canal embankment, constructed of and founded on peat, near Edenderry, Ireland (Pigott et al., 1992)

(mean of $6.9 \mathrm{kPa} ; n=55$ ) and $3.9-9.8 \mathrm{kPa}$ (mean of $6.5 \mathrm{kPa}$; $n=6$ ) for the field and laboratory testing, respectively. For the nearly saturated Sphagnum peat material $\left(w_{\mathrm{o}}=853-1056 \%\right.$, $H_{(6)}-H_{(8)}$ von Post) sampled from below the standing groundwater table located at $0.7 \mathrm{~m}$ depth, the corresponding $\sigma_{\max }$ DT values ranged $5 \cdot 1-9 \cdot 8 \mathrm{kPa}$ (mean of $8 \cdot 0 \mathrm{kPa} ; n=12$ ) and $3 \cdot 9-7 \cdot 3 \mathrm{kPa}$ (mean of $5 \cdot 6 \mathrm{kPa} ; n=4)$ - that is, compared with the field tests, the laboratory tests mobilised slightly lower tensile strength on account of their significantly slower loading rate ( $2 \mathrm{~kg} / \mathrm{min}$ and $2 \mathrm{~kg} / \mathrm{d}$, respectively). Near the ground surface, the tensile strength increased with depth despite the degree of humification also increasing (Figures 21(b) and 21(c)), which Helenelund (1967) explained by the fact that the living plant structures and fresh remnants within the lesser-decomposed surface peat layer were standing almost vertically, but the measured tensile strength values were for loading applied in the horizontal direction.

Dykes (2008) reported on the laboratory undrained tensile strength of the acrotelm layer for three upland blanket bog peats (see Figure 23). In the tension box device employed, two sets of steel 'fingers' were pushed vertically through the centre of the $100 \mathrm{~mm}$ square end by up to $60 \mathrm{~mm}$ thick field-wet peat specimen, leaving four intact vertical strips of peat (each $12.5 \mathrm{~mm}$ wide $\times 100 \mathrm{~mm}$ long) between the steel fingers to resist the tension force, which was applied to the peat specimen in increments - that is, every $30 \mathrm{~s}$ in $200 \mathrm{~g}$ steps up to 1 or $2 \mathrm{~kg}$, then in $100 \mathrm{~g}$ steps until specimen failure occurred. Potential shortcomings of the presented experimental set-up are not only the relatively small specimen size but particularly also the small 


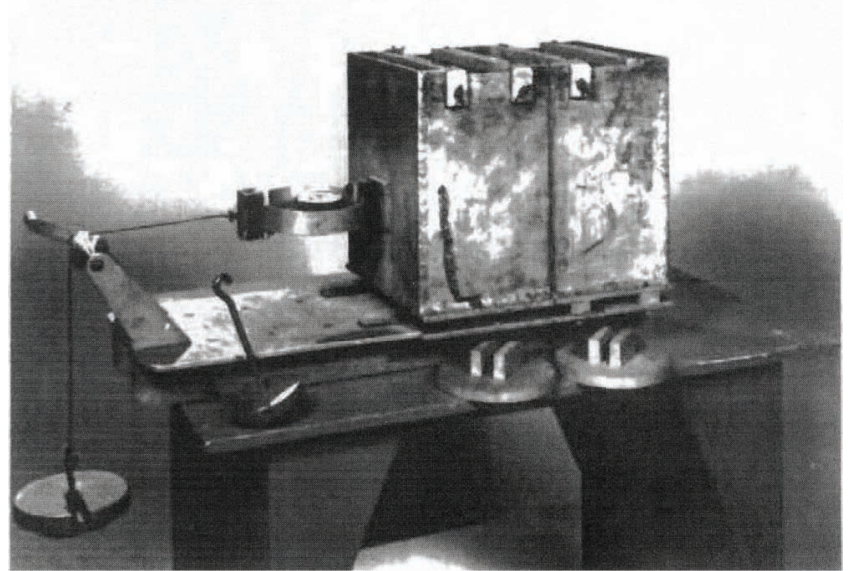

(a)

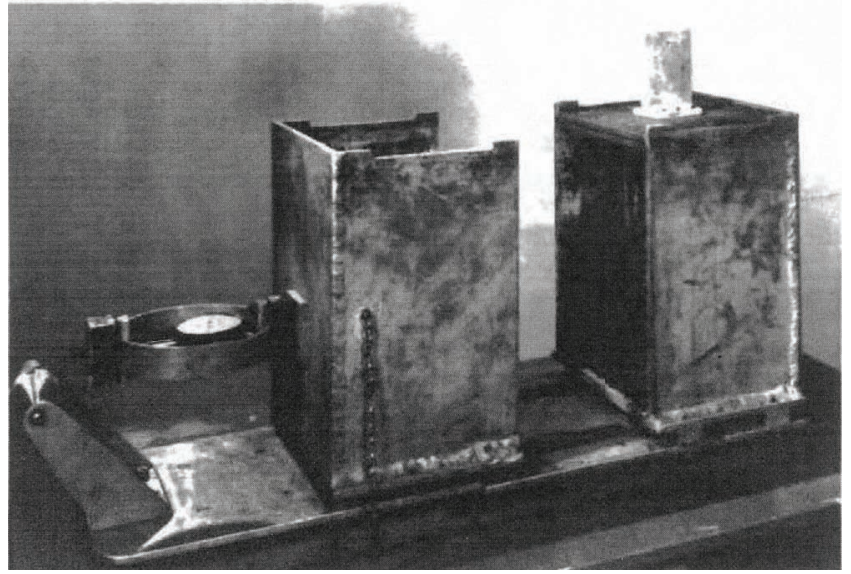

(b)

Figure 20. Tension box apparatus for determining the tensile strength of $203 \mathrm{~mm}$ wide $\times 254 \mathrm{~mm}$ deep $\times 305 \mathrm{~mm}$ long fibrous peat specimen, showing (a) the assembled apparatus and (b) the two half-boxes separated, but without the test specimen installed (Helenelund, 1967) @ Canadian Science Publishing

cross-sectional areas of the four intact strips of peat that resist the applied tension force; these points could be simply addressed by upscaling the apparatus and test-specimen dimensions. Dykes (2008) noted that most of the tensile strength was provided by the fibres connecting the two halves of the test specimen as they were pulled apart at the central vertical cross-section.

From the author's independent analysis of tabulated data presented by Dykes (2008) for three blanket bog peats, the $\sigma_{\max \text { DT }}$ values ranged $1 \cdot 6-7 \cdot 9 \mathrm{kPa}$ (mean of $4 \cdot 2 \mathrm{kPa} ; n=33$ ) for the acrotelm layer and $1.6-3.9 \mathrm{kPa}$ (mean of $2.5 \mathrm{kPa} ; n=8$ ) for the catotelm peat material tested. Compared with the laboratory-determined values reported for the Mer Bleue Sphagnum peat-mat material investigated by Helenelund (1967), the respective strengths for the acrotelm and catotelm blanket bog peat materials investigated by Dykes (2008) are, on average, 35\% and 55\% lower. Referring to Figure 23 for the blanket bog peats, the tensile strength shows a general trend of decreasing with increasing depth, reducing sharply in value below the mid-acrotelm depth, and with the level of humification increasing from $H_{(4)}-H_{(5)}$ to $H_{(8)}-H_{(9)}-$ that is, the

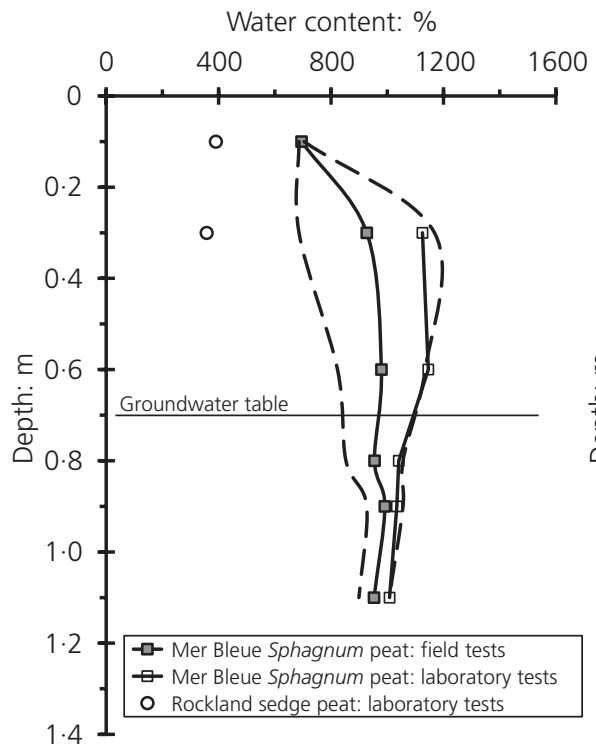

(a)

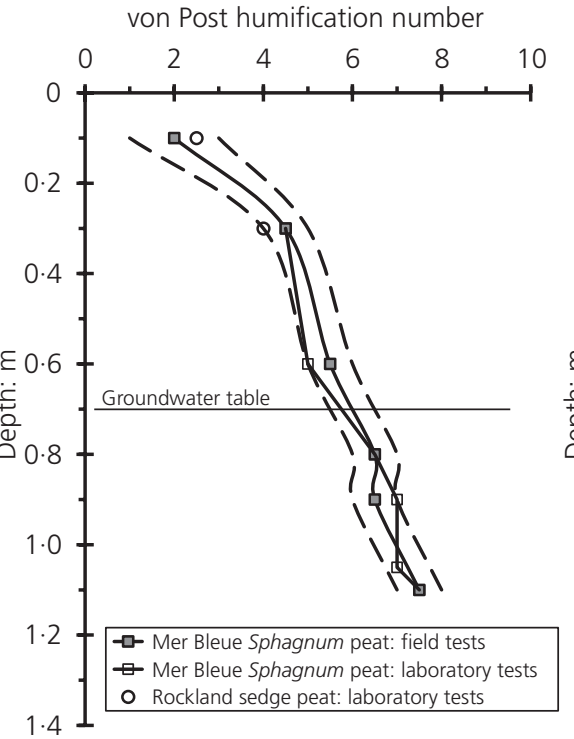

(b)
Undrained tensile strength: $\mathrm{kPa}$

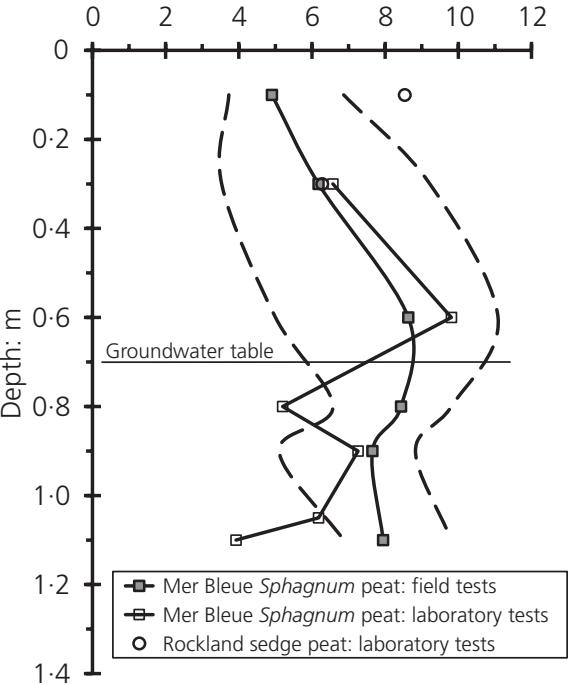

(c)

Figure 21. In situ profiles of (a) water content, (b) degree of humification and (c) undrained tensile strength for the Mer Bleue Sphagnum peat and Rockland sedge peat deposits (created in the present investigation based on data presented by Helenelund (1967)). Note: dashed curves indicate lower and upper bounds for the Mer Bleue Sphagnum peat field test data 
Measurement, interpretation and

recommended use of laboratory strength

properties of fibrous peat

O'Kelly

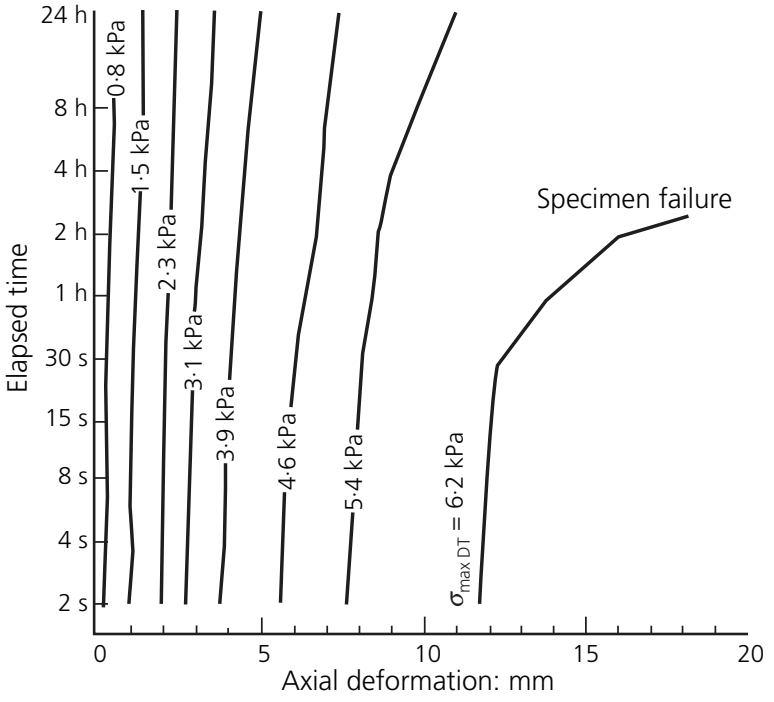

Figure 22. Axial deformation against elapsed time responses for the Mer Bleue Sphagnum peat sampled from $1.05 \mathrm{~m}$ depth and incrementally loaded in direct tension using the apparatus shown in Figure $20(w \approx 1000 \%$ (measured at the specimen failure plane after completing the tension test), $H_{(7)}$ von Post) (adapted from Helenelund (1967) @ Canadian Science Publishing)

more intact fibres in less-humified peat nearer the ground surface mobilise greater tensile strength. Some test specimens taken from 0.35 and $0.50 \mathrm{~m}$ depths at the Cuilcagh and Geevagh Blanket Bogs, respectively, were saturated in deionised water in the laboratory before performing the tension box testing, with Dykes (2008) reporting that higher tensile strengths were mobilised for these saturated specimens compared with field-wet specimens sampled from the same depth. However, from the author's perspective, and as evident from comparison of the data reported in Figure 23, the difference in measured tensile strength between the field-wet and laboratory-saturated specimens sampled from the same location and depth is considered negligible. Neither of the tension box devices developed by Dykes (2008) and Helenelund (1967) measured the $p_{\mathrm{wp}}$ developed at the centre of the test specimen. Such measurements would be helpful in determining the progress of the consolidation stage and the appropriate loading rate to be applied in performing CU (and CD) direct-tension tests.

\section{Drained tensile strength}

Abebaw (2005) and Rowe et al. (1984) reported horizontal drained tensile strength $\sigma_{\max \text { DT }}^{\prime}$ values for fibrous peats determined from drained direct-tension tests (i.e. no lateral confinement stress was applied). There are no reported investigations for fibrous peats on the effect of increasing lateral effective confinement stress on the mobilised $\sigma_{\max }^{\prime}$ DT value: this aspect is considered in the section headed 'Effect of confinement on tensile strength'.

Rowe et al. (1984) reported a mean $\sigma_{\max }^{\prime}$ DT value of $2 \cdot 2 \mathrm{kPa}(n=$ $5, \sigma=0.2 \mathrm{kPa}$ ) for $52 \mathrm{~mm}$ dia. specimens of peat material, along with $c_{\mathrm{DSS}}^{\prime}$ of $1 \cdot 1 \mathrm{kPa}$ for $\phi_{\mathrm{DSS}}^{\prime}$ of $26^{\circ}$ and $c_{\mathrm{DS}}^{\prime}$ of $3.0 \mathrm{kPa}$ for $\phi_{\mathrm{DS}}^{\prime}$ of

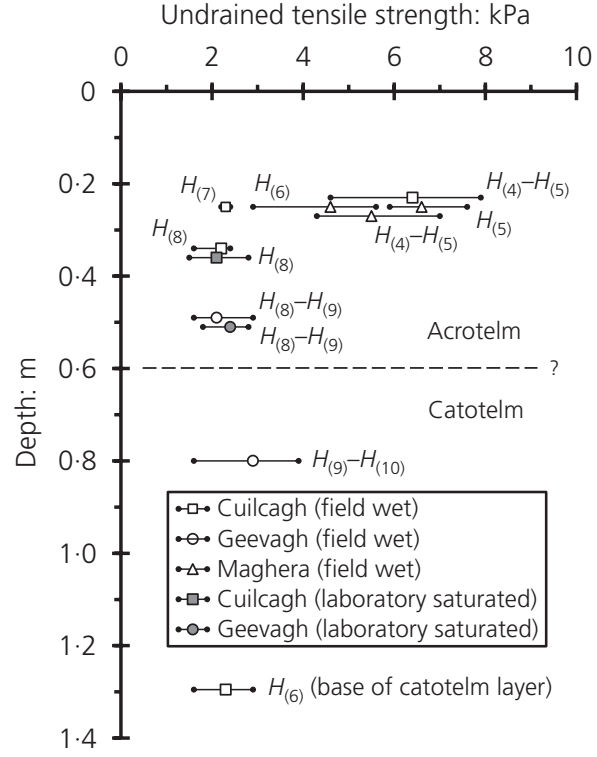

Figure 23. Undrained tensile strength against depth determined from tension box tests performed on a $100 \mathrm{~mm}$ square end by $60 \mathrm{~mm}$ thick block samples of the Cuilcagh, Geevagh and Maghera Blanket Bog peats (prepared in the present investigation from tabulated data presented by Dykes (2008) with permission of Springer)

$27^{\circ}$ (no further details were reported for the peat material or whether the test specimens were unsubmerged or submerged during the tension tests). From Equation 3 (deduced from the Mohr-Coulomb failure criterion, with $\sigma_{\mathrm{v}}^{\prime}=0$ ), the mean $\sigma_{\max }^{\prime}$ DT value of $2 \cdot 2 \mathrm{kPa}$ equates to an effective cohesion in drained direct tension $c_{\mathrm{DT}}^{\prime}$ value of $2.0 \mathrm{kPa}$, which is in the middle of the $c^{\prime}$ range for the DSS and DS tests on the same peat material reported by Rowe et al. (1984)

3. $\sigma_{\max \mathrm{DT}}^{\prime}=c_{\mathrm{DT}}^{\prime} \cos \phi_{\mathrm{DSS}(\mathrm{DS})}^{\prime}$

Abebaw (2005) reported on four drained direct-tension tests performed at an axial strain rate of $12 \% / \mathrm{h}$ on $66 \mathrm{~mm}$ dia. $\times$ $100 \mathrm{~mm}$ long horizontally carved Krimpen woody peat specimens $\left(w_{\mathrm{o}}=460-570 \%\right)$, sampled from between 0.5 and $0.9 \mathrm{~m}$ depth (just below the groundwater table), and which were fitted at both ends with tension caps by casting in gypsum. Of these, two unsubmerged test specimens mobilised $\sigma_{\max }^{\prime}$ DT values of 3.5 and $5.0 \mathrm{kPa}$, whereas two submerged test specimens mobilised $\sigma_{\max }^{\prime}$ DT values of 0 and $2 \mathrm{kPa}$ (i.e. from Equation 3, $c_{\mathrm{DT}}^{\prime}=0$ and $2.3 \mathrm{kPa}$, respectively, assuming $\phi_{\mathrm{DSS}}^{\prime} \approx 28^{\circ}$ (see the section headed 'DSS effective friction angle and normalised undrained strength ratio for conventionally sized peat specimens')). The higher $\sigma_{\max }^{\prime}$ DT values mobilised for the two unsubmerged specimens were explained by suction pressures, which increase interfibre friction and pull-out resistance (Den Haan and Kruse, 2007), although it is generally difficult to get a reliable assessment of the influencing effect of root and wood remnants present in fibrous peats, even if the tension tests are performed on relatively 
large test specimens (Helenelund, 1967). The $c_{\mathrm{DT}}^{\prime}$ values of $2 \cdot 3$ (submerged specimen) and $2.0 \mathrm{kPa}$ deduced for $c_{\mathrm{DSS}}^{\prime}$ from the Abebaw (2005) and Rowe et al. (1984) data, respectively, fall within the typical range of $2-3 \mathrm{kPa}$ deduced for $c_{\mathrm{DSS}}^{\prime}, c_{\mathrm{DS}}^{\prime}$ and $c_{\mathrm{RS}}^{\prime}$ by the author for fibrous peat materials (see the section headed 'DSS effective friction angle and normalised undrained strength ratio for conventionally sized peat specimens').

Since back-analyses of slope and foundation failures involving peat deposits indicate that even a small $\sigma_{\max }^{\prime}$ DT $\left(c_{\mathrm{DT}}^{\prime}\right)$ value of $\sim 2 \mathrm{kPa}$ can play a significant role (Den Haan and Kruse, 2007), further investigations on the drained tensile strength mobilised for submerged peat test specimens with different botanical compositions are necessary, considering the dramatic reduction in $\sigma_{\max \text { DT }}^{\prime}$ due to the inundation of the test specimen, as indicated by Abebaw (2005).

\section{Tensile strength and cohesion}

The incorporation of peat tensile strength in routine geotechnical analysis and design is rare, even for stability assessments of upland blanket bog peat deposits, for which the tensile strength of the acrotelm may have a particular importance (Dykes, 2008). Since the in situ effective stresses can be small or negligible, realistic effective-stress stability assessments must incorporate the resistance contribution derived from the peat cohesion $c^{\prime}$. However, with laboratory shear strength testing usually performed at much higher stress levels due to the limitations of the standard testing equipment, the determination of the $c^{\prime}$ value becomes intimately linked to the interpretation of $\phi^{\prime}$. Linear extrapolation of the failure envelope deduced for the tested $\mathrm{NC}$ peat specimens back to the lower in situ stress levels compounds the problem, potentially resulting in significant underestimations of the available shear strength and cohesion for OC peat deposits. Drained tensile strength testing provides an alternative and potentially more reliable approach to the determination of $c^{\prime}$ values and can be performed relatively quickly, since undisturbed fibrous peat typically has a relatively high permeability, permitting relatively high axial strain rates during drained tension tests while still achieving substantial dissipation of the excess $p_{\mathrm{wp}}$. For instance, axial tension failure (cracking) occurs for undrained TC of vertically carved fibrous peat specimens when the ESP trace reaches the TCO line, as demonstrated by Zwanenburg and Van (2015) from testing of $400 \mathrm{~mm}$ dia. triaxial specimens (see the section headed 'Scale effect related to test-specimen size'). In this case, the true cohesion $\left(c_{\mathrm{TC}}^{\prime}\right)$ value for the TC condition can be approximated from drained direct-tension testing of horizontally carved test specimens.

Since most fibrous peat deposits are inherently cross-anisotropic, the tensile strength mobilised for tension loading orthogonal to the cross-anisotropic plane is much smaller or even negligible. An exception is upland blanket bog peat material, for which the fibres are generally orientated and spaced randomly (Long and Jennings, 2006), and according to Dykes (2008), no pattern was detected in the horizontal and vertical undrained tensile strength values measured for the Maghera Blanket Bog peat deposit.
For undrained stability assessments of fibrous peat deposits, the tensile strength provides an approximation of the general peat strength (Dykes, 2008; Helenelund, 1967), which follows from Equation 3, when expressed in terms of total stress - that is, $\sigma_{\text {max DT }}$ for saturated material $\left(\phi_{\mathrm{u}}=0\right)$. For instance, compared with the field mean $\sigma_{\max }$ DT value of $6.9 \mathrm{kPa}(n=55)$ for depths of up to $1.1 \mathrm{~m}$ at the Mer Bleue Sphagnum peat deposit (see the section headed 'Undrained tensile strength'), the $s_{\mathrm{u}} \mathrm{FV}$ values determined using a $100 \mathrm{~mm}$ dia. cruciform vane (height-todiameter ratio of 2) for depths of between 0.2 and $2.0 \mathrm{~m}$ ranged $4 \cdot 9-27.5 \mathrm{kPa}$, with a mean $s_{\mathrm{u}} \mathrm{FV}$ value of $13.7 \mathrm{kPa}(n=10)$ (Helenelund, 1967). In other words, with $\mu_{\mathrm{FV}}=0.5$ (Mesri and Ajlouni, 2007; Zwanenburg and Jardine, 2015), the corrected mean vane strength $(6.85 \mathrm{kPa})$ agrees closely with the mean undrained tensile strength, based on the field measurements reported by Helenelund (1967). However, more extensive testing of peats with different botanical compositions is recommended to confirm relationships between tensile strength, other strength parameters and humification level.

\section{Fibrous peat as reinforced soil}

As evident from the preceding sections, the engineering behaviour/properties of fibrous peat material depend, among other factors, on its fibre content, which is also the case observed for fibre-reinforced soil. In present-day construction practice, the use of fibre additives is one of the cost-effective and environmentally friendly ground improvement techniques for enhancing soil strength and stability. The subject of fibre-reinforced soil engineering has developed greatly over the past 30-35 years - for example, see Consoli et al. (2003), Parka and Tan (2005), Ranjan et al. (1996), Shukla (2017) and Tang et al. (2016), to name a few. For most applications, short and discrete natural, synthetic or waste fibres are simply mixed with the soil, resulting in the fibre additives having a random orientation in the composite material. Coarse soil can also be reinforced using continuous fibres/yarns, whereby a single monofilament is spun or injected in a random pattern simultaneously with the soil deposition (Shukla, 2017).

Most studies performed on fibre-reinforced soil are based on laboratory and small-scale tests (i.e. TC, DS, unconfined compression, direct tension, California bearing ratio and plate load tests), with the fibre-reinforced soil exhibiting significantly increased peak strength, a smaller loss of post-peak strength and greater extensibility (more ductile response) compared to the soil alone. Experimental measurements and observations of the engineering behaviour/properties of fibre-reinforced soils, the analyses of the results obtained from these tests, the models for predicting their behaviour and their possible field applications, including construction guidelines, are presented by Shukla (2017).

\section{Discussion}

\section{Scale effect related to test-specimen size}

For fibrous peat, the coarse fibres may have a length on the order of the test-specimen dimensions, such that it may be questioned 
whether triaxial tests on conventionally sized specimens of fibrous peat are relevant for field conditions. Huang et al. (2009) expected that the fibre reinforcement effect on strength may be more substantial for peat specimens at the laboratory scale than, for instance, large volumes of the in situ peat material loaded by a road embankment. This hypothesis appears consistent with experience of vane testing in peat, with the mobilised shear strength found to decrease with increasing size (diameter) of the vane (Landva, 1980), possibly due to the effect of the coarse fibres.

Research on the scale effect for TC of fibrous peat is very limited, with only one reported experimental investigation comparing conventionally sized and larger-sized specimens in TC (Zwanenburg and Van, 2015), testing the same Uitdam sedge-reed peat material and thereby allowing direct inferences regarding the scale effect. CU triaxial testing of large-diameter specimens creates its own challenges - for example, inhomogeneous consolidation behaviour, with a clear Mandel-Cryer peak occurring for the triaxial consolidation stage (see Zwanenburg (2005)). In this experimental programme, the CU TC tests performed on $400 \mathrm{~mm}$ dia. Uitdam peat specimens (six NC and six at approximately the field stress level) showed the same general behaviour as recorded for the $65 \mathrm{~mm}$ dia. specimens investigated - that is, strain hardening occurred for $\varepsilon_{\mathrm{a}}>2-3 \%$ and the ESP traces reached the TCO line, with the traces for the six NC specimens continuing up along the TCO line. However, unlike conventionally sized triaxial specimens ( $65 \mathrm{~mm}$ dia. in this instance) that tend to exhibit some barrelling-type deformation in undrained compression, steep failure planes formed in the $400 \mathrm{~mm}$ dia. $\mathrm{NC}$ specimens (i.e. axial tensile failure mode; see Figure 24) for $\varepsilon_{\mathrm{a}}$ values of between 15 and $30 \%$, resulting in an abrupt decline in the mobilised deviator stress (e.g. compare Figures 7(a) and 25(a)). Further, the six $400 \mathrm{~mm}$ dia. specimens consolidated at the field stress level failed shortly after reaching the TCO line.

The remarkable difference in deformation behaviour between the conventionally sized and larger-sized triaxial specimens at failure is explained by the scale effect. According to Zwanenburg and Van (2015), although the specimen strain might be large for conventionally sized specimens (i.e. $\varepsilon_{\mathrm{a}} \geq 20 \%$ ), the (lateral) displacements remain relatively small, such that the fibres do not break or slip, and hence, a rupture plane does not materialise. For the larger-sized specimens, however, much greater deformations occur, causing more straining of the fibres (fibre tensioning) and finally rupture failure. Rupture surfaces also formed for $\gamma=$ $20-25 \%$ during the DSS tests performed on the $260 \mathrm{~mm}$ long $\times$ $220 \mathrm{~mm}$ wide $\times 75 \mathrm{~mm}$ high Uitdam sedge-reed peat specimens by Den Haan and Grognet (2014). A notable feature of these tests was that a clear $\tau_{\mathrm{h} \text { max }}$ condition was reached, with little or no softening or continuing hardening occurring for $\gamma>40 \%$ (Figures 17(a) and 17(b)), unlike the gradual softening behaviour usually experienced by conventionally sized peat test specimens (Figure 17(c)): this difference may also be explained on account of the scale effect.

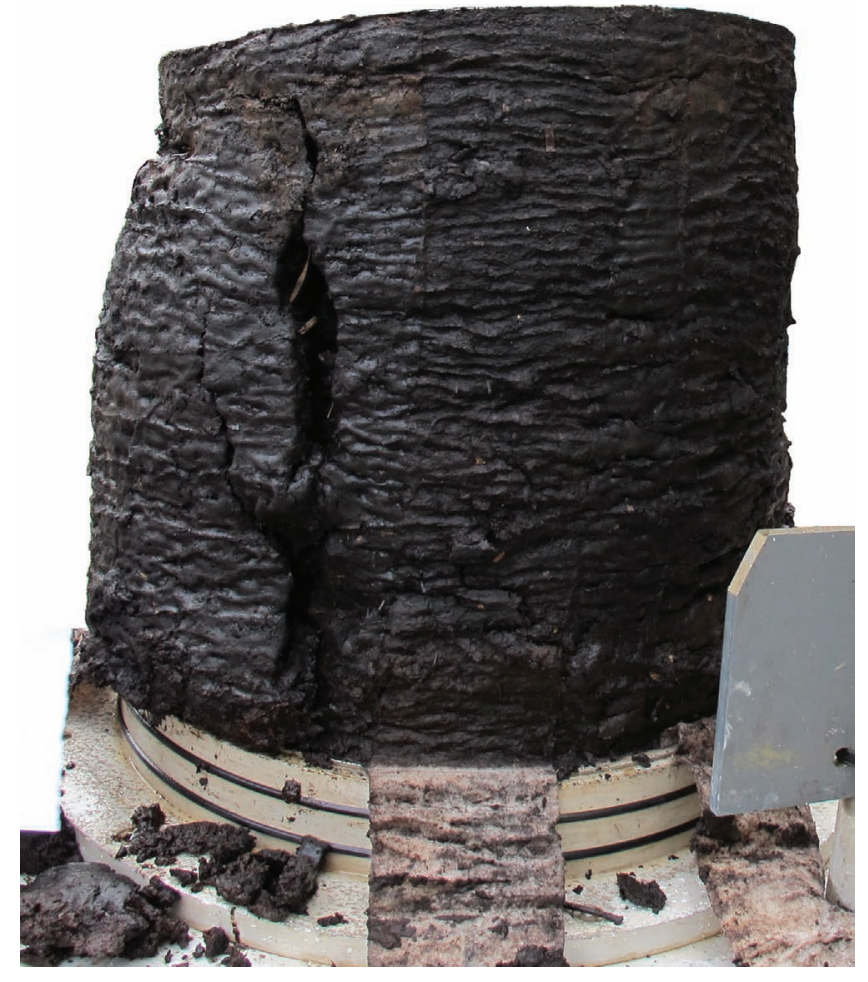

Figure 24. Axial tensile failure mode for $400 \mathrm{~mm}$ dia. NC Uitdam sedge-reed peat specimen in CKo UC triaxial testing $\left(\sigma_{\mathrm{vc}}^{\prime} \approx\right.$ $67 \mathrm{kPa}$ ) (adapted from Zwanenburg and Van (2015) with permission from IOS Press)

For $\mathrm{CK}_{0} \mathrm{UC}$ triaxial testing of the same Uitdam sedge-reed peat material, Zwanenburg and Van (2015) reported that the six NC $400 \mathrm{~mm}$ dia. specimens produced a larger $\left(s_{\mathrm{u} \text { fTC }} / \sigma_{\mathrm{vc}}^{\prime}\right)_{\mathrm{NC}}$ value of $0.63(n=6, \sigma=0.05)$, compared with $\left(s_{\mathrm{ufTC}} / \sigma_{\mathrm{vc}}^{\prime}\right)_{\mathrm{NC}}=$ $0.54(n=8, \sigma=0.13)$ for the $65 \mathrm{~mm}$ dia. specimens investigated, leading them to conclude that TC-derived strength parameter values determined for conventionally sized fibrous peat specimens may be conservative values. The author deduced a higher $\phi_{\mathrm{cv}}^{\prime}$ value $\left(\sim 55^{\circ}\right)$ from the reported $p^{\prime}-q$ traces for the $400 \mathrm{~mm}$ dia. specimens, compared with $\phi_{\mathrm{cv}}^{\prime} \approx 47^{\circ}$ for the $65 \mathrm{~mm}$ dia. specimens (from analyses of Figures 25(b) and 7(b), respectively), supporting their conclusion. Note that $\left(s_{\mathrm{u} \mathrm{fTC}} / \sigma_{\mathrm{vc}}^{\prime}\right)_{\mathrm{NC}}$ values of 0.59 (Zwanenburg and Jardine, 2015) $(n=22$, with $\sigma=$ 0.072 deduced from Table 4 in the same study) and 0.62 (from Figure 11) for $\mathrm{C} K_{0} \mathrm{UC}$ triaxial testing of conventionally sized specimens (Uitdam and Marken peats, respectively) suggest that the mean $\left(s_{\mathrm{ufTC}} / \sigma_{\mathrm{vc}}^{\prime}\right)_{\mathrm{NC}}$ value of 0.54 determined by Zwanenburg and Van (2015) for Uitdam peat material may be on the low side. Nonetheless, the standard deviation value of $\left(s_{\mathrm{ufTC}} / \sigma_{\mathrm{vc}}^{\prime}\right)_{\mathrm{NC}}$ for testing of the conventionally sized Uitdam peat specimens was considerably greater than that reported for the larger sized specimens investigated, from which Zwanenburg and Van (2015) suggested that triaxial test results for conventionally sized specimens lead to a larger variation in measured strength parameter values than what is relevant for a potential sliding plane 


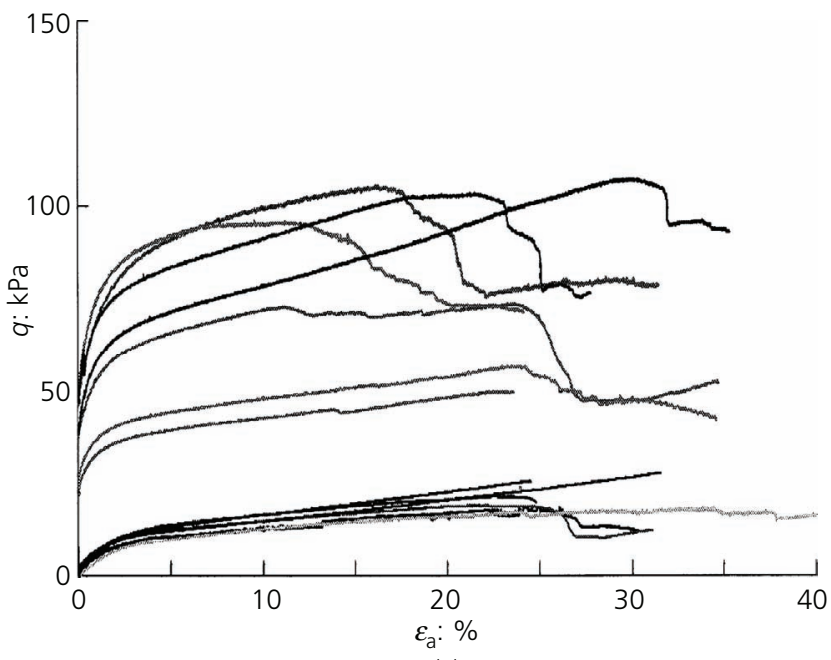

(a)

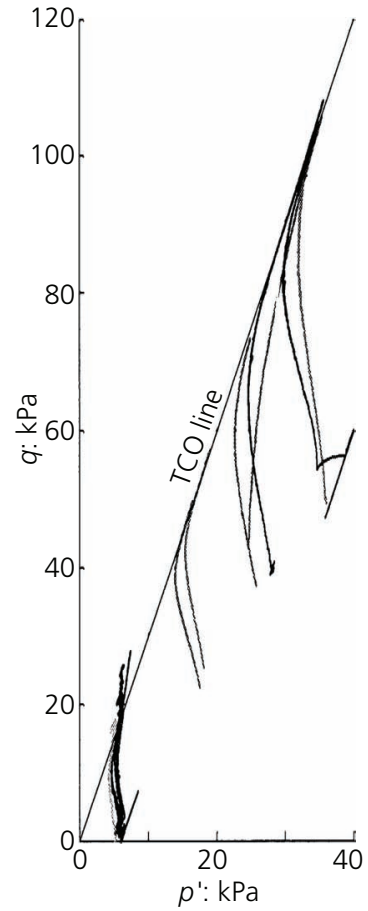

(b)

Figure 25. CKo UC triaxial testing of $400 \mathrm{~mm}$ dia. by $800 \mathrm{~mm}$ long Uitdam sedge-reed peat specimens $\left(w_{0}=800-1020 \%, H_{(2)}-H_{(3)}\right.$ von Post): (a) deviator stress against axial strain (adapted from Zwanenburg and Van (2015) with permission from IOS Press); (b) ESPS (adapted from Zwanenburg and Van (2015) with permission from IOS Press)

in the field. Helenelund (1967) reported similar findings for unconsolidated-undrained tension box testing of the Mer Bleue Sphagnum peat - that is, smaller test specimens often mobilised lower strength values or produced greater scattering in the strength data compared with larger-sized specimens. These findings are pertinent in the context of using probabilistic methods, where the variations in soil properties must be accounted for in testing and analysing - for example, the stability and deformation responses of embankments and dikes on peat deposits.

For DSS testing, experimental data concerning the specimen scale effect for fibrous peat material are very sparse. From DSS testing of a single large $(260 \mathrm{~mm}$ long) NC Uitdam sedge-reed peat specimen by using the apparatus illustrated in Figure 16, Den Haan and Grognet (2014) reported a $\phi_{\mathrm{DSS}}^{\prime}$ value of $37 \cdot 4^{\circ}$, but they acknowledged that more research was required to substantiate this finding. This $\phi_{\mathrm{DSS}}^{\prime}$ value is significantly greater than the $28^{\circ}$ typically associated with standard DSS testing of NC fibrous peat materials (refer to the section headed 'DSS effective friction angle and normalised undrained strength ratio for conventionally sized peat specimens'), but it would tend to agree with the conclusion of Zwanenburg and Van (2015) in relation to CU TC testing of fibrous peat - namely, larger-sized specimens produce higher normalised undrained strength ratio values compared with conventionally sized specimens. On the other hand, from the $\tau_{\mathrm{h}}-\sigma_{\mathrm{v}}^{\prime}$ trace presented in Figure 17(a) for the
Uitdam peat specimen 11 tested using the same large DSS device, the author deduced a $\phi_{\mathrm{DSS}}^{\prime}$ value of $29^{\circ}$ by using Equation 2, with the yield strain based on crack width formation and also assuming $c_{\mathrm{DSS}}^{\prime}=0$. In this instance, the deduced $\phi_{\mathrm{DSS}}^{\prime}$ value is in close agreement with the $28^{\circ}$ typically associated with standard DSS testing of $\mathrm{NC}$ fibrous peat materials, possibly suggesting that compared with TC testing, the scale effect may not be as significant for DSS testing, since the shear deformation mainly occurs in the direction of the predominantly horizontally aligned fibres. A plausible explanation for the lower $\phi_{\mathrm{DSS}}^{\prime}$ value deduced for this large peat specimen was that it was sheared in an OC state (overconsolidation ratio OCR $=1 \cdot 4$ ). However, considering the limited experimental data available, further investigations of the scale effect for both triaxial and DSS test specimens are necessary to draw definitive conclusions in respect of $s_{\mathrm{u}}, s_{\mathrm{u}} / \sigma_{\mathrm{vc}}^{\prime}, \phi_{\mathrm{cv}}^{\prime}$ and $K_{0}$ determinations for fibrous peat materials. The possible effect of the ratio of the specimen height to its length in the shearing direction for DSS testing also merits investigation. Such work would be of great interest and value in determining appropriate test-specimen sizes (dimensions) for routine laboratory-strength testing of fibrous peat materials (Den Haan and Kruse, 2007; Hollingshead and Raymond, 1972; O'Kelly, 2015a). The same recommendations apply to $K_{0}$ determinations using instrumented consolidation-cell and CRS $K_{0}$ oedometer devices (section headed 'At-rest earth pressure coefficient for conventionally sized NC peat specimens'). 


\section{Effect of confinement on tensile strength}

As described in the section headed 'Drained tensile strength', only two investigations reported on the drained tensile strength of peat, although neither considered the effect of the lateral effective confinement stress on the mobilised resistance (i.e. the effect of increasing $\sigma_{\mathrm{vc}}^{\prime}$ on the $\sigma_{\max }$ DT value mobilised in the crossanisotropic plane), which is pertinent, for example, in assesing the increase in tensile capacity of the $K_{0}$-compressed peat mat during embankment construction over peat deposits.

In the present investigation, the author makes use of the $q-\varepsilon_{\mathrm{a}}$ traces presented in Figure 25(a) to determine the $c_{\mathrm{DT}}^{\prime}$ and $\sigma_{\max \text { DT }} / \sigma_{\mathrm{vc}}^{\prime}$ ratio values for NC Uitdam sedge-reed peat material. Since these traces are obtained from $\mathrm{C} K_{0} \mathrm{UC}$ triaxial tests, the stress-induced cross-anisotropic fabric complements the inherent fabric of the undisturbed peat specimens. Referring to Figure 25(a), axial tension failure of the test specimens occurred when the axial strain applied during the compression stage was large enough, causing an abrupt drop $\Delta q$ from the peak deviator stress $q_{\max }$. The tensile strength of the compressed specimen can be approximated as

4. $\sigma_{\max \mathrm{DT}}=\Delta q \frac{A_{1}}{A_{2}}$

where $A_{1}$ and $A_{2}$ are the enlarged horizontal and reduced vertical cross-sectional areas, respectively, for axial tension failure of the compressed specimen.

Following axial tension failure, the gradual increase in $q$ with increasing $\varepsilon_{\mathrm{a}}$ (evident for some of the traces in Figure 25(a)) can be explained by the increasing confinement pressure provided by the enclosing latex membrane against further radial straining of the test specimen. Regression analysis performed by the author of the data for $\sigma_{\mathrm{vc}}^{\prime}=33 \cdot 3,50$ and $66 \cdot 7 \mathrm{kPa}$ in a $\sigma_{\mathrm{max} \mathrm{DT}}-\sigma_{\mathrm{vc}}^{\prime}$ plot gives $c_{\mathrm{DT}}^{\prime} \approx 2 \mathrm{kPa}$ and $\sigma_{\text {max DT }} / \sigma_{\mathrm{vc}}^{\prime} \approx 0 \cdot 30(n=6)$ for the NC Uitdam sedge-reed peat material investigated. These experimental findings are consistent with the $c_{\mathrm{DT}}^{\prime}$ values of $2 \cdot 0$ and $2 \cdot 3 \mathrm{kPa}$ deduced by the author for different submerged peat materials from reported direct-tension data (see the section headed 'Drained tensile strength') and the mean $\sigma_{\max }$ DT values of 6.6 and $4.2 \mathrm{kPa}(n=43$ and 33 , respectively) deduced by the author for the acrotelm layer of the Mer Bleue Sphagnum and upland blanket bog peat materials (section headed 'Undrained tensile strength'), assuming $\sigma_{\max }^{\prime}$ values ranging $12-15 \mathrm{kPa}$, typical of many virgin peat deposits, and an overconsolidation ratio $\left(\mathrm{OCR}=\sigma_{\max }^{\prime} / \sigma_{\mathrm{vc}}^{\prime}\right)$ value of unity.

\section{Effect of overconsolidation}

Natural peat deposits are generally OC to some degree (O'Kelly, 2005a, 2006a; Zwanenburg and Jardine, 2015; Zwanenburg and Van, 2015; Zwanenburg et al., 2012), with an apparent preconsolidation (yield) pressure of $\sim 12-15 \mathrm{kPa}$ measured for many virgin peat deposits, reflecting the effects of ageing, historical groundwater cycles and also possibly non-hydrostatic pore-pressure development in depth (e.g. subartesian pressure present in an underlying, more permeable layer; e.g., see O'Kelly (2015b)) and (or) overburden that has been removed. The effect is significant since, combined with the waterlogged condition, low particle density and, hence, small or negligible in situ stresses, it often results in many natural peat deposits having high OCR values. The limited reported investigations on the effects of stress history on the strength and $K_{0}$ values for peat materials are summarised and discussed in the following.

\section{Normalised undrained strength ratio}

The following expression is generally used to relate the normalised undrained strength ratio for the $\mathrm{OC}$ state with that for the $\mathrm{NC}$ state

5. $\left(\frac{s_{\mathrm{u}}}{\sigma_{\mathrm{vc}}^{\prime}}\right)_{\mathrm{OC}}=\mathrm{OCR}^{m_{1}}\left(\frac{s_{\mathrm{u}}}{\sigma_{\mathrm{vc}}^{\prime}}\right)_{\mathrm{NC}}$

where OCR $=\sigma_{\max }^{\prime} / \sigma_{\mathrm{vc}}^{\prime}$ and $m_{1}$ is the gradient of the $s_{\mathrm{u}} / \sigma_{\mathrm{vc}}^{\prime}-\mathrm{OCR}$ relationship, when plotted on a double-logarithmic scale graph.

From a full review of the literature, only two studies investigated this relationship for peat material. In examining the effect of stress history for the Uitdam sedge-reed peat, Zwanenburg and Jardine (2015) consolidated test specimens under nominally $K_{0}$ conditions, unloaded them by different amounts to achieve OCR values of $1 \cdot 25,2,5$ and 10 , before shearing them in DSS mode, from which the following equation was produced

6. $\left(\frac{s_{\mathrm{u} \mathrm{DSS}}}{\sigma_{\mathrm{vc}}^{\prime}}\right)_{\mathrm{OC}}=0.47 \mathrm{OCR}^{0.96}$

Based on Equation 6 and the reported $\sigma_{\max }^{\prime}$ range of $5-14 \mathrm{kPa}$ (Zwanenburg and Jardine, 2015), the DSS $\tau_{\mathrm{h} \max }-\sigma_{\mathrm{v}}^{\prime}$ limits for the Uitdam sedge-reed peat material were computed by the author and plotted in Figure 26. As evident from this figure, the experimental $m_{1}$ value of 0.96 (i.e. approximately unity) implies that the material's $s_{\mathrm{u}}$ DSs value is relatively insensitive to recompression effective stresses until $\sigma_{\mathrm{vc}}^{\prime}>\sigma_{\max }^{\prime}$. For Antoniny peat, Lechowicz (1994) reported $\mathrm{C} K_{0} \mathrm{UC}$ triaxial $\left(s_{\mathrm{u}} / \sigma_{\mathrm{vc}}^{\prime}\right)_{\mathrm{NC}}$ and $m_{1}$ values of $0 \cdot 47$ and $0 \cdot 80$, respectively, along with a DSS $\left(s_{\mathrm{u}} / \sigma_{\mathrm{vc}}^{\prime}\right)_{\mathrm{NC}}$ value of $0 \cdot 38$, with the lower $m_{1}$ value of $0 \cdot 80$ suggesting that the undrained shear strength for this material is somewhat more sensitive to recompression stresses. However, both of the Antoniny peat $\left(s_{\mathrm{u}} / \sigma_{\mathrm{vc}}^{\prime}\right)_{\mathrm{NC}}$ values tend on the low side for NC fibrous peat materials

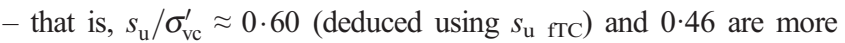
representative for $\mathrm{CK}_{0} \mathrm{UC}$ triaxial and DSS testing, respectively, with a tentative lower bound of $\sim 0.40$ having been identified for the latter (see the sections headed 'Triaxial effective-stress friction angle, undrained strength and normalised undrained strength ratio for conventionally sized NC peat specimens' and 'DSS effective friction angle and normalised undrained strength ratio for conventionally sized peat specimens'). 
Measurement, interpretation and

recommended use of laboratory strength

properties of fibrous peat

O'Kelly

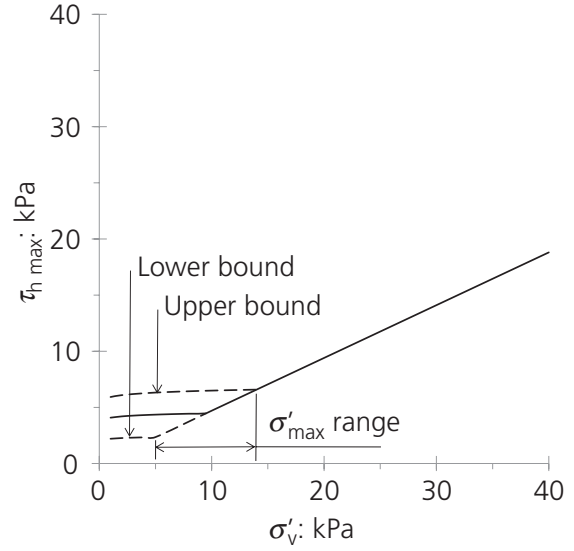

Figure 26. Upper- and lower-bound failure envelopes for the Uitdam sedge-reed peat material in DSS (based on Equation 6 and reported $\sigma_{\max }^{\prime}$ range of $5-14 \mathrm{kPa}$ )

Although the general understanding is that for a given $\mathrm{NC}$ peat material, the $\left(s_{\mathrm{u}} / \sigma_{\mathrm{vc}}^{\prime}\right)_{\mathrm{NC}}$ value remains unchanged with increasing vertical effective stress, Lechowicz (1994) and Przystański (1994) reported that their experiences for NC peat indicate that this ratio value changes (but to a much lesser extent than for OC peat), depending on the vertical effective stress increment. For instance, see Figure 27 for VSL $\leq 1$, where VSL (vertical effective stress level), plotted on the $x$-axis, is defined as the ratio of the initial value of the preconsolidation pressure to the $\sigma_{\mathrm{vc}}^{\prime}$ value under consideration. Using this approach, Lechowicz (1994) argued that the $\mathrm{CK}_{0} \mathrm{UC}$ triaxial, DSS and field-vane testing performed on the NC Antoniny peat material all indicate that $\left(s_{\mathrm{u}} / \sigma_{\mathrm{vc}}^{\prime}\right)_{\mathrm{NC}}$ reduces in value for larger stress increments. As evident from this figure, the same also applies for gyttja material: a particular Scandinavian term applied to organic bottom deposits in eutrophic lakes.

In support of this viewpoint, the general trend in the DSS test results presented for the NC (i.e. 'Arbitrary stress' data points) peat materials in Figure 18 indicates that the $\left(s_{\mathrm{uDSS}} / \sigma_{\mathrm{vc}}^{\prime}\right)_{\mathrm{NC}}$ value reduces, but at a decreasing rate, for higher consolidation stress. In other words, according to Lechowicz (1994), for $\sigma_{\mathrm{vc}}^{\prime}$ values greater than the initial preconsolidation pressure, the mobilised undrained strength value may be considerably lower than that estimated using a fixed experimentally derived $\left(s_{\mathrm{uDSS}} / \sigma_{\mathrm{vc}}^{\prime}\right)_{\mathrm{NC}}$ value, with the relative difference of greater magnitude for increasing vertical effective consolidation stress. Since the induced vertical effective stresses exceed the low initial preconsolidation pressure value by several times for staged embankment construction on peat deposits, further research is necessary to draw a firm conclusion on this particular aspect of NC peat behaviour.

\section{Failure envelope and stress paths for TC}

Close examination of the triaxial ESP traces for the $400 \mathrm{~mm}$ dia. NC Uitdam sedge-reed peat specimens presented in Figure 25 indicates that on reaching the TCO line fitted through the origin, all six of the $\mathrm{C}_{0} \mathrm{UC}$ triaxial traces continued up along this line until specimen failure occurred in axial tension. In contrast, all six of the CIUC triaxial traces for the tests performed at the field stress level (i.e. the group of ESP traces that start at $p^{\prime}=5 \mathrm{kPa}$ ) overshoot the TCO line. Zwanenburg and Van (2015) explained this overshoot as owing to the combination of the measurement accuracy of these tests, the low stress levels investigated and the reinforcing influence of the specimen membrane. An equally valid and possibly more plausible explanation for these ESP traces overshooting the TCO line is the OC state for these peat specimens (i.e. $\sigma_{\max }^{\prime}$ ranged $8 \cdot 4-15 \cdot 2 \mathrm{kPa}$ (Zwanenburg

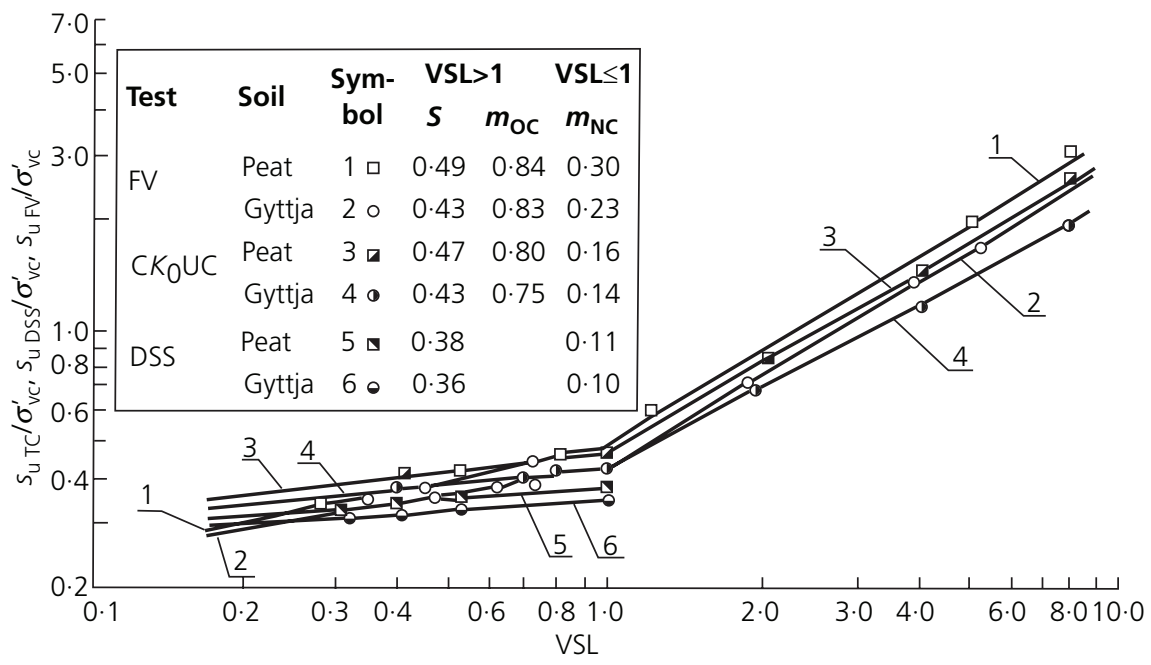

Figure 27. Normalised undrained strength ratio against vertical effective stress level (VSL) from field and laboratory testing of $3.1 \mathrm{~m}$ thick peat layer overlying $4.7 \mathrm{~m}$ thick gyttja layer at the Antoniny site, Noteé River Valley, Poland (adapted from Lechowicz (1994)): FV, field vane (corrected); VSL, ratio of initial preconsolidation pressure value to $\sigma_{v c}^{\prime} ; S, s_{u} / \sigma_{v c}^{\prime}$ value for VSL of unity; $m_{N C}$ and $m_{O C}$, gradients of $\log s_{\mathrm{u}} / \sigma_{\mathrm{vc}}^{\prime}$ against log VSL relationships for the NC (VSL $\left.\leq 1\right)$ and OC (VSL > 1) states, respectively 
and Van, 2015)), along with the tensile strength mobilised for axial tensile failure. Note that for conventionally sized triaxial specimens, some of the CIUC ESP traces that start at $p^{\prime} \leq 12 \mathrm{kPa}$ for the Uitdam sedge-reed peat (see Figure 7(b)) and all of the CIUC ESP traces that start at $p^{\prime} \leq 8 \mathrm{kPa}$ for the Booneschans fibrous peat (refer to figure 13 presented in the paper by Zwanenburg et al. (2012)) also overshoot the TCO line, fitted through the origin. With reported $\sigma_{\max }^{\prime}$ typically ranging 5-14 $\mathrm{kPa}$ (but up to $24 \mathrm{kPa}$ ) (Zwanenburg and Jardine, 2015) and $22-38 \mathrm{kPa}$ (Zwanenburg et al., 2012), it is probable that the OC state of these triaxial specimens was primarily responsible for their ESP traces overshooting the TCO line. Similar behaviours are evident in the $\tau_{\mathrm{h} \text { max }}-\sigma_{\mathrm{v}}^{\prime}$ plots determined from DSS and RS testing of the Booneschans and Escuminac fibrous peat materials (refer to Figure 14 presented in Zwanenburg et al. (2012) and Figure 14 in Landva and La Rochelle (1983)), where the estimated true cohesion intercept is approximately double the reported apparent intercept $c_{\mathrm{DSS}}^{\prime}$ and $c_{\mathrm{RS}}^{\prime}$ values of $2 \cdot 3$ and $2.4 \mathrm{kPa}$, respectively.

Further, where it occurred, the overshoot by the CIUC triaxial ESP traces of the TCO line was greater for those traces that started out at lower $p^{\prime}$ values (i.e. specimens with higher OCR values), in agreement with expressions of the form given by Equation 5 and suggesting that the test specimens' OC state was the dominant reason. In other words, the TCO line fitted through the origin (i.e. $c^{\prime}=0$ ) does not represent the real behaviour of OC fibrous peat, which is further demonstrated in terms of the failure envelope, with $\sigma_{\mathrm{v}}^{\prime}<\sigma_{\max }^{\prime}$, for the Uitdam peat material presented in Figure 26. Conversely, standard strength testing in which undisturbed peat specimens are consolidated to induce an $\mathrm{NC}$ state before the shearing stage commences grossly underestimates the $c^{\prime}$ value and overestimates the $\phi^{\prime}$ value appropriate for in situ $\sigma_{\mathrm{v}}^{\prime}<\sigma_{\max }^{\prime}$.

\section{At-rest earth pressure coefficient}

With most natural peat deposits OC to some degree, knowledge of the associated at-rest earth pressure coefficient (i.e. $K_{0,}$ oc) value is an important precursor, for instance, in performing numerical analysis for geotechnical applications (Hayashi et al., 2012). Numerous correlations have been proposed to establish the value of $K_{0, \text { OC }}$ from the $K_{0, \mathrm{NC}}$ and OCR values for inorganic soil (e.g. see Mayne and Kulhawy (1982)), building on the formulation given by the following equation, after Schmidt (1966)

7. $K_{0, \mathrm{OC}}=K_{0, \mathrm{NC}} \mathrm{OCR}^{m_{2}}$

where the exponent $m_{2}$ is the at-rest rebound parameter.

Compared with inorganic soils (from Equation 8, typically $m_{2}=$ 0.5 for $\phi_{\mathrm{cv}}^{\prime} \approx 30^{\circ}$ ), very limited experimental $m_{2}$ data have been reported for peat and other organic soils. Based on $\mathrm{CK}_{0} \mathrm{UC}$ triaxial tests, Kanmuri et al. (1998) reported an $m_{2}$ value of 0.5 for fibrous peat, although this value seems much too low given the anticipated high $\phi_{\mathrm{TC}}^{\prime}$ value for fibrous peat material. Using a similar approach for testing $75 \mathrm{~mm}$ dia. $\times 75 \mathrm{~mm}$ long triaxial specimens (in combination with flat dilatometer tests), Hayashi et

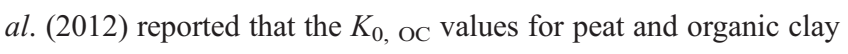
materials investigated $(N=6-91 \%)$ depend more strongly on OCR, with the $m_{2}$ value increasing in proportion with the $N$ value, according to Equation 9. With peat defined as soil containing more than $75 \%$ organics by dry mass (ASTM, 2013), Equation 9 suggests that for most peat materials $0.82<m_{2} \leq 0.95$

\section{8. $m_{2}=\sin \phi^{\prime} \quad$ (after Mayne and Kulhawy (1982))}

where $\phi^{\prime}$ is taken to signify the $\phi_{\mathrm{cv}}^{\prime}$ value (after Mesri and Ajlouni (2007) and Mesri and Hayat (1993))

\section{9. $m_{2}=0.45+0 \cdot 005 N$}

where $N$ is the loss in dry mass on ignition (as \%), determined for an ignition temperature of $700-800^{\circ} \mathrm{C}$ in this instance.

Note that the ignition temperature range of $700-800^{\circ} \mathrm{C}$ used in developing the correlation given by Equation 9 is considered too high (a lower ignition temperature of $440^{\circ} \mathrm{C}$ is specified in ASTM (2014) and BSI (1990)) and produce measured $N$ values that can overestimate the organic content to a slightly greater extent (see Skempton and Petley (1970)). Nonetheless, Equations 8 and 9 appear to produce broadly consistent results. For instance, from Equation 9, the highest experimental $N$ value of $91 \%$ investigated in the Hayashi et al. (2012) study gives $m_{2}=0.905$, which, according to Equation 8, would correspond to a $\phi_{\mathrm{cv}}^{\prime}$ value of $\sim 65^{\circ}$. Similarly, $m_{2}=0.48$ and $\phi_{\mathrm{cv}}^{\prime}=29^{\circ}$ are deduced for organic clay with $N=6 \%$ : the lowest experimental $N$ value investigated by Hayashi et al. (2012). Although they did not measure the $\phi_{\mathrm{cv}}^{\prime}$ (or $\left.\phi_{\mathrm{TC}}^{\prime}\right)$ values of the different peat and organic clay materials investigated, the $\phi_{\mathrm{cv}}^{\prime}$ values deduced using Equation 8, with the $m_{2}$ values predicted using Equation 9, seem reasonable.

The value of the $m_{2}$ parameter can also be estimated from the oedometer compression ratio $\left(C_{\mathrm{R}}\right)$ and recompression ratio $\left(R_{\mathrm{R}}\right)$ values (see Equation 10, after Ladd and Foott (1974)). Using this approach, Zwanenburg and Jardine (2015) deduced $m_{2}=$ $0 \cdot 82-0 \cdot 92$ for the Uitdam sedge-reed peat $(N=75-92 \%)$, which is in excellent agreement with the $m_{2}$ range of $0 \cdot 83-0.91$ predicted using Equation 9

$$
\text { 10. } m_{2}=\frac{C_{\mathrm{R}}-R_{\mathrm{R}}}{C_{\mathrm{R}}}
$$

\section{Guidance for operational shear strength assessments for bearing capacity and stability calculations involving peat}

In assessing the stability of a peat deposit, an important task is to identify the general field shear mode and drainage condition that dictate the peat behaviour during a particular failure scenario. Since the drainage condition could possibly vary from fully undrained to 
fully drained, an undrained stability assessment is often undertaken and represents the more conservative approach (Boylan and Long, 2014), assuming that the peat material is NC. Further, the strengthtesting method adopted must induce a shearing condition that is representative of the anticipated general field shear mode. Effectivestress strength analysis is also routinely performed (e.g. for FE modelling of embankments and dikes on fibrous peat and highly organic clay (den Haan and Feddema, 2013; Rowe et al., 1984) and highway construction in peat bogs (Tan, 2008)), with both the undrained and effective-stress strength approaches discussed in greater detail in the following, with reference to a number of case studies that encompass different foundation width $(B)$ to peat stratum thickness $(D)$ ratios.

In other words, the undrained shear strength of $\mathrm{NC}$ peat material (i.e. $\left.s_{\mathrm{u}} \mathrm{NC}\right)$ can be assessed for a particular in situ vertical effective stress $\left(\sigma_{\mathrm{v}_{1}}^{\prime}\right)$ by using an appropriate value (i.e. consistent with the general field shear mode) of the normalised undrained strength ratio or using the Mohr-Coulomb criterion incorporating appropriate values of the effective-stress strength parameters $\left(c^{\prime}\right.$, $\left.\phi^{\prime}\right)$. Then, from Equation 5, the undrained strength of the same peat material for the OC state, $s_{\mathrm{u} \text { OC }}$ (i.e. corresponding to $\sigma_{\mathrm{v}_{2}}^{\prime}<$ $\sigma_{\mathrm{v}_{1}}^{\prime}\left(=\sigma_{\max }^{\prime}\right)$ ), can be determined as

11.

$$
s_{\mathrm{u} \mathrm{OC}}=\sigma_{\mathrm{v}_{2}}^{\prime} \mathrm{OCR}^{m_{1}}\left(\frac{s_{\mathrm{u} \mathrm{NC}}}{\sigma_{\mathrm{v}_{1}}^{\prime}}\right)
$$

where OCR $=\sigma_{\mathrm{v}_{1}}^{\prime} / \sigma_{\mathrm{v}_{2}}^{\prime}$.

For instance, pertinent representative values for preliminary assessment of the shear strength of $\mathrm{NC}$ fibrous peat material in DSS mode are $c_{\mathrm{DSS}}^{\prime} \approx 2 \mathrm{kPa}, \phi_{\mathrm{DSS}}^{\prime} \approx 28^{\circ}$ (see the section headed 'DSS effective friction angle and normalised undrained strength ratio for conventionally sized peat specimens'), $\left(s_{\mathrm{uDSS}} / \sigma_{\mathrm{vc}}^{\prime}\right)_{\mathrm{NC}}=0.46$ (Foott and Ladd, 1981; Zwanenburg and Jardine, 2015; Zwanenburg et al., 2012) and $m_{1}=0.96$ (Zwanenburg and Jardine, 2015), with tentative lower-bound $\left(s_{\mathrm{u} \text { DSS }} / \sigma_{\mathrm{vc}}^{\prime}\right)_{\mathrm{NC}}$ and $m_{1}$ values of $0 \cdot 40$ (Boylan and Long, 2014) and $0 \cdot 80$, respectively, noting that assumed values should be confirmed through laboratory testing.

It is also important to note that stability assessments for peat embankments, dikes and natural slopes require methods that deal with uncertainties concerning the ambient conditions, as well as their effects on the soil properties, conditions and behaviour for instance, the effect of a possible drought or biogas produced internally reducing the self-weight of the peat mass, the influence of gas formation at the base of dikes on their stability, effectivestress reductions due to hydraulic connections by way of shrinkage cracks and (or) more permeable layers underlying the peat layer (see Bezuijen et al. (2005), Boylan et al. (2008), Den Haan and Kruse (2007) and van Baars (2005)).

Decomposition of the organic matter in peat generates various gases, with the volumetric gas fraction trapped within the peat layers typically ranging 5-12\% (Baird and Waldron, 2003). The potential causes of exsolution and expansion of these gases within the peat layers are atmospheric pressure changes, total stress reduction, lowering of the groundwater table and temperature oscillations. The effects of decomposition on some physical properties of the Ballydermot Raised Bog fibrous peat material were reported by O'Kelly and Pichan (2014). Investigations on the effects of the by-product gases on the hydromechanical behaviour of fibrous peat include field monitoring over a 3-year period of the temperature, $p_{\mathrm{wp}}$ and vertical settlement at different depths within the peat subgrade beneath a railway embankment (Acharya et al., 2016) and TC testing of undisturbed Markermeer peat specimens in which gas had been exsolved by flushing the specimens with carbonated water followed by isotropic undrained unloading (Jommi et al., 2017). The pore pressures within the peat subgrade were found to increase significantly (by $>10 \mathrm{kPa}$ ) during warmer months and were strongly correlated with the seasonal temperature changes (Acharya et al., 2016). Gas exsolution during isotropic undrained unloading produced further significant reductions in the effective confining stress, with the mechanical response during the following undrained TC stage dominated as well by the ratio between the compressibility of the fluid and the compressibility of the soil skeleton (Jommi et al., 2017). Further, the pore pressures of peat specimens placed within a triaxial cell apparatus and subjected to a constant confinement pressure showed a direct correlation with incremental increases in the temperature of the specimens - for example, a $10^{\circ} \mathrm{C}$ temperature increase produced a $30 \mathrm{kPa}$ increase in pore pressure for the peat subgrade material investigated by Acharya et al. (2016). More research is necessary, particularly on the influence and impact of gas formation at the base of dikes and embankments on their stability. The behaviours described earlier have also been measured, but with more pronounced effects, for biosolids (sewage sludge) materials on account of their significantly greater levels of bioactivity (O'Kelly, 2005b, 2006b, 2013).

\section{Effective-stress analysis using limit equilibrium approach}

Since large deformations in peat deposits cause the in situ stresses to be redistributed from areas of peak stress to neighbouring areas, which results in the propagation of the failure surface and a reduction in the mobilised shear strength value, the $\phi_{\mathrm{cv}}^{\prime}$ parameter should be used in performing effective-stress stability and bearing capacity analyses. However, $\phi_{\mathrm{cv}}^{\prime}$ values are rarely reported in the literature for peat, rather only peak $\phi^{\prime}$ values. The $\phi_{\mathrm{cv}}^{\prime}$ value can be deduced from regression analysis of the phase transformation (yield) points corresponding to three or more ESP traces derived from $\mathrm{CU}$ triaxial testing, with the $\mathrm{CK}_{0} \mathrm{UC}$ approach preferred over the CIUC approach, since isotropic consolidation induces a new structural anisotropy (over the existing cross-anisotropic structure) that is generally not representative of field conditions. Large test specimens should be used, if feasible, to mitigate the scale effect related to the peat's coarse fibres.

For NC peat material, Den Haan (2002) and Den Haan and Kruse (2007) reported on the determination of the critical-state stress ratio $M$ (and thence $\phi_{\mathrm{cv}}^{\prime}$ ) value by using a detailed equation (presented 
Measurement, interpretation and recommended use of laboratory strength properties of fibrous peat O'Kelly by Den Haan and Feddema (2013)) involving compressibility parameter values derived from the unload and relaxation stages in CRS $K_{0}$ oedometer tests. The value of $M$ found in this way need not correspond to the triaxial-derived value, although many problems will involve stress states far from the critical state, and it may be preferable to use parameter values that give reasonable correspondence with 1D states rather than critical states (Den Haan and Kamao, 2003). Alternatively, an assessment of the $\phi_{c v}^{\prime}$ value corresponding to TC of vertically carved NC peat material can be made using the Jaky correlation (Equation 1) incorporating $K_{0}$ values obtained from consolidation cell, CRS oedometer or triaxial consolidation tests. Further, in correlating $K_{0}$, oc with the $K_{0}$, NC and OCR values, based on the limited reported experimental data for peat materials, it would appear that appropriate values of the at-rest rebound parameter $m_{2}$ can be reasonably estimated using established relationships with $\phi_{\mathrm{cv}}^{\prime}$ and $N$ (see Equations 8 and 9).

\section{Undrained strength approach}

\section{Cases for $B / 2<D<B$ and $D>B$}

Zwanenburg and Jardine (2015) investigated strip foundation loading of a peat layer $(D=5 \mathrm{~m})$ at Uitdam, the Netherlands, with axisymmetric and asymmetric shear (described as approximately circular slip) failure modes developing for $B / 2<D<B$ (see Figures 28(a) and 28(b)) and $D>B$, respectively. In other words, with the entire soil foundation failure occurring within the peat layer (Zwanenburg, 2012), the foundation width in relation to the peat layer depth determines whether an axisymmetric or asymmetric shear-failure mode develops. From simple Tresca-based FE analyses of five instrumented strip foundations that had been loaded in multiple stages to failure, Zwanenburg and Jardine (2015) found that $\left(s_{\mathrm{ufTC}} / \sigma_{\mathrm{vc}}^{\prime}\right)_{\mathrm{NC}}=0 \cdot 59$, determined from conventional CIUC triaxial testing, closely matched the field-test shear strength interpretation (Figure 28(c)). Note that the $s_{\mathrm{u}}$ fTC value is used in determining this

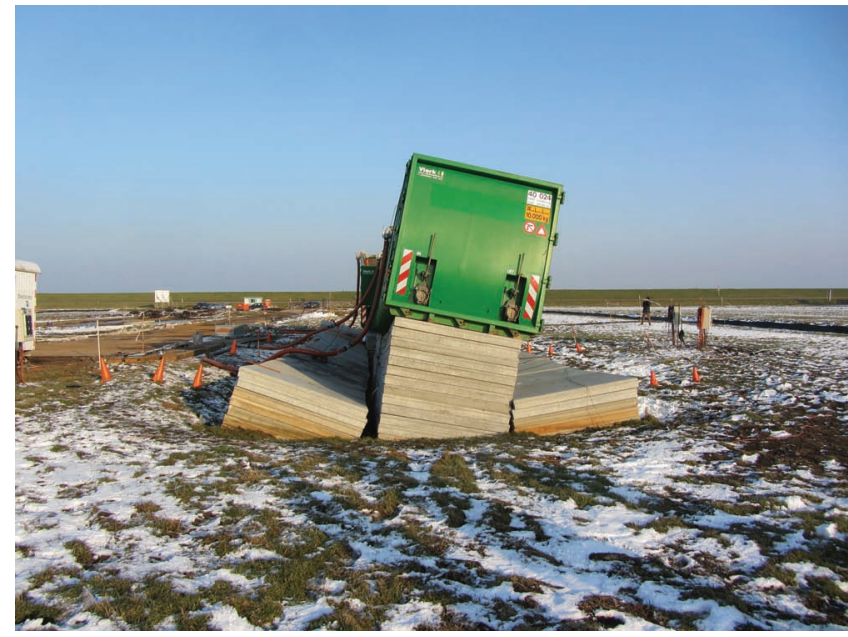

(a)

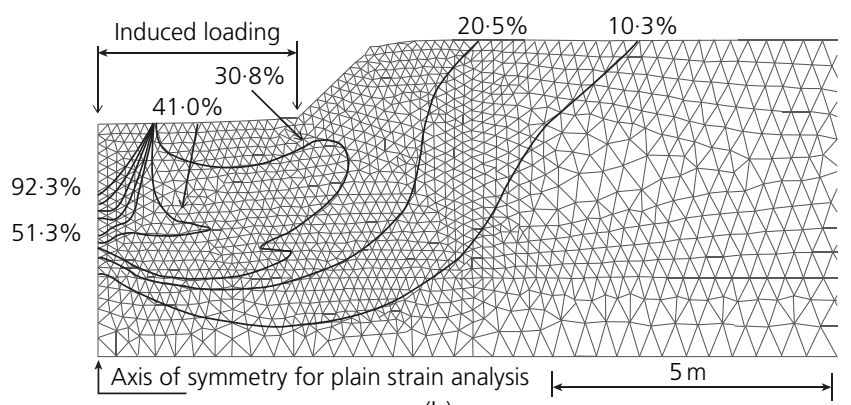

(b)

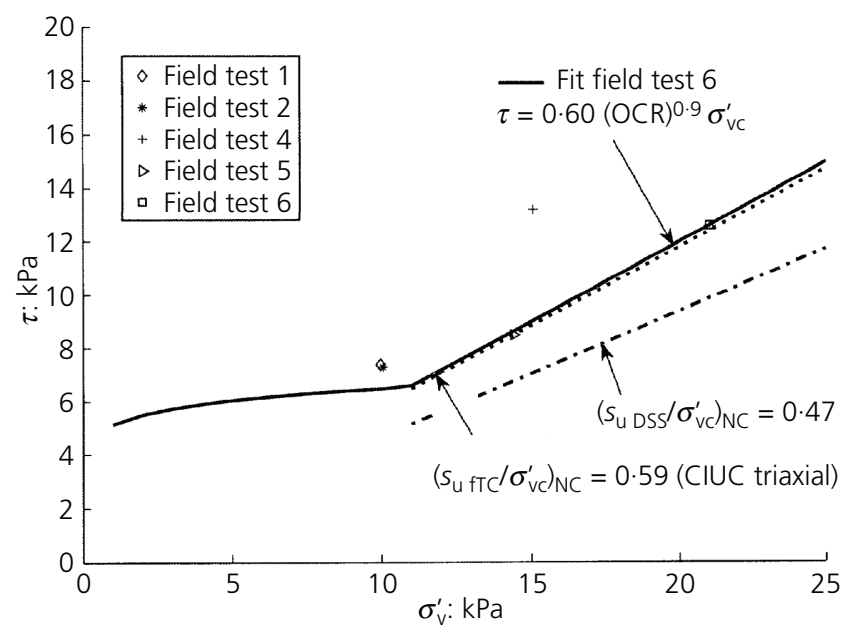

(c)

Figure 28. Uitdam strip foundation field trials: (a) photograph post-failure for field test 6 with $B>D / 2$, where $D=5 \mathrm{~m}$ deep peat layer (Zwanenburg and Jardine, 2015); (b) failure mechanism from numerical analysis for field test 6 showing total displacement contours expressed as a percentage of maximum total vector length (adapted from Zwanenburg and Jardine (2015)); (c) overall simplified field shear strength interpretation (adapted from Zwanenburg and Jardine (2015)) 
normalised undrained strength ratio value, rather than the peak $s_{\mathrm{u}}$ TC value; the latter would result in a less conservative and potentially unsafe approach where the axial strain applied during the compression stage is continued beyond such levels that the specimen drainage condition changes from undrained to semi-drained (section headed 'CU TC testing').

For asymmetric loading of the strip foundations at Uitdam, near-vertical and subhorizontal fractures were observed to dominate the active side of the failure, while at the passive side, the peat was compressed (Zwanenburg, 2012). Fracturing at the active side was also observed for the Booneschans trial embankment constructed on peat (Zwanenburg et al., 2012), with both of these case studies indicating that the tensile strength of the peat material seems important in understanding foundation failure better. Hence, the close agreement found between the field and triaxial interpretations (i.e. rather than the DSS interpretation or some intermediate condition between the triaxial and DSS interpretations) for the Uitdam strip foundation loading trials described earlier may have been somewhat fortuitous.

\section{Case of $D \ll B$}

Due to the nature of the specimen deformation for DSS testing, the DSS-derived strength parameter values generally correspond satisfactorily with field measurements for many dike and embankment failures involving a peat substratum (Figures 19(a) and 19 (b)) - that is, $D \ll B$. Examples include the $6 \mathrm{~m}$ high trial embankment constructed on a $3 \mathrm{~m}$ deep fibrous peat layer in Booneschans, the Netherlands (see Figure 19(a) and Zwanenburg et al. (2012)) and the geotextile-reinforced embankment constructed over a $7.7 \mathrm{~m}$ deep peat layer reported by Rowe et al. (1984). For these scenarios, the high $s_{\mathrm{ufTC}} / \sigma_{\mathrm{vc}}^{\prime}$ values derived for TC testing (e.g. 0.61 for CIUC triaxial testing of the Booneschans fibrous peat material in the Zwanenburg et al. (2012) investigation) are not representative of the bulk behaviour of the peat layer, with the combined effects of the rotation of the principal stress states during loading and the strong structural anisotropy of fibrous peat reducing the average strength value mobilised along the sliding plane, which is generally located at/ near the base of the peat layer. In other words, with the direction of shear coincident with the cross-anisotropic plane, DSS testing tends to measure the interparticle frictional strength of the peat matrix material, thereby providing a conservative assessment of the operational shear strength in peat. If the DSS testing method is not available, the use of DS and RS apparatus (ideally testing large specimens, so as to negate the scale effect related to the peat's coarse fibres), may be considered as an alternative means of providing pertinent strength parameter values (see the section headed 'DSS effective friction angle and normalised undrained strength ratio for conventionally sized peat specimens'), at least for performing preliminary analyses of routine stability problems involving fibrous peat layers.

For the Booneschans embankment trial, Zwanenburg et al. (2012) reported that the overall failure mechanism was dominated by translational movement, in which the $3 \mathrm{~m}$ deep fibrous peat layer and overlying clay units of the embankment had slid horizontally, largely intact, into an excavated ditch (see Figure 19(a)). With the effect of consolidation on the strength development during the embankment construction included in the analysis, the stability calculated using the DSS test results (i.e. $s_{\mathrm{uDSS}} / \sigma_{\mathrm{vc}}^{\prime}=0.46$ ) for the DS part of the failure surface compared well with the observed general translational failure. Zwanenburg et al. (2012) described that the horizon between the peat layer and underlying sand deposit was not perfectly flat, with contact between the peat and sand materials remaining locally intact in some locations, whereas elsewhere, the sand/peat intersection was cut off, which indicated that the shear zone was located in the peat layer and underlying sand deposit, respectively. Further, a thin shear zone involving both peat and loose saturated (appeared liquefied) sand had apparently developed upon failure. In other words, there was some uncertainty as to, firstly, the predominant location of the shear zone (plane) (i.e. whether the material parameter values used in the analysis should relate to the DSS properties of the peat layer or the underlying loose saturated sand) and, secondly, the significance of the tensile strength contribution of the peat material, with wide vertical cracks observed in the peat layer (and also the overlying clay units of the embankment), indicating that local tension failure had also occurred. The tension cracks resolved at the base of the peat layer on subhorizontal shear planes that were inclined in a downslide direction, just above the contact with the underlying sand deposit (Zwanenburg et al., 2012).

\section{Natural peat slopes}

Almost all of the peat slope failures (slides, bog bursts and bogflows) that occurred in the British Isles, from the early twentieth century to the present, have involved blanket bog peat deposits (Dykes, 2008). A historical review of the types, occurrence, scale and likely causal factors for peat slope failures in Ireland is given by Boylan et al. (2008). The occurrence of these failures can, in many instances (but not always), be explained by the presence of trigger factors, including intense rainfall, surface loading or excavation of peat deposits, along with the presence of pre-existing factors, such as morphological, geomorphological, hydrological and geological characteristics.

Peat slope failures in upland blanket bogs mostly resemble shallow planar translational slides, with a shear-failure mechanism operating at or near the peat-substrate interface (Boylan et al., 2008; Long and Jennings, 2006). Bog bursts usually involve the rupture of the peat mat or the peat margins, with liquefied basal peat material often expelled through surface tears or at the margins of the peat mass (Warburton et al., 2004). Following failure, both peat slides and bog bursts may degenerate into a mobile mass of floating acrotelm rafts, leading to their description as bogflows. According to Dykes (2008), several of the twentieth century bogflow events are thought to have involved the relatively thin fibrous acrotelm layer giving way to the pressure exerted by the underlying semi-liquid catotelm peat material, particularly at the edges of escarpments or even at very small convex breaks of slope - that is, 
the undrained tensile strength of the acrotelm layer was insufficient to contain the underlying slurried catotelm peat material, which breaks out from its normally confined position. In other words, significant tensile resistance is mobilised within the acrotelm layer, with peat slope failure initiated once $\sigma_{\max }$ DT is mobilised, leading to crack development along the backscarp, failure margins and locations of other surface tears, in addition to the full (but much smaller) $s_{\mathrm{u}}$ DSs value mobilised along the sliding plane. Hence, anthropogenic activities that involve cutting (slicing) of the peat mat, localised excavation of the peat deposit and (or) applied surface loading can potentially have a devastating effect on the global stability of the peat deposit.

\section{PEAT SLIDES}

Because of the difficulties associated with reliable $c^{\prime}$ determinations from standard strength-testing and evaluation techniques, the conservative and more practical approach to stability assessments of sliding failure of peat slopes usually employs undrained infiniteslope analysis and generally assumes that steady seepage occurs parallel to the ground surface. The passive resistance provided by the material located at the toe of the failure volume, as well as the tensile strength resistance mobilised at the backscarp and from the failure margins become less significant with increasing ratio of the translational failure length to the peat stratum thickness (hence, these resistances are usually not considered in the analysis), with the factor of safety $\left(F_{\mathrm{s}}\right)$ against sliding failure largely dictated by the $s_{\mathrm{u}}$ DSs value (Boylan et al., 2008; O'Kelly, 2015a). Natural peat slopes are generally in an OC state, frequently with quite high OCR values, meaning that the $\left(s_{\mathrm{uDSS}} / \sigma_{\mathrm{vc}}^{\prime}\right)_{\mathrm{OC}}$ value can range up to 1.3 (see 'In situ stress' data points in Figure 18). For the NC state, a preliminary assessment of the in situ undrained strength profile for fibrous peat slopes can be made using an $\left(s_{\mathrm{uDSS}} / \sigma_{\mathrm{vc}}^{\prime}\right)_{\mathrm{NC}}$ value of 0.46 (Foott and Ladd, 1981; Zwanenburg and Jardine, 2015; Zwanenburg et al., 2012) or a tentative lower-bound value of $0 \cdot 40$ (Boylan and Long, 2014). The assumed values should be confirmed through laboratory and (or) field strength testing.

Effective-stress infinite slope analysis can also be performed using the equations originally presented by Haefli (1948) and subsequently by Skempton and De Lory (1957). With low in situ effective stress and high OCR, the $\phi_{\text {DSs }}^{\prime}$ value of the blanket bog peat material is generally small (i.e. its $m_{1}$ value is near unity, as reported for other peats by Zwanenburg and Jardine (2015) and Lechowicz (1994)), meaning that the frictional resistance component is generally small or negligible, with the $F_{\mathrm{s}}$ value against sliding failure then largely dictated by its $c_{\mathrm{DSS}}^{\prime}$ value. For instance, referring to Figure 29, for the scenario described in the figure caption, the $c_{\mathrm{DSS}}^{\prime}$ value of $3 \mathrm{kPa}$ accounts for $\sim 90 \%$ of the $F_{\mathrm{s}}$ value developed against sliding, with the water table positioned at the ground surface (i.e. $z_{\mathrm{w}} / z=1 \cdot 0$ ) and the sliding mass having a bulk unit weight of $10 \mathrm{kN} / \mathrm{m}^{3}$, typical of saturated fibrous peat material. For a scenario like this, the $c_{\text {DSS }}^{\prime}$ value is best measured using DSS apparatus of the types presented by Boylan and Long (2009) and Den Haan and Grognet (2014). Further, with its fibres orientated and spaced randomly (Long and

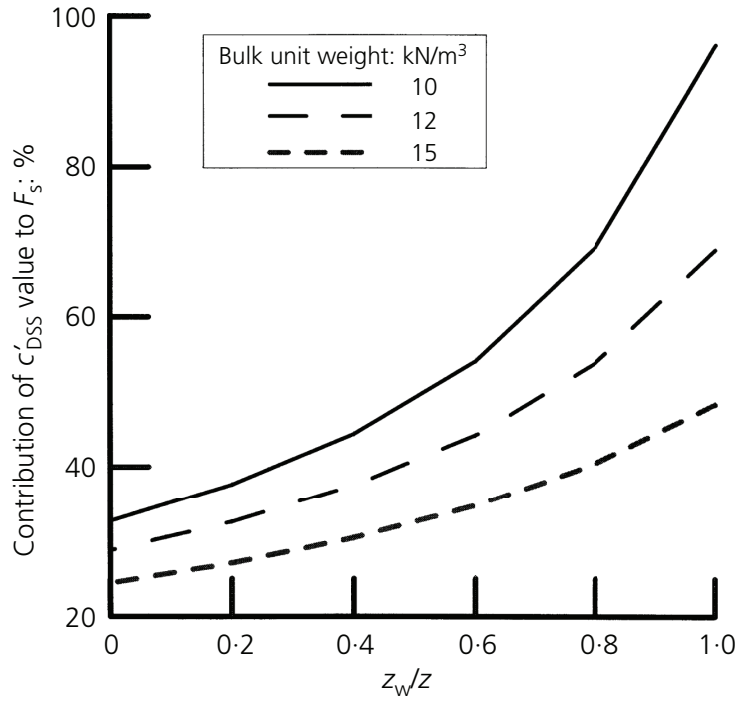

Figure 29. Sensitivity analysis of the effective-stress infinite slope method considering a peat deposit with $20^{\circ}$ slope angle on base of sliding, the failure surface located at a depth $(z)$ of $1.0 \mathrm{~m}$, with $c_{\mathrm{DSS}}^{\prime}=3 \mathrm{kPa}$ and $\phi_{\mathrm{DSS}}^{\prime}=35^{\circ}$ (adapted from Boylan et al. (2008)). Note: $F_{\mathrm{s}}$, factor of safety against sliding; $z_{\mathrm{w}}$, height of groundwater table above failure surface (i.e. $z_{w} / z=1$ implies that the groundwater table is located at the ground surface, with steady seepage occurring in a direction parallel to the slope)

Jennings, 2006) and no pattern detected between its measured horizontal and vertical undrained tensile strengths (Dykes, 2008), upland blanket bog peat material is not strongly cross-anisotropic, unlike other peat types. Hence, when the sliding plane is located entirely within the peat layer, $c_{\mathrm{DSS}}^{\prime} \approx c_{\mathrm{DT}}^{\prime}$ (see the section headed 'Drained tensile strength'), meaning that direct-tension testing of the basal peat material at its in situ effective-stress levels provides an additional and arguably more reliable means for the determination of the drained cohesion value for upland blanket bog peat material.

There are many recorded 'peat slope failures' where the slippage plane was not located in the peat deposit, but within the underlying soil. For example, most of the 30 or more slope failures that occurred in the upland blanket bog peat deposits at Pollatomish (County Mayo, Ireland) in September 2003 were due to shear failure occurring in the underlying weathered rock (classified as medium dense peaty sand material with $c_{\mathrm{DS}}^{\prime}=0$ and $\phi_{\mathrm{DS}}^{\prime}=45^{\circ}$ ), triggered by shear resistance reductions caused by rapid elevated $p_{\mathrm{wp}}$ development arising from intense rainfall (Long and Jennings, 2006).

\section{BOG BURSTS}

According to Dykes (2008), the undrained tensile strength of the acrotelm layer has a significant influence on the occurrence and development of bog bursts. Since internal change in a peat slope leading to slope failure is thought to be rapid in most (if not all) cases, stability assessments are generally performed using an 
undrained approach, employing standard limit-equilibrium methods. Individual high-intensity rainfall events or large rainfall depths accumulated over just a few days are cited as the most common trigger factor. For such analysis, undrained tensile strength measurements from direct-tension tests provide an approximation of the general peat strength (Dykes, 2008; Helenelund, 1967) (see the section headed 'Tensile strength and cohesion').

\section{Incorporating tensile strength of fibrous peat in routine design}

From the preceding sections, it is apparent that the contribution of the peat tensile strength to the overall stability of peat deposits can be significant. The tensile strength magnitude and its dependence on the orientation of the loading direction relative to the cross-anisotropic plane mean that the TCO line for a given fibrous peat material is not fixed in the $p^{\prime}-q$ space with $\sigma_{3}^{\prime}=0$ but is translated marginally along the negative $p^{\prime}$ axis depending on the tensile strength capacity of the peat element for the shearing condition under consideration. For geotechnical design practice, an important question is how to incorporate the tension capacity of fibrous peat in routine design. For instance, the bearing capacity failures for the strip foundation trials reported by Zwanenburg (2012) and Zwanenburg and Jardine (2015) and also the trial embankment failure by general translational movement reported by Zwanenburg et al. (2012) indicated that the underlying fibrous peat layers had failed locally with tension cracks developed along near-vertical planes, in addition to subhorizontal cracking. It may have been somewhat fortuitous, therefore, that the laboratory-derived $\left(s_{\mathrm{u} \mathrm{TC}} / \sigma_{\mathrm{vc}}^{\prime}\right)_{\mathrm{NC}}$ and $\left(s_{\mathrm{u} \mathrm{DSS}} / \sigma_{\mathrm{vc}}^{\prime}\right)_{\mathrm{NC}}$ values for the fibrous peat materials were found to provide good estimates of the field-test shear strength interpretations for the strip foundation and embankment failures, respectively.

Using the numerical method with a constitutive model, in which the TCO condition applied for a given fibrous peat element permits some tensile stress (strength) mobilisation, provides one approach to incorporating the tension capacity of fibrous peat material in routine geotechnical design. In such analysis, the magnitude of the tensile stress (strength) mobilised is dependent on the orientation of the tension crack development for that element relative to the general cross-anisotropic fabric. In the absence of a systematic investigation, the author suggests a cosinesquared relationship to relate the tensile strength value of a given fibrous peat material and the orientation of the direct-tension load relative to its cross-anisotropic plane (see Figure 30). In this model, the maximum and minimum tensile strength values are mobilised for direct-tension loading along and orthogonal to the cross-anisotropic plane, respectively, with the relative difference between these values indicating the degree of structural anisotropy present. The presented approach provides a framework for estimating appropriate values of $\sigma_{\max } \mathrm{DT}, c_{\mathrm{DT}}^{\prime}$ and $\sigma_{\max \text { DT }}^{\prime}$ for undrained and drained stability analysis of peat deposits.

\section{Summary and conclusions}

Peat deposits are heterogeneous and anisotropic. For fibrous peat material, its structure, fabric and level of humification have

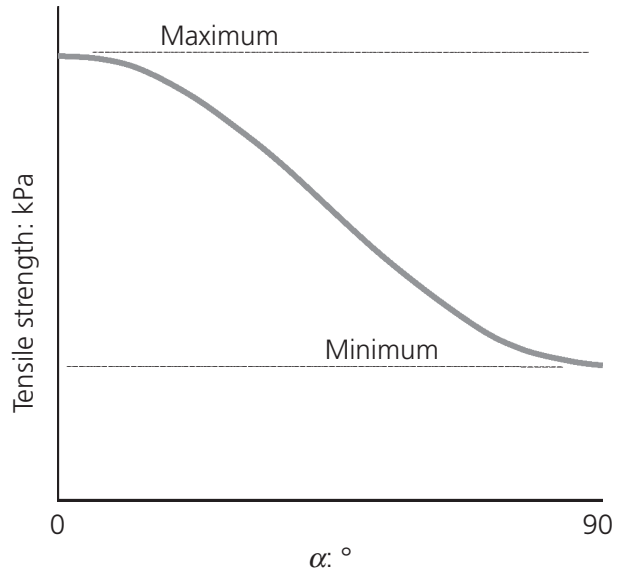

Figure 30. Proposed relationship between tensile strength and the orientation $(\alpha)$ of the direct-tension load relative to the crossanisotropic plane for fibrous peat materials

considerable impacts on its engineering behaviour, which is also influenced to some extent by its genesis and botanical composition. Apart from upland blanket bog, most fibrous peat deposits are inherently cross-anisotropic, such that for a given fibrous peat material, the measured values of $s_{\mathrm{u}}, c^{\prime}$ and $\phi^{\prime}$ are dependent on the orientation of the shearing plane relative to its predominantly horizontally orientated fabric.

For TC testing, with the $\mathrm{C} K_{0} \mathrm{UC}$ approach preferred over the CIUC one, fibre tensioning produces very high $M$ and $\phi_{\mathrm{TC}}^{\prime}$ values and low $K_{0}$ and $v^{\prime}$ values, with axial tensile failure occurring for larger test specimens at $\varepsilon_{\mathrm{a}}=15-30 \%$. For initial void ratio and effective confining pressure combinations that during shear lead to contractive response followed by dilative behaviour the true undrained strength of a fibrous peat material in TC, $s_{\mathrm{u}}$ fTC, is determined by extrapolating the central linear part of the $\mathrm{CU}$ triaxial ESP trace to intersect the TCO line. Further, the $\phi_{\mathrm{cv}}^{\prime}$ value is determined from regression analysis of the phase transformation (yield) points identified on three or more CU triaxial ESP traces. The test-specimen size can influence deduced strength values, with the limited reported TC data for fibrous peat material suggesting that compared with large test specimens (i.e. $400 \mathrm{~mm}$ dia.), conventionally sized specimens may give conservative strength parameter values, but the data obtained for the latter also have a larger scatter.

In its $\mathrm{NC}$ state, a fibrous peat material is essentially frictional, whereas in its OC state, the material is largely cohesional, generally with a small $\phi^{\prime}$ value, with $\sigma_{\max }^{\prime}$ for virgin peat deposits typically ranging $\sim 12-15 \mathrm{kPa}$. In general, for $\mathrm{NC}$ fibrous peat material, $s_{\mathrm{u}}$ TC $\gg s_{\mathrm{u}}$ DSS, $\phi_{\mathrm{TC}}^{\prime} \gg \phi_{\mathrm{DS}}^{\prime} \approx \phi_{\mathrm{RS}}^{\prime}>\phi_{\mathrm{DSS}}^{\prime} \approx 28^{\circ}$ and $c_{\mathrm{TC}}^{\prime}>c_{\mathrm{DS}}^{\prime} \approx c_{\mathrm{RS}}^{\prime}>c_{\mathrm{DSS}}^{\prime}$, with $c_{\mathrm{DSS}}^{\prime}$ values typically ranging $2-3 \mathrm{kPa}$. Further, $\left(s_{\mathrm{u}} / \sigma_{\mathrm{vc}}^{\prime}\right)_{\mathrm{NC}} \approx 0.60$ (deduced using $s_{\mathrm{u}}$ fTC) and 0.46 for triaxial and DSS modes, respectively, with a tentative lower-bound value of 0.40 identified for the latter mode. The 
initial OC state and the tensile strength associated with the fibres contribute to relatively high $c^{\prime}$ and $s_{\mathrm{u}}$ values for fibrous peat materials at the low effective stresses often encountered in situ. In these circumstances, drained tensile strength testing provides an alternative and potentially more reliable approach than triaxial and DSS testing for the determination of $c^{\prime}$ values, particularly for upland blanket bog peat material, which usually does not have a strong cross-anisotropic fabric even though it has a high fiber content.

$K_{0}$ values for fibrous peats and other organic soils can be readily measured using instrumented consolidation cell or CRS oedometer devices, although the potential for the test-specimen size to influence deduced results unduly merits further investigation. Alternatively, the $K_{0}$ value of a fibrous peat material can be approximated using reported correlations for inorganic soil. In other words, the Jaky correlation incorporating the TC $\phi_{\mathrm{cv}}^{\prime}$ parameter can also be used for NC peat material, and either $N$ (after Hayashi et al. (2012)) or experimental load-unload-reload oedometer data (after Ladd and Foot (1974)) can be used in establishing the value of the exponent $m_{2}$ for the power law relationship incorporating OCR in relation to $\mathrm{OC}$ peat material, with $m_{2}$ increasing in value with increasing $N\left(0 \cdot 82<m_{2}<=0 \cdot 95 ; N \geq 75 \%\right)$.

For stability assessments, approximately axisymmetric and asymmetric circular-type shear-failure modes appear relevant for $B / 2<D<B$ and $D>B$, respectively, with analysis employing the normalised undrained strength ratio $\left(s_{\mathrm{ufTC}} / \sigma_{\mathrm{vc}}^{\prime}\right)_{\mathrm{NC}}$ appearing to match the field-test shear strength interpretation for full-scale trials. DSS-derived strength parameter values generally correspond well with field strength interpretations for embankments, dikes and foundations bearing on shallow peat deposits (i.e. $D \ll B$ ), as well as for planar translational slides occurring in natural peat slopes. Peatland hydrology plays a significant role in many of the peat slope failures, particulalry for upland blanket bog peat deposits.

The tensile strength of fibrous peat material is important in understanding bog burst and bogflow events in upland blanket bog peat deposits, for the stability of 'floating' roads over peatland, and also seems important in stability assessments of embankments, dikes and foundations over peat substratum. For instance, based on the limited reported data for the acrotelm layer, $\sigma_{\max }$ DT typically ranges $3-8 \mathrm{kPa}$ and $3 \cdot 5-11 \mathrm{kPa}$ for upland blanket bog and Sphagnum peat materials, respectively, with $c_{\mathrm{DT}}^{\prime}$ and $\sigma_{\max \text { DT }} / \sigma_{\mathrm{vc}}^{\prime}$ values of $\mathrm{NC}$ fibrous peat material tentatively estimated at $\sim 2 \mathrm{kPa}$ and $0 \cdot 30$, respectively. Since back-analyses of slope and foundation failures involving peat deposits indicate that even a small $\sigma_{\max }$ DT or $c_{\mathrm{DT}}^{\prime}\left(\sigma_{\max \mathrm{DT}}^{\prime}\right)$ value can play a significant role, further investigations on the tensile strength mobilised for submerged test specimens with different botanical compositions are necessary, along with a renewed effort on understanding tensile strength development and fracturing of in situ peat deposits under loading.

\section{REFERENCES}

Abebaw BJ (2005) Experimental Study on Shear and Tensile Strength of Peat Soil. MSc thesis, IHE Delft Institute for Water Education (UNESCO-IHE), Delft, the Netherlands.

Acharya MP, Hendry MT and Martin CD (2016) Thermally induced pore pressure response in peat beneath a railway embankment. International Journal of Geotechnical Engineering 10(2): 145-154, http://dx.doi.org/10.1179/1939787915Y.0000000022.

Adams JI (1961) Laboratory compression tests on peat. In Proceedings of the 7th Muskeg Research Conference, Hamilton, Ontario (MacFarlane IC and Butler J (eds)). National Research Council of Canada, Ottawa, ON, Canada, Technical Memorandum 71, pp. 36-53.

Adams JI (1965) The engineering behavior of a Canadian muskeg. In Proceedings of the 6th International Conference on Soil Mechanics and Foundation Engineering, Montreal, Canada. University of Toronto Press, Toronto, ON, Canada, vol. 1, pp. 3-7.

Airey DW and Wood DM (1987) An evaluation of direct simple shear tests on clay. Géotechnique 37(1): 25-35, http://dx.doi.org/10.1680/ geot.1987.37.1.25.

Airey DW, Budhu M and Wood DM (1985) Some aspects of the behaviour of soils in simple shear. In Developments in Soil Mechanics and Foundation Engineering: Vol. 2: Stress-Strain Modelling of Soils (Banerjee PK and Butterfield R (eds)). Elsevier Applied Science, London, UK, pp. 185-213.

Ajlouni MA (2000) Geotechnical Properties of Peat and Related Engineering Problems. PhD thesis, University of Illinois at Urbana-Champaign, Urbana, IL, USA.

Amaryan LS (1993) Soft Soils Properties and Testing Methods. Balkema, Rotterdam, the Netherlands.

ASTM (2013) D 4427-13: Standard classification of peat samples by laboratory testing. ASTM International, West Conshohocken, PA, USA.

ASTM (2014) D 2974-14: Standard test methods for moisture, ash, and organic matter of peat and other organic soils. ASTM International, West Conshohocken, PA, USA.

Baird AJ and Waldron S (2003) Shallow horizontal groundwater flow in peatlands is reduced by bacteriogenic gas production. Geophysical Research Letters 30(20): 2043, http://dx.doi.org/10.1029/ 2003 GL018233.

Bezuijen A, Kruse GAM and Van MA (2005) Failure of peat dikes in the Netherlands. In Proceedings of the 16th International Conference on Soil Mechanics and Geotechnical Engineering, Osaka, Japan. Millpress Science Publishers/IOS Press, Amsterdam, the Netherlands, vol. 3, pp. 1857-1860, http://dx.doi.org/10.3233/978-1-61499-656-9-1857.

Boylan N and Long M (2009) Development of a direct simple shear apparatus for peat soils. Geotechnical Testing Journal 32(2): 126-138, http://dx.doi.org/10.1520/GTJ101703.

Boylan N and Long M (2014) Evaluation of peat strength for stability assessments. Proceedings of the Institution of Civil Engineers Geotechnical Engineering 167(5): 421-430, http://dx.doi.org/10.1680/ geng. 12.00043 .

Boylan N, Jennings P and Long M (2008) Peat slope failure in Ireland. Quarterly Journal of Engineering Geology and Hydrogeology 41(1): 93-108, http://dx.doi.org/10.1144/1470-9236/06-028.

BSI (1990) BS EN 1377-3:1990: Methods of test for soils for civil engineering purposes (chemical and electro-chemical tests). BSI, London, UK.

Carlsten P (2000) Geotechnical properties of some Swedish peats. In Proceedings of the 13th Nordic Geotechnical Meeting (NGM-2000), Helsinki, Finland (Rathmayer H (ed.)). Building Information Ltd. Helsinki, Finland, pp. 51-60.

Cola S and Cortellazzo G (2005) The shear strength behaviour of two peaty soils. Geotechnical and Geological Engineering 23(6): 679-695, http://dx.doi.org/10.1007/s10706-004-9223-9.

Consoli NC, Casagrande MDT, Prietto PDM and Thomé A (2003) Plate load test on fiber-reinforced soil. Geotechnical and Geoenvironmental 
Engineering 129(10): 951-955, http://dx.doi.org/10.1061/(ASCE) 1090-0241(2003)129:10(951).

Den Haan EJ (1997) An overview of the mechanical behavior of peats and organic soils and some appropriate construction techniques. In Proceedings of the International Conference on Recent Advances in Soft Soil Engineering, Kuching, Sarawak, Malaysia (Huat BBK and Bahia HM (eds)). Samasa Press Sdn Bhd, Kuching, Malaysia, vol. 1, pp. $17-45$.

Den Haan EJ (2002) The influence of creep ageing on $K_{0, \text { nc }}$. In Learned and Applied: Soil Mechanics Out of Delft (Barends FBJ and Steijger PMPC (eds)). Balkema, Lisse, the Netherlands, pp. 63-68.

Den Haan E and Feddema A (2013) Deformation and strength of embankments on soft Dutch soil. Proceedings of the Institution of Civil Engineers - Geotechnical Engineering 166(3): 239-252 http://dx.doi.org/10.1680/geng.9.00086.

Den Haan EJ and Grognet M (2014) A large direct simple shear device for the testing of peat at low stresses. Géotechnique Letters 4(4): 283-288, http://dx.doi.org/10.1680/geolett.14.00033.

Den Haan EJ and Kamao S (2003) Obtaining isotache parameters from a C.R.S. $K_{0}$-oedometer. Soils and Foundations 43(4): 203-214, http://dx.doi.org/10.3208/sandf.43.4_203.

Den Haan EJ and Kruse GAM (2007) Characterisation and engineering properties of Dutch peats. In Proceedings of the 2nd International Workshop on Characterisation and Engineering Properties of Natural Soils, Singapore (Tan TS, Phoon KK, Hight DW and Leroueil $\mathrm{S}$ (eds)). CRC Press/Balkema, Leiden, the Netherlands, vol. 3, pp. 2101-2133, http://dx.doi.org/10.1201/NOE0415426916.ch13.

Dhowian AW (1978) Consolidation Effects on Properties of Highly Compressive Soils-Peats. $\mathrm{PhD}$ thesis, University of Wisconsin-Madison, Madison, WI, USA.

Doherty J and Fahey M (2011) Three-dimensional finite element analysis of the direct simple shear test. Computers and Geotechnics 38(7): 917-924, http://dx.doi.org/10.1016/j.compgeo.2011.05.005.

Dykes AP (2008) Tensile strength of peat: laboratory measurement and role in Irish blanket bog failures. Landslides 5(4): 417-429, http://dx. doi.org/10.1007/s10346-008-0136-1.

Dyvik R, Berre T, Lacasse S and Raadim B (1987) Comparison of truly undrained and constant volume direct simple shear tests. Géotechnique 37(1): 3-10, http://dx.doi.org/10.1680/geot.1987.37.1.3.

Edil TB and Alanazy AS (1992) Lateral swelling pressures. In Proceedings of the 7th International Conference on Expansive Soils, Dallas, TX. Texas Tech University Press, Lubbock, TX, USA, vol. 1, pp. 227-232.

Edil TB and Dhowian AW (1981) At-rest lateral pressure of peat soils. Journal of the Geotechnical Engineering Division, ASCE 107(2): 201-217.

Edil TB and Wang X (2000) Shear strength and $K_{0}$ of peats and organic soils. In Geotechnics of High Water Content Materials (Edil TB and Fox PJ (eds)). ASTM International, West Conshohocken, PA, USA, ASTM STP 1374, pp. 209-225, http://dx.doi.org/10.1520/STP14369S.

Farrell ER (2012) Organics/peat soils. In ICE Manual of Geotechnical Engineering: Volume 1, Geotechnical Engineering Principles, Problematic Soils and Site Investigation (Burland J, Chapman T, Skinner H and Brown M (eds)). ICE Publishing, London, UK, ch. 35 , pp. 463-479, http://dx.doi.org/10.1680/moge.57074.0463.

Farrell ER and Hebib S (1998) The determination of geotechnical parameters of organic soils. In Proceedings of the International Symposium on Problematic Soils (IS-TOHOKU-98), Sendai, Japan (Yanagisawa E, Moroto N and Mitachi T (eds)). Balkema, Rotterdam, the Netherlands, vol. 1, pp. 33-36.

Farrell ER, Jonker SK, Knibbeler AGM and Brinkgreve RBJ (1999) The use of a direct simple shear test for the design of a motorway on peat. In Proceedings of the 12th European Conference on Soil Mechanics and Geotechnical Engineering, Amsterdam, the Netherlands (Barends FBJ, Lindenberg J, Luger HJ, de Quelerij L and Verruijt A (eds)). Balkema, Rotterdam, the Netherlands, vol. 2, pp. 1027-1033.
Foott R and Ladd CC (1981) Undrained settlement of plastic and organic clays. Journal of the Geotechnical Engineering Division, ASCE 107(8): 1079-1094.

Forrest JB and MacFarlane IC (1969) Field studies of response of peat to plate loading. Journal of the Soil Mechanics and Foundations Division, ASCE 95(4): 949-967.

Haefli R (1948) The stability of slopes acted upon by parallel seepage. In Proceedings of the 2nd International Conference on Soil Mechanics and Foundation Engineering, Rotterdam, the Netherlands. Keesmaat, Haarlem, the Netherlands, vol. 1, pp. 134-148.

Hanrahan ET (1954) An investigation of some physical properties of peat. Géotechnique 4(3): 108-123.

Hanrahan ET and Walsh JA (1965) Investigation of the behavior of peat under varying conditions of stress and strain. In Proceedings of the 6th International Conference on Soil Mechanics and Foundation Engineering, Montreal, Canada. University of Toronto Press, Toronto, ON, Canada, vol. 1, pp. 226-230.

Hanrahan ET, Dunne JM and Sodha VG (1967) Shear strength of peat. Proceedings of the Geotechnical Conference, Oslo, Norway, vol. 1, pp. 193-198.

Hayashi H, Yamazoe N, Mitachi T, Tanaka H and Nishimoto S (2012) Coefficient of earth pressure at rest for normally and overconsolidated peat ground in Hokkaido area. Soils and Foundations 52(2): 299-311, http://dx.doi.org/10.1016/j.sandf.2012.02.007.

Helenelund KV (1967) Tension Tests on Fibrous Peat. Division of Building Research, National Research Council of Canada, Ottawa, ON, Canada, Internal Report 346, http://dx.doi.org/10.4224/20338044.

Hendry MT, Sharma JS, Martin CD and Barbour SL (2012) Effect of fibre content and structure on anisotropic elastic stiffness and shear strength of peat. Canadian Geotechnical Journal 49(4): 403-415, http://dx.doi.org/10.1139/t2012-003.

Hobbs NB (1986) Mire morphology and the properties and behaviour of some British and foreign peats. Quarterly Journal of Engineering Geology 19(1): 7-80, http://dx.doi.org/10.1144/GSL.QJEG.1986.019.01.02.

Hollingshead GW and Raymond GP (1972) Field loading tests on Muskeg. Canadian Geotechnical Journal 9(3): 278-289, http://dx.doi. org/10.1139/t72-031.

Huang PT, Patel M, Santagata MC and Bobet A (2009) Classification of Organic Soils. School of Civil Engineering, Purdue University, West Lafayette, IN, USA, Report No. FHWA/IN/JTRP-2008/2. See http://docs.lib.purdue.edu/cgi/viewcontent.cgi? article $=2676$ \&context=jtrp (accessed 15/07/2017).

Ishihara K, Tatsouka F and Yasuda S (1975) Undrained deformation and liquefaction of sand under cyclic stresses. Soils and Foundations 15(1): 29-44, http://doi.org/10.3208/sandf1972.15.29.

Jaky J (1948) Pressure in silos. In Proceedings of the 2nd International Conference on Soil Mechanics and Geotechnical Engineering. Balkema, Rotterdam, the Netherlands, vol. 1, pp. 103-109.

Jommi C, Muraro S, Trivellato E and Zwanenburg C (2017) Evidences of the effects of free gas on the hydro-mechanical behaviour of peat. In Advances in Laboratory Testing and Modelling of Soils and Shales (Ferrari A and Laloui L (eds)). Springer, Cham, Switzerland, pp. $112-119$, http://dx.doi.org/10.1007/978-3-319-52773-4_12.

Kanmuri H, Kato M, Suzuki O and Hirose E (1998) Shear strength of $K_{0}$ consolidated undrained peat. In Proceedings of the International Symposium on Problematic Soils (IS-TOHOKU-98), Sendai, Japan (Yanagisawa E, Moroto N and Mitachi T (eds)). Balkema, Rotterdam, the Netherlands, vol. 1, pp. 25-29.

Kellner E, Waddington JM and Price JS (2005) Dynamics of biogenic gas bubbles in peat: potential effects on water storage and peat deformation. Water Resources Research 41(8): W08417, http://dx.doi.org/10.1029/2004WR003732.

Komatsu J, Oikawa H, Tsushima M and Igarashi M (2011) Ring shear test on peat. In Proceedings of the 21st International Offshore and Polar 
Engineering Conference, Maui, Hawaii, USA (Chung JS, Hong SY, Langen I and Prinsenberg SJ (eds)). International Society of Offshore and Polar Engineers, Cupertino, CA, USA, vol. 2, pp. 393-396.

Koumoto T and Houlsby GT (2001) Theory and practice of the fall cone test. Géotechnique 51(8): 701-712, http://dx.doi.org/10.1680/geot. 2001.51.8.701.

Kulhawy FH and Mayne PW (1990) Manual on Estimating Soil Properties for Foundation Design. Electric Power Research Institute, Palo Alto, CA, USA, Report No. EL-6800. See https://www.epri.com/\#/pages/ product/EL-6800/ (accessed 09/08/2017).

Ladd CC (1991) Stability evaluation during staged construction. Journal of the Geotechnical Engineering, ASCE 117(4): 540-615, https://doi. org/10.1061/(ASCE)0733-9410(1991)117:4(540).

Ladd CC and Foott R (1974) New design procedure for stability of soft clays. Journal of Geotechnical Engineering Division, ASCE 100(7): 763-786.

Landva AO (1980) Vane testing in peat. Canadian Geotechnical Journal 17(1): 1-19, http://dx.doi.org/10.1139/t80-001.

Landva AO (2007) Characterization of Escuminac peat and construction on peatland. In Proceedings of the 2nd International Workshop on Characterisation and Engineering Properties of Natural Soils, Singapore (Tan TS, Phoon KK, Hight DW and Leroueil S (eds)). Taylor \& Francis/Balkema, Leiden, the Netherlands, vol. 3 , pp. 2135-2191, http://dx.doi.org/10.1201/NOE0415426916.ch14.

Landva AO and La Rochelle P (1983) Compressibility and shear characteristics of Radforth peats. In Testing of Peats and Organic Soils (Jarrett PM (ed.)). ASTM International, West Conshohocken, PA, USA, ASTM STP 820, pp. 157-191, http://dx.doi.org/10.1520/ STP37341S.

Landva AO and Pheeney PE (1980) Peat fabric and structure. Canadian Geotechnical Journal 17(3): 416-435, http://dx.doi.org/10.1139/t80-048.

Landva AO, Pheeney PE, La Rochelle P and Briaud JL (1986) Structures on peatland - geotechnical investigations. In Proceedings of the Conference on Advances in Peatlands Engineering, Ottawa, ON, Canada. National Research Council of Canada, Ottawa, ON, Canada, pp. 31-52.

Lea ND and Brawner CO (1959) Foundation and pavement design for highways on peat. In Proceedings of the Canadian Good Roads Association 40th Convention, Vancouver, BC. Foundation of Canada Engineering Corporation, Toronto, ON, Canada, pp. 406-424.

Lechowicz Z (1994) An evaluation of the increase in shear strength of organic soils. In Proceedings of the International Workshop on Advances in Understanding and Modelling the Mechanical Behaviour of Peat, Delft, the Netherlands (Den Haan E, Termaat R and Edil TB (eds)). CRC Press/Balkema, Rotterdam, the Netherlands, vol. 1, pp. $167-180$.

Lindsay RA and Bragg OM (2005) Wind Farms and Blanket Peat: the Bog Slide of 16th October 2003 at Derrybrien, Co. Galway, Ireland, 2nd edn. Derrybrien Development Cooperative Ltd, Gort, Ireland.

Long M (2005) Review of peat strength, peat characterisation and constitutive modelling of peat with reference to landslides. Studia Geotechnica et Mechanica 27(3-4): 67-90. See http://www.sgem.pwr. edu.pl/iss/2005/no34/art04_no34_2005.pdf (accessed 09/08/2017).

Long M and Boylan N (2012) In-situ testing of peat - a review and update on recent developments. Geotechnical Engineering Journal of the SEAGS \& AGSSEA 43(4): 41-55. See http://seags.ait.asia/journals/ 2012/43-4-december/15660-in-situ-testing-of-peat-a-review-andupdate-on-recent-developments/ (accessed 09/08/2017).

Long M and Jennings P (2006) Analysis of the peat slide at Pollatomish, County Mayo, Ireland. Landslides 3(1): 51-61, http://dx.doi.org/ 10.1007/s10346-005-0006-z.

Long $\mathrm{M}$, Jennings $\mathrm{P}$ and Carroll R (2011) Irish peat slides 2006-2010. Landslides 8(3): 391-401, http://dx.doi.org/10.1007/s10346-011-0254-z.

Marachi ND, Dayton DJ and Dare CT (1983) Geotechnical properties of peat in San Joaquin Delta. In Testing of Peats and Organic Soils
(Jarrett PM (ed.)). ASTM International, West Conshohocken, PA, USA, ASTM STP 820, pp. 207-217, http://dx.doi.org/10.1520/ STP37343S.

Mayne PW and Kulhawy FH (1982) $K_{0}-O C R$ relationships in soil. Journal of the Geotechnical Engineering Division, ASCE 108(6): 851-869

McInerney GP, O'Kelly BC and Johnston PM (2006) Geotechnical aspects of peat dams on bog land. In Proceedings of the 5th International Congress on Environmental Geotechnics, Cardiff, UK (Thomas HR (ed.)). Thomas Telford, London, UK, vol. 2, pp. 934-941.

Mesri G and Ajlouni M (2007) Engineering properties of fibrous peat. Geotechnical and Geoenvironmental Engineering 133(7): 850-866, http://dx.doi.org/10.1061/(ASCE)1090-0241(2007)133:7(850).

Mesri G and Hayat TM (1993) The coefficient of earth pressure at rest. Canadian Geotechnical Journal 30(4): 647-666, http://dx.doi.org/ 10.1139/t93-056.

Moran, Proctor, Mueser and Rutledge (1958) Study of Deep Soil Stabilization by Vertical Sand Drains. Bureau of Yards and Docks, Department of the Navy, Washington, DC, USA, OTS Rep. PB151692, Publication No. 88812.

O'Kelly BC (2005a) Compressibility of some peats and organic soils. In Proceedings of the 1st International Conference on Problematic Soils, Famagusta, North Cyprus (Bilsel H and Zalihe N (eds)). Eastern Mediterranean University Press, Famagusta, Northern Cyprus, vol. 3, pp. 1193-1202.

O'Kelly BC (2005b) Consolidation properties of a dewatered municipal sewage sludge. Canadian Geotechnical Journal 42(5): 1350-1358, http://dx.doi.org/10.1139/t05-054.

O'Kelly BC (2006a) Compression and consolidation anisotropy of some soft soils. Geotechnical and Geological Engineering 24(6): 1715-1728, http://dx.doi.org/10.1007/s10706-005-5760-0.

O'Kelly BC (2006b) Geotechnical properties of municipal sewage sludge. Geotechnical and Geological Engineering 24(4): 833-850, http://dx.doi.org/10.1007/s10706-005-6611-8.

O'Kelly BC (2008) On the geotechnical design and use of peat bunds in the conservation of bogs. In Innovative Geotechnical Engineering: Proceedings of the 1st International Conference on Geotechnical Engineering, Hammamet, Tunisia (Bouassida M, Romdhane NB and Hamdi E (eds)). Nouha Editions, Sfax, Tunisia, vol. 1, pp. 259-267.

O'Kelly BC (2013) Discussion of 'Enhancement of the shear strength of wastewater residuals using industrial waste by-products'. Journal of Environmental Engineering 139(2): 312-315, http://dx.doi.org/10. 1061/(ASCE)EE.1943-7870.0000608.

O'Kelly BC (2015a) Effective stress strength testing of peat. Environmental Geotechnics 2(1): 33-44, http://dx.doi.org/10.1680/envgeo.13.00112.

O'Kelly BC (2015b) Case studies of vacuum consolidation ground improvement in peat deposits. In Ground Improvement Case Histories: Embankments with Special Reference to Consolidation and Other Physical Methods (Indraratna B, Chu J and Rujikiatkamjorn C (eds)). Butterworth-Heinemann, Oxford, UK, pp. 315-345, http://dx.doi.org/ 10.1016/B978-0-08-100192-9.00011-9.

O'Kelly BC (2016) Geotechnics of municipal sludges and residues for landfilling. Geotechnical Research 3(4): 148-179, http://dx.doi.org/10. 1680/jgere.16.00013.

O'Kelly BC (2017) Fall-cone strength testing of municipal sludges and residues. Environmental Geotechnics, http://dx.doi.org//10.1680/jenge. 15.00080 .

O'Kelly BC and Naughton PJ (2005) Development of a new hollow cylinder apparatus for stress path measurements over a wide strain range. Geotechnical Testing Journal 28(4): 345-354, http://dx.doi.org/ $10.1520 / \mathrm{GTJ} 12252$

O'Kelly BC and Naughton PJ (2009) Study of the yielding of sand under generalized stress conditions using a versatile hollow cylinder torsional apparatus. Mechanics of Materials 41(3): 187-198, http://dx.doi.org/10.1016/j.mechmat.2008.11.002. 
O'Kelly BC and Orr TLL (2014) Effective-stress strength of peat in triaxial compression. Proceedings of the Institution of Civil Engineers Geotechnical Engineering 167(5): 417-420, http://dx.doi.org/10.1680/ geng.13.00143.

O'Kelly BC and Pichan SP (2013) Effects of decomposition on the compressibility of fibrous peat - a review. Geomechanics and Geoengineering 8(4): 286-296, http://dx.doi.org/10.1080/17486025. 2013.804210.

O'Kelly BC and Pichan SP (2014) Effect of decomposition on physical properties of fibrous peat. Environmental Geotechnics 1(1): 22-32, http://dx.doi.org/10.1680/envgeo.13.00012.

O'Kelly BC and Sivakumar V (2014) Water content determinations for peat and other organic soils using the oven-drying method. Drying Technology 32(6): 631-643, http://dx.doi.org/10.1080/07373937.2013.849728.

O'Kelly BC and Zhang L (2013) Consolidated-drained triaxial compression testing of peat. Geotechnical Testing Journal 36(3): 310-321, http://dx.doi.org/10.1520/GTJ20120053.

Ozden ZS and Wilson NE (1970) Shear strength characteristics and structure of organic soils. In Proceedings of the 13th Muskeg Research Conference, Fredericton, NB, Canada. National Research Council of Canada, Ottawa, ON, Canada, Technical Memorandum 99, pp. 8-26. See http://nparc.cisti-icist.nrc-cnrc.gc.ca/eng/view/accepted/?id= 0cf2d4b6-9ff8-45eb-9260-d3e37ebc2171 (accessed 10/08/2017).

Parka T and Tan SA (2005) Enhanced performance of reinforced soil walls by the inclusion of short fiber. Geotextiles and Geomembranes 23(4): 348-361, http://dx.doi.org/10.1016/j.geotexmem.2004.12.002.

Pichan SP and O'Kelly BC (2012) Effect of decomposition on the compressibility of fibrous peat. In GeoCongress 2012: State of the Art and Practice in Geotechnical Engineering (Hryciw RD, AthanasopoulosZekkos A and Yesiller N (eds)). American Society of Civil Engineers, Reston, VA, USA, GSP 225, pp. 4329-4338, http://dx.doi.org/10. 1061/9780784412121.445.

Pichan SP and O'Kelly BC (2013) Stimulated decomposition in peat for engineering applications. Proceedings of the Institution of Civil Engineers - Ground Improvement 166(3): 168-176, http://dx.doi.org/ 10.1680/grim.12.00003.

Pigott PT, Hanrahan ET and Somers N (1992) Major canal reconstruction in peat. Proceedings of the Institution of Civil Engineers - Water, Maritime and Energy 96(3): 141-152.

Przystański J (1994) Application of Kondner's nonlinear model in describing stress-strain relation in peat, considering consolidation. In Proceedings of the International Workshop on Advances in Understanding and Modelling the Mechanical Behaviour of Peat, Delft, the Netherlands (Den Haan E, Termaat R and Edil TB (eds)). Balkema, Rotterdam, the Netherlands, vol. 2, pp. 203-210.

Ranjan G, Vasan RM and Charan HD (1996) Probabilistic analysis of randomly distributed fiber-reinforced soil. Journal of Geotechnical Engineering, ASCE 122(6): 419-426, http://dx.doi.org/10.1061/ (ASCE)0733-9410(1996)122:6(419).

Rong XN, Xu RQ and Lu JY (2017) Physical derivation of effective stress from balance law and experimental evidence. International Journal of Geomechanics, ASCE 17(9): 1-11, https://doi.org/10.1061/(ASCE) GM.1943-5622.0000953.

Rowe RK and Mylleville BLJ (1996) A geogrid reinforced embankment on peat over organic silt: a case history. Canadian Geotechnical Journal 33(1): 106-122, http://dx.doi.org/10.1139/t96-027.

Rowe RK, MacLean MD and Soderman KL (1984) Analysis of a geotextile reinforced embankment constructed on peat. Canadian Geotechnical Journal 21(3): 563-576, http://dx.doi.org/10.1139/t84-058.

Schmertmann JH (1983) A simple question about consolidation. Journal of Geotechnical Engineering, ASCE 109(1): 119-122, https://doi.org/ 10.1061/(ASCE)0733-9410(1983)109:1(119).

Schmidt B (1966) Discussion of 'Earth pressures at rest related to stress history'. Canadian Geotechnical Journal 3(4): 239-242, http://dx.doi. org/10.1139/t66-028.
Shukla SK (2017) Fundamentals of Fibre-reinforced Soil Engineering. Springer Nature, Singapore, http://dx.doi.org/10.1007/978-981-10-3063-5. Skempton AW and De Lory FA (1957) Stability of natural slopes in London clay. In Proceedings of the 4th International Conference on Soil Mechanics and Foundation Engineering, London, UK. Butterworths, London, UK, vol. 2, pp. 378-381.

Skempton AW and Petley DJ (1970) Ignition loss and other properties of peats and clays from Avonmouth, King's Lynn and Cranberry Moss. Géotechnique 20(4): 343-356, http://dx.doi.org/10.1680/geot.1970.20. 4.343 .

Tan Y (2008) Finite element analysis of highway construction in peat bog. Canadian Geotechnical Journal 45(2): 147-160, http://dx.doi.org/10. 1139/T07-076.

Tang CS, Wang DY, Cui YJ, Shi B and Li J (2016) Tensile strength of fiber-reinforced soil. Journal of Materials in Civil Engineering 28(7): 04016031, http://dx.doi.org/10.1061/(ASCE)MT.1943-5533.0001546.

Termaat RJ (1994) General report session 2: stress-strain and strength behaviour. In Proceedings of the International Workshop on Advances in Understanding and Modelling the Mechanical Behaviour of Peat, Delft, the Netherlands (Den Haan E, Termaat R and Edil TB (eds)). Balkema, Rotterdam, the Netherlands, vol. 2, pp. 311-326.

Tomczak A (2013) Peat dikes and strength parameters - unexpected results. Peatlands International 2013(2): 18-22.

Tsushima M and Oikawa H (1982) Shear strength and dilatancy of peat. Soils and Foundations 22(2): 133-141, http://doi.org/10.3208/ sandf1972.22.2_133 (in Japanese).

Tsushima M, Miyakawa I and Iwasaki T (1977) Some investigations on shear strength of organic soil. Journal of the Japanese Society of Soil Mechanics and Foundation Engineering 235: 13-18 (in Japanese).

van Baars S (2005) The horizontal failure mechanism of the Wilnis peat dyke. Géotechnique 55(4): 319-323, http://dx.doi.org/10.1680/geot. 2005.55.4.319.

Warburton J, Holden J and Mills AJ (2004) Hydrological controls of surficial mass movements in peat. Earth-Science Reviews 67(1-2): 139-156, http://dx.doi.org/10.1016/j.earscirev.2004.03.003.

Yamaguchi H, Ohira Y, Kogure K and Mori S (1985a) Undrained shear characteristics of normally consolidated peat under triaxial compression and extension conditions. Soils and Foundations 25(3): 1-18, http://dx.doi.org/10.3208/sandf1972.25.31.

Yamaguchi H, Ohira Y, Kogure K and Mori S (1985b) Deformation and strength properties of peat. In Proceedings of the 11th International Conference on Soil Mechanics and Foundation Engineering, San Francisco, CA, USA (Publications Committee of the 11th ICSMFE (ed.)). Balkema, Rotterdam, the Netherlands, vol. 4, pp. 2461-2464.

Yamaguchi H, Mori S, Ohira Y and Kogure K (1985c) Anisotropic shear characteristics of undisturbed peat. Journal of the Japanese Society of Soil Mechanics and Foundation Engineering 4(12): 189-198 (in Japanese).

Yamaki M, Yamanashi T and Hayashi H (2015) Effect of cyclic loading on shear modulus of peat. Proceedings of the 6th International Conference on Earthquake Geotechnical Engineering, Christchurch, New Zealand, p. 9.

Yang ZX, Zhao CF, Xu CJ et al. (2016) Modelling the engineering behaviour of fibrous peat formed due to rapid anthropogenic terrestrialization in Hangzhou, China. Engineering Geology 215(19): 25-35, http://dx.doi.org/10.1016/j.enggeo.2016.10.009.

Yasuhara K and Takenaka H (1977) Physical and mechanical properties. In Engineering Problems of Organic Soils in Japan (Yamanouchi $\mathrm{T}$ (ed.)). Japanese Society of Soil Mechanics and Foundation Engineering, Tokyo, Japan, pp. 49-67.

Zhang L and O'Kelly BC (2013) Constitutive models for peat - a review. In Proceedings of the 12th International Conference on Computational Plasticity - Fundamentals and Applications, Barcelona, Spain (Oñate 
Measurement, interpretation and recommended use of laboratory strength properties of fibrous peat O'Kelly
E, Owen DRJ, Peric D and Suárez B (eds)). International Center for Numerical Methods in Engineering, Universitat Politècnica de Catalunya, Barcelona, Spain, pp. 1294-1304.

Zhang L and O'Kelly BC (2014) The principle of effective stress and triaxial compression testing of peat. Proceedings of the Institution of Civil Engineers - Geotechnical Engineering 167(1): 40-50, http://dx.doi.org/10.1680/geng.12.00038.

Zhang L and O'Kelly BC (2015) Effect of salt grain additions on fibrous peat consolidation. Proceedings of the Institution of Civil Engineers Ground Improvement 168(1): 14-21, http://dx.doi.org/10.1680/grim. 12.00034 .

Zhang L, O'Kelly BC and Nagel T (2017) Tensile and compressive contributions of fibres in peat. In Poromechanics VI: Proceedings of the 6th Biot Conference on Poromechanics (Vandamme M, Dangla P, Pereira J-M and Ghabezloo S (eds)). American Society of Civil Engineers, Reston, VA, USA, pp. 1466-1473, https://doi.org/ 10.1061/9780784480779.182.

Zwanenburg C (2005) The Influence of Anisotropy on the Consolidation Behaviour of Peat. PhD thesis, Delft University of Technology, Delft, the Netherlands. See http://repository.tudelft.nl/islandora/object/ uuid:45ca5593-a69e-44aa-835d-400b048d8a28?collection=research (accessed 15/07/2017).

Zwanenburg C (2012) Field tests for operational shear strength assessment in peat at Uitdam, the Netherlands. Proceedings of the 2nd European Conference on Physical Modelling in Geotechnics (EUROFUGE 2012), Delft, the Netherlands. Delft University of Technology and Deltares, Delft, the Netherlands, http://dx.doi.org/ 10.4233/uuid:f9cb0d90-c4d4-4639-a43b-1554f3eac05c.

Zwanenburg C and Jardine RJ (2015) Laboratory, in situ and full-scale load tests to assess flood embankment stability on peat. Géotechnique 65(4): 309-326, http://dx.doi.org/10.1680/geot.14.P.257.

Zwanenburg C and Van MA (2015) Comparison between conventional and large scale triaxial compression tests on peat. In Proceedings of the 6th International Symposium on Deformation Characteristics of Geomaterials, Buenos Aires, Argentina (Rinaldi VA, Zeballos ME and Clariá (eds)). ISO Press, Amsterdam, the Netherlands, pp. 543-550, http://dx.doi.org/10.3233/978-1-61499-601-9-543.

Zwanenburg C, Den Haan EJ, Kruse GAM and Koelewijn AR (2012) Failure of a trial embankment on peat in Booneschans, the Netherlands. Géotechnique 62(6): 479-490, http://dx.doi.org/10.1680/geot.9.P.094.

\section{How can you contribute?}

To discuss this paper, please submit up to 500 words to the editor at journals@ice.org.uk. Your contribution will be forwarded to the author(s) for a reply and, if considered appropriate by the editorial board, it will be published as a discussion in a future issue of the journal. 